\title{
Neural Substrates of Eyeblink Conditioning: Acquisition and Retention
}

\author{
Kimberly M. Christian ${ }^{1}$ and Richard F. Thompson \\ Neuroscience Program, University of Southern California, Los Angeles, California 90089-2520, USA
}

\begin{abstract}
Classical conditioning of the eyeblink reflex to a neutral stimulus that predicts an aversive stimulus is a basic form of associative learning. Acquisition and retention of this learned response require the cerebellum and associated sensory and motor pathways and engage several other brain regions including the hippocampus, neocortex, neostriatum, septum, and amygdala. The cerebellum and its associated circuitry form the essential neural system for delay eyeblink conditioning. Trace eyeblink conditioning, a learning paradigm in which the conditioned and unconditioned stimuli are noncontiguous, requires both the cerebellum and the hippocampus and exhibits striking parallels to declarative memory formation in humans. Identification of the neural structures critical to the development and maintenance of the conditioned eyeblink response is an essential precursor to the investigation of the mechanisms responsible for the formation of these associative memories. In this review, we describe the evidence used to identify the neural substrates of classical eyeblink conditioning and potential mechanisms of memory formation in critical regions of the hippocampus and cerebellum. Addressing a central goal of behavioral neuroscience, exploitation of this simple yet robust model of learning and memory has yielded one of the most comprehensive descriptions to date of the physical basis of a learned behavior in mammals.
\end{abstract}

We begin by expressing our profound gratitude to two scientists who pioneered the use of classical conditioning of the eyeblinknictitating membrane response of the rabbit as a model system to study basic processes of associative learning and memory: Isidore Gormezano and Allan Wagner (e.g., Gormezano et al. 1983; Wagner and Donegan 1989). Between them and their many associates they contributed an extraordinary body of empirical and theoretical knowledge that has made feasible the analysis of neurobiological substrates of Pavlovian conditioning of discrete behavioral responses.

Evidence is now overwhelming that the cerebellum and its associated circuitry are the essential-the necessary and sufficient-circuitry for classical conditioning of the eyeblink and other discrete responses learned for dealing with aversive stimuli in the standard delay procedure, where the conditioned stimulus (CS) and unconditioned stimulus (US) overlap and coterminate (see, e.g., Thompson and Krupa 1994; Thompson et al. 1997; Yeo and Hesslow 1998; Nores et al. 2000; Steinmetz 2000a; Steinmetz and Woodruff-Pak 2000; Woodruff-Pak and Steinmetz 2000).

Our focus in this review is on the neuronal substrates of learning, the acquisition and retention of the conditioned response. Much less is known about brain substrates of extinction, conditioned inhibition, and other presumed inhibitory processes. Two specialized literatures, computational-mathematical cerebellar models of eyeblink conditioning and eyeblink conditioning in mutant and transgenic mouse preparations, deserve separate reviews; we reference these literatures only briefly here. We also exclude coverage of two other very important areas that have recently been reviewed in depth: development (see Ivkovich et al. 2000; Stanton and Freeman Jr. 2000) and aging (see, e.g., Green and Woodruff-Pak 2000a; Woodruff-Pak 2000). Although the eyeblink response (in the rabbit, external eyelid closure and nictitating membrane extension-it is all one coordinated response) has been most widely studied, to the extent tested, re-

\footnotetext{
'Corresponding author.
}

E-MAIL kimc@neuro.usc.edu; FAX (213) 740-5687.

Article and publication are at http://www.learnmem.org/cgi/doi/10.1101/ Im.59603. sults appear to apply equally to classical conditioning of all discrete responses (limb flexion, head turn, etc.) learned for dealing with aversive events. In an elegant review, Thach et al. (1992) summarized considerable evidence supporting the view that the cerebellum is critically involved in the acquisition and storage of learned multijoint movements in primates. Although direct evidence is lacking, we note that these two aspects of cerebellardependent learning of movements describe very well how a human infant learns to make adaptive movements to avoid punishing consequences, as in learning to walk.

Even with a seemingly simple response such as the eyeblink, if the training procedure is made more complex, other brain structures become critically involved as well. In particular, the hippocampus plays a key role, along with the cerebellum, in the trace procedure where a period of no stimulation separates CS offset from US onset (see Thompson and Kim 1996). Eyeblink conditioning with the standard delay procedure is prototypic of what has been termed procedural or implicit learning. Recent studies, primarily with humans, argue strongly that trace eyeblink conditioning is an example of declarative or explicit (cognitive) learning (see Clark and Squire 2000). Thus, this simple conditioned response exhibits the two basic aspects or forms of learning and memory characteristic of the mammalian brain.

\section{Hippocampal System and “Declarative” Memory}

Interest in the critical role of the hippocampus in memory dates from the classic studies of patient HM (e.g., Scoville and Milner 1957). Since that time a large number of studies on humans, monkeys, rabbits, rats, and mice have focused on animal models of human amnesia and on the presumed role(s) of the hippocampus and related structures in memory. The memory deficit following hippocampal lesions is not global but rather much more specific for one kind of memory, termed "declarative" (or explicit or relational; Squire 1992). Declarative memory is sometimes associated with consciousness or awareness, in contrast to many other forms of memory, including implicit (priming) memory in humans and a range of associative memory phenomena in humans and other mammals; motor and perceptual skills, 
classical conditioning, operant conditioning, habit formation, etc.

\section{Delay Conditioning}

In eyeblink conditioning, neuronal unit cluster recordings in hippocampal fields CA1 and CA3 increase in discharge frequency in paired [tone CS-corneal airpuff US] training trials very rapidly, shift forward in time as learning develops, and form a predictive "temporal model" of the learned behavioral response, both within trials and over the trials of training (Berger et al. 1976; Berger and Thompson 1978a). To summarize a large body of research, the growth of the hippocampal unit response is, under normal conditions, an invariable and strongly predictive concomitant of subsequent behavioral learning (reviewed in Swanson et al. 1982; Berger et al. 1983, 1986). This increase in neuronal activity in the hippocampus becomes significant by the second or third trial of training, long before behavioral signs of learning develop, as would be expected of a declarative memory system. This initial hippocampal unit increase is in the US period; increases in the CS period appear at about the time point in training when behavioral conditioned responses (CRs) appear. With continued training the hippocampal neuronal model eventually declines (Katz and Steinmetz 1994).

Many neurons that could be identified as pyramidal neurons in CA1 and CA3 (antidromic stimulation and collision) showed learning-related increases in discharge frequency in the trial period (many unidentified neurons showed decreases in the trial period), as seen in Figure 1 (Berger and Thompson 1978b; Berger et al. 1983). Typically, a given neuron modeled only some limited time period of the trial. Cumulating many such single pyramidal neuron responses produced the typical unit cluster model of the behavioral learned response. Thus, the pyramidal neuron representation of the behavioral learned response is distributed over both space and time in the hippocampus. The high percentage of learning-influenced pyramidal neurons and their spatially distributed loci have been strikingly verified in studies by Disterhoft and associates (Disterhoft et al. 1986; de Jonge et al. 1990) using in vitro studies of hippocampal slices from trained versus control animals (see below).

The work described above was all done using the basic delay paradigm, where hippocampal lesions do not impair simple acquisition (Schmaltz and Theios 1972; Solomon and Moore 1975). Similarly, humans with hippocampal-temporal lobe anterograde amnesia are able to learn simple acquisition of the eyeblink CR, but cannot describe it (Weiskrantz and Warrington 1979). However, the hippocampal lesions severely impair discrimination reversal in the delay paradigm (rabbits; Berger and Orr 1983). Studies by Daum, Gray, and associates (Daum et al. 1991, 1992) on humans with brain damage show that hippocampal-medial temporal lobe lesion subjects are massively impaired on conditional discriminations in eyeblink conditioning (compared to frontal lesion or normal controls) but not on acquisition or simple discriminations (ruling out deficits in response inhibition). In a conditional task the subject must learn to blink to a CS (e.g., tone) only if it is preceded by another stimulus (e.g., a light). Ross et al. (1984) had shown similar hippocampal lesion deficits in rats (locomotor response) in a conditional discrimination paradigm. Daum et al. $(1991,1992)$ make a strong case that the deficits seen in eyeblink conditional discriminations in humans and discrimination reversal in rabbits reflect deficits in declarative memory. Indeed, patients with hippocampal-medial temporal lobe amnesia are markedly impaired on eyeblink discrimination reversal (Carrillo et al. 2001).

Interestingly, the rate of acquisition of the simple delay conditioned eyeblink response can be markedly influenced by actions of the basal forebrain system. In trained animals, the neuronal model of the learned response is projected from the hippocampus to the lateral septum (Berger and Thompson 1977, 1978c). However, the medial septum, the basal forebrain origin of the septo-hippocampal cholinergic projection, shows only
$\mathbf{A}$

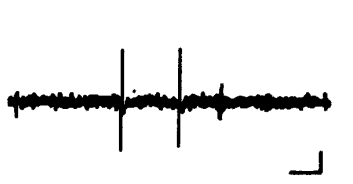

B $\downarrow$

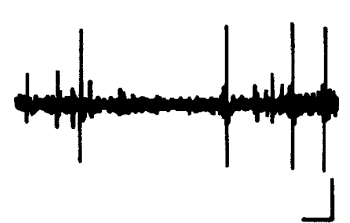

NM
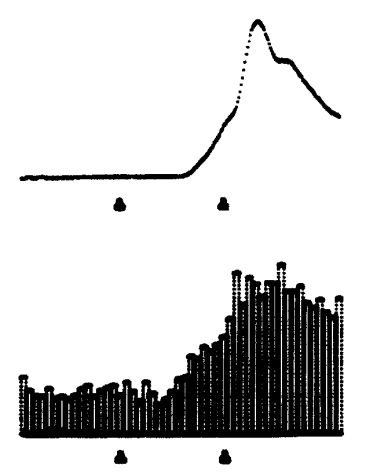

NM

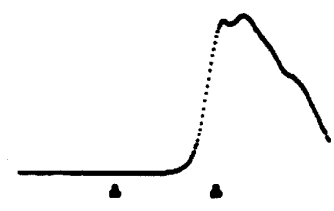

CA1

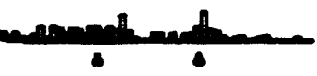

Figure 1 Rabbit eyeblink conditioning. Averaged behavioral nictitating membrane (NM) response and hippocampal single-unit poststimulus histograms generated over the course of $1 \mathrm{~d}(13$ blocks) of paired conditioning trials. Upper traces: Raw data record of single unit recorded in each case. $(A)$ Single pyramidal neuron data showing a close correlation of the unit histogram and the behavioral response (third paired day). (B) Single-unit (unidentified) data showing no correlation with the behavioral response (second paired day). Both units recorded from CA1 pyramidal layer. Unit calibrations equal $160 \mu \mathrm{V}$ and $10 \mathrm{msec}$. The first histogram bar in $A$ equals 28 unit counts per $15 \mathrm{msec}$ time bin. Total duration of NM trace and histogram $750 \mathrm{msec}$, first cursor indicates tone on, second indicates airpuff on; they coterminate at end of trace (from Berger and Thompson 1978b).

\section{Learning \& Memory}

www.learnmem.org evoked responses to CS and US onsets. Lesions of the medial septum (rabbits) markedly retard acquisition of delay eyeblink conditioning (Berry and Thompson 1979). Systemic administration of scopolamine, a cholinergic antagonist, can markedly impair delay eyeblink conditioning, an effect that is reversed by hippocampal lesions (Solomon et al. 1983). Scopolamine administration suppresses neuronal responses in the hippocampus and lateral septum, whereas it slows the acquisition rate (Salvatierra and Berry 1989). Note that hippocampal lesions, per se, do not have any of these effects. It would appear that disruption of the septo-hippocampal system impairs delay learning much more than does simply removing the hippocampus, consistent with a presumed modulatory role.

Patients with anterior communicating artery (AcoA) aneurysm rupture were studied with standard delay eyeblink conditioning (Myers et al. 2001). These patients exhibit an anterograde amnesia syndrome similar to that shown by patients with hippocampal-medial temporal lobe damage. However, the damage appears to be primarily to the basal forebrain and frontal areas, rather than to the hippocampus and medial 
temporal lobe. As we noted, patients with hippocampal-medial temporal lobe amnesia are not impaired in delay eyeblink acquisition. In marked contrast, patients with AcoA amnesia are markedly impaired in standard delay eyeblink conditioning, much like rabbits with medial septal lesions.

\section{Trace Conditioning}

Trace conditioning was first described by Pavlov; the CS terminates and there is a period of no stimulation between CS offset and US onset (as Pavlov stressed, the organism must maintain a "trace" of the CS in the brain in order for the CS and the US to become associated). In eyeblink conditioning in animals, a typical trace interval is $500 \mathrm{msec}$. The trace CR is more difficult to learn than the standard "delay" procedure where the CS and US overlap in time.

Simply comparing standard delay conditioning with trace conditioning can confound CS-US onset interval: In the delay procedure the CS-US onset interval is typically from $250 \mathrm{msec}$ to $500 \mathrm{msec}$, whereas in the trace procedure it might range from 500 to $1000 \mathrm{msec}$, depending on duration of the trace interval. Solomon and Groccia-Ellison (1996) found that the trace procedure is more difficult to learn than the long-delay procedure, with CSUS onset interval the same in both. L. Thompson et al. (1996) found that aged rabbits were much more impaired on trace than comparable long-delay conditioning. Hippocampal lesions that markedly impair trace learning (see below) do not significantly impair comparable long-delay conditioning (Berger and Orr 1983; Beylin et al. 2001). However, hippocampal lesions (rat) do impair acquisition of a very-long-delay paradigm matched in difficulty to a shorter trace paradigm (Beylin et al. 2001), thus raising a fundamental issue of interpretation. Disterhoft and others have made extensive use of the trace procedure to explore effects of age, drugs, and, importantly, mechanisms of neuronal/synaptic plasticity in the hippocampus, to be discussed later in this review.

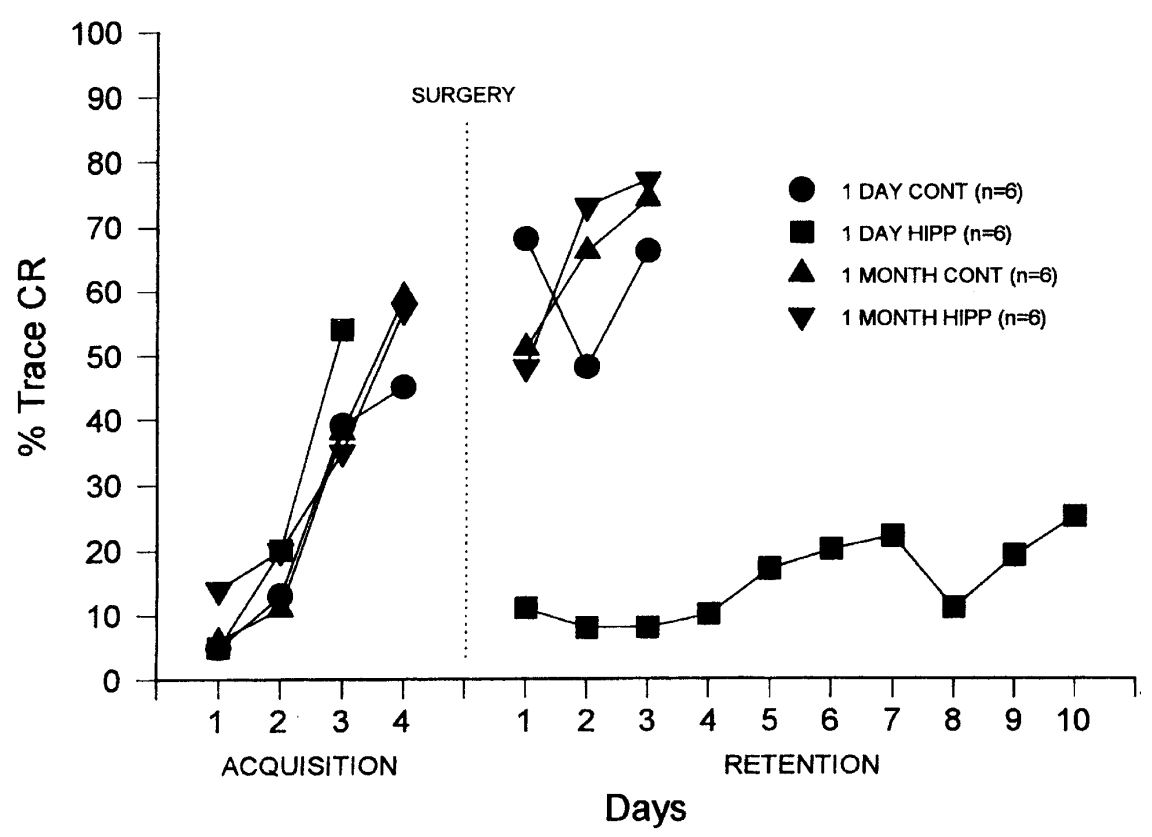

Figure 2 Mean percentage of trace eyeblink CRs (rabbit) during initial training and following postoperative testing training (large bilateral aspiration lesions of the hippocampus). 1 DAY CONT, cortical and sham control lesions made $1 \mathrm{~d}$ after training; 1 MONTH CONT, same but lesions made 1 mo after training; 1 DAY HIPPO, hippocampal lesions made $1 \mathrm{~d}$ after training; 1 MONTH HIPPO, same but lesions made $1 \mathrm{mo}$ after training. Retention training was always begun $7 \mathrm{~d}$ after surgery (from Kim et al. 1995).
McEchron and Disterhoft (1997) reported marked increases in hippocampal neuronal activity in trace conditioning, as was reported earlier for delay conditioning (see above). Further, with extensive training, the neuronal model declines (McEchron and Disterhoft 1997). Very large bilateral removal of the dorsal plus some ventral hippocampus in rabbits markedly impaired subsequent acquisition of the 500-msec trace CR, an example of anterograde amnesia (Solomon et al. 1986; Moyer et al. 1990). Smaller lesions are not effective (Port et al. 1986; James et al. 1987). Consistent with this finding, scopolamine at doses sufficiently low to have little effect on delay learning completely prevents acquisition of the trace CR (Kaneko and Thompson 1997). If rabbits are first trained in the trace procedure, large bilateral hippocampal lesions made immediately after training completely abolish the trace CR (such immediate lesions have little effect on the delay CR). However, if these same hippocampal lesions are made 1 mo after training, they do not impair performance of the trace CR at all, as shown in Figure 2 (Kim et al. 1995).

To summarize, large bilateral lesions of the hippocampus made before training markedly impair learning of the trace CR. If the animals are first trained, lesions immediately after training abolish the trace CR but lesions made 1 mo after training have no effect on memory of the trace CR. These results are strikingly consistent with the literature concerned with the declarative memory deficit following damage to the hippocampal-medial temporal lobe system in humans and monkeys. These deficits have two key temporal characteristics: (1) profound and permanent anterograde amnesia, and (2) profound but clearly timelimited retrograde amnesia. Subjects have great difficulty learning new declarative tasks/information and have substantial memory loss for events for some period just preceding brain damage ( 1 or more yrs in humans, $2-3$ mos for monkeys) but relatively intact memory for earlier events (Zola-Morgan and Squire 1990). Very similar results were found for classical conditioning of fear to context in rats (Kim and Fanselow 1992).

These results from studies on animals suggest that trace eyeblink conditioning provides a simple model of hippocampaldependent declarative memory, a possibility strongly supported by studies of humans with hippocampal-medial temporal lobe amnesia. In brief, such patients are markedly impaired on acquisition of trace eyeblink conditioning if the trace interval is sufficiently long (see reviews by McGlinchey-Berroth et al. 1997; Clark and Squire 1998; McGlinchey-Berroth 2000; but see Woodruff-Pak and Papka 1996 regarding shorter trace intervals), a result similar to impairments seen in such patients with conditional and reversal discriminations (see above). It is important to emphasize that lesions of the cerebellar interpositus nucleus completely and permanently abolish the trace conditioned eyeblink response (rabbits; Woodruff-Pak et al. 1985).

Imaging studies of eyeblink conditioning in humans have shown close correspondences with the animal literature. In brief, all imaging studies show engagement of the cerebellum (Molchan et al. 1994; Logan and Grafton 1995; Blaxton et al. 1996; Timmann et al. 1996 [human leg flexion conditioning]; Schreurs et al. 1997; Ramnani et 
al. 1999; Lemieux and Woodruff-Pak 2000). Other brain areas also show activation, including temporal areas of the neocortex and hippocampus (for reviews, see Lemieux and Woodruff-Pak 2000; McIntosh and Schreurs 2000). There is thus an extraordinarily close correspondence between the animal and human literatures. For humans, as for other animals, cerebellar lesions abolish delay eyeblink conditioning. Some reports state that cerebellar patients have shown intact responses described as naturally conditioned eyeblinks to visual threats (Bracha et al. 1997, 2000). In the same studies, acquisition of conditioned eyeblinks to novel stimuli and extinction of the previously acquired responses were prevented. In addition, unilateral cerebellar damage prevented acquisition of conditioned eyeblinks to a midline forehead-tap US. These data are difficult to interpret due to individual differences in the loci of the cerebellar lesions and the stated damage to the deep nuclei in several patients, especially in the absence of figures depicting the extent of damage. Further, it is not at all clear that eyeblinks to visual threats are indeed conditioned.

Delay eyeblink conditioning is intact in amnesic patients with bilateral medial temporal lobe (MTL) lesions; PET and fMRI studies show activation in both cerebellum and MTL in delay conditioning that parallels the development of behavioral CRs; amnesic patients with MTL lesions are markedly impaired in trace conditioning. As Gabrieli et al. (1998) stress: "the learning of delay eyeblink conditioning in humans appears to depend on a cerebellar memory system, but parallel learning occurs simultaneously in the MTL. The MTL learning is irrelevant for delay conditioning but critical for other sorts of conditioning such as trace conditioning. The cerebellar and MTL systems appear to operate independently (delay conditioning) or cooperatively (trace conditioning) during eyeblink conditioning" (p. 279). However, neural correlates of learning do develop in the hippocampus during delay conditioning, arguing for potential involvement of this structure in this form of learning and against dismissing its activity as irrelevant. Although studies to date have not supported the necessity of the hippocampus in delay conditioning, it appears to play an important modulatory role in some aspects of behavioral integration and may also support a secondary path of memory encoding and consolidation. Indeed, Akase et al. (1989) reported that hippocampal lesions under certain conditions can impair both consolidation and extinction of the delay conditioned eyeblink response.

In a similar vein, Green and Woodruff-Pak (2000b) note that the cerebellar system is essential in all discrete-response aversive classical conditioning paradigms, whereas the hippocampal system is not essential to form the association between a coterminating CS and a US-UR (but may play a modulatory role). However, the hippocampal system is essential when the paradigm requires the learning of associations between neutral stimuli. Green and Woodruff-Pak argue that the neutral stimulus association versus the simple stimulus-response association distinction is one of the ways in which declarative or relational memory can be separated from nondeclarative memory. Strong support for this neutral stimulus association view of hippocampal function is provided in studies by Patterson and associates showing that hippocampal lesions prevent the learning of sensory preconditioning (Port and Patterson 1984; Port et al. 1987). See also the discussion of the role of the hippocampus in eyeblink conditioning by Schmajuk and Di Carlo (1992).

Clark and Squire $(1998,1999)$ made the striking observation that awareness of the training contingencies in normal human subjects correlated highly with the degree of trace conditioning. They showed that awareness played no role in delay conditioning, that awareness does play a role in both single cue and differential trace conditioning, and that expectancy of US occur- rence influenced trace but not delay conditioning (Clark and Squire 2000; Manns et al. 2000a,b; Clark et al. 2001). They conclude that delay and trace conditioning are fundamentally different phenomena, delay inducing nondeclarative or procedural memory and trace inducing declarative memory. LaBar and Disterhoft (1998) raised questions about the initial Clark and Squire (1998) paper, which were in turn explored in the more recent Clark, Squire, and Manns papers and by Disterhoft and colleagues (Knuttinen et al. 2001). Specifically, LaBar and Disterhoft questioned the interpretability of the results in the original finding, citing several procedural factors including age of subjects, task complexity, and temporal resolution of self-reported awareness. Latter studies have controlled for subject age and employed a simpler single-cue protocol; the results support the general finding that awareness correlates with successful performance in trace eyeblink conditioning. An important issue raised by LaBar and Disterhoft concerns the temporal correlation between the onset of awareness and the learned behavior, a key feature not addressed by posttraining questionnaires to assay awareness. Manns et al. (2000b) measured subjects' awareness on a trial-bytrial basis and reported that awareness and stimulus discrimination develop in parallel. Although these results are intriguing, there is much work to be done to understand how awareness influences this form of learning and the nature of hippocampal involvement in such an interaction. This is a most interesting and important current area of research.

\section{Mechanisms of Hippocampal Plasticity in Eyeblink Conditioning}

\section{Long-Term Potentiation}

There are a number of lines of evidence supporting the possibility that the learning-induced increase in hippocampal neural unit activity in both delay and trace eyeblink conditioning involves the process of long-term potentiation (LTP). Thus, measuring the monosynaptic population spike of dentate granule cells to perforant path test pulses given between trials (rabbits-delay eyeblink), there is a marked and persisting increase in the population spike in trained but not unpaired control animals that develops in close correlation with the behavioral CR over the course of $2 \mathrm{~d}$ of training (Weisz et al. 1984). In both the delay and trace paradigms (rabbits), there is a substantial and highly significant increase in AMPA binding, but no change in NMDA receptor binding, in the hippocampus of well trained animals versus control animals given the same number of pseudorandom unpaired CSs and USs (Tocco et al. 1991; 1992a). This pattern of increased AMPA binding in the hippocampus closely parallels the increased AMPA binding in vivo (rat) following perforant path stimulation, that is, LTP (Tocco et al. 1992b; Maren et al. 1993).

The learning-induced increase in hippocampal neuronal activity, particularly in the US period, closely parallels the properties of hippocampal LTP in a number of other ways as well (Berger et al. 1986; Thompson 1997): Both are expressed by pyramidal (and granule) neurons; both result in pronounced and long-lasting increases in neuronal excitability; both decay with a very slow time course (days to weeks); only a small number of stimulations are needed for each; both show a similar rapid timecourse of development; the magnitude of increase in neuronal response (excitability) is similar in both; very specific patterns of stimulation are needed for each; both exhibit "associativity"; and the $\theta$ frequency is critical for both (stimulation; spontaneous activity).

Particularly striking is the time-limited duration of this learning-induced neural activity in the hippocampus, closely paralleling both the period of time when the hippocampus is necessary for retention of trace conditioning (Sears and Steinmetz 1990; Katz and Steinmetz 1994; Kim et al. 1995; L. Thomp-

\section{Learning \& Memory}


son et al. 1996; Disterhoft and McEchron 2000) and the time period of duration of LTP induced in the hippocampus in vivo (Staubli and Lynch 1987; Shors and Matzel 1997). In addition to these correspondences, Berger (1984) showed that perforant path induction of LTP markedly facilitated subsequent eyeblink discrimination learning in rabbits.

Consistent with the LTP hypothesis of learning-induced increases in hippocampal unit activity, Disterhoft and associates (L. Thompson et al. 1992) showed that pharmacological manipulation of the NMDA receptor, for example by agonists, markedly facilitated acquisition of the behavioral trace eyeblink CR. Further, two NMDA noncompetitive antagonists given systemically (intramuscularly), MK 801 and PCP, blocked acquisition of the trace CR at doses that caused significant slowing of delay acquisition, but did not impair performance of the learned CR (L. Thompson and Disterhoft 1997). However, Cox et al. (1994) administered MK801 intravenously and reported almost complete prevention of acquisition of the delay eyeblink CR and virtually complete abolition of CR performance. On the other hand, Servatius and Shors (1996) found that intraperitoneal injection of the NMDA competitive antagonist CGP-39551 (rat) prevented learning but not performance of the delay CR, in general agreement with Disterhoft and associates. A small caveat: Because of the nonspecific routes of administration, these NMDA receptor modulators could act on virtually any structure in the brain.

\section{Afterhyperpolarization and Protein Kinase $C$}

In a series of studies, Alkon, Disterhoft, and associates explored alterations in excitability of pyramidal neurons following eye-

$\mathbf{A}$

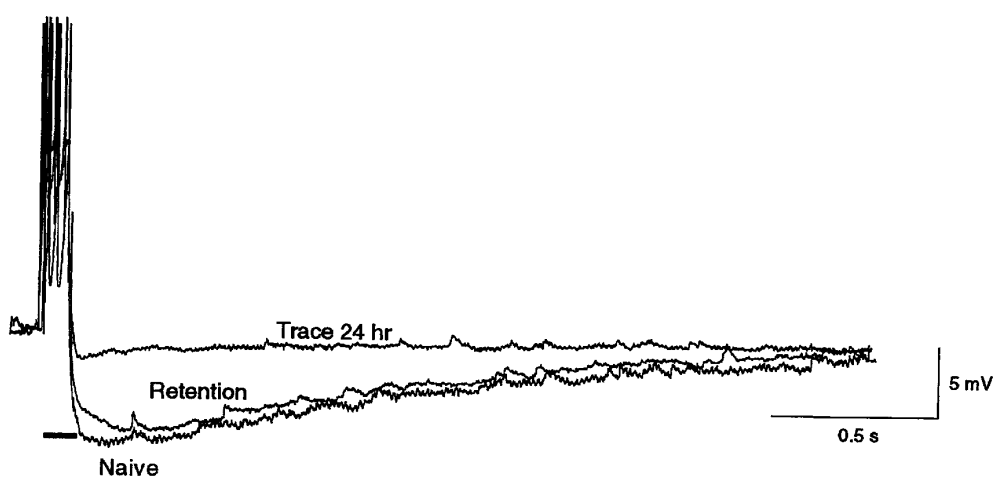

B

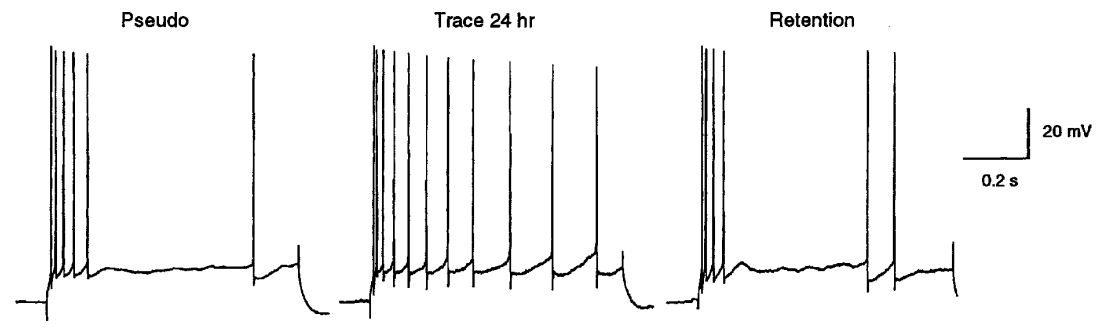

Figure 3 Hippocampal CA1 pyramidal cells (intracellular recordings) exhibit a transient increase in excitability following acquisition of trace eyeblink conditioning. ( $A$ ) Overlapping traces of AHPs in CA1 neurons following injection of a $100-\mathrm{msec}$ depolarizing current (horizontal bar). Current injection was the minimum required to elicit burst of four action potentials and did not differ significantly between groups. Amplitude and duration of AHP are similar in recordings from animals not exposed to training stimuli (Naïve) and recordings from animals $14 \mathrm{~d}$ after acquisition (Retention). Recordings from pyramidal cells $24 \mathrm{~h}$ following acquisition show a significant decrease in the duration and amplitude of the AHP (Trace 24 h). (B) Spike accommodation in response to 800 msec depolarizing current is significantly reduced in CA1 pyramidal neurons $24 \mathrm{~h}$ after acquisition (Trace $24 \mathrm{~h}$ ) compared to pyramidal cells from animals receiving explicitly unpaired stimuli presentations (Pseudo) or animals trained $14 \mathrm{~d}$ prior to recording (from Moyer et al. 1996). blink conditioning, using both delay and trace procedures (e.g., Disterhoft et al. 1986; Coulter et al. 1989; Sanchez-Andres and Alkon 1991; Moyer et al. 1996; L. Thompson et al. 1996). In brief postburst afterhyperpolarization (AHP), were measured in in slices obtained from trained and pseudoconditioned raboccurred $1 \mathrm{~h}$ after behavioral training, peaked $24 \mathrm{~h}$ after training and decayed over a period of about 1 wk (Fig. 3A). et al. 1996). Spike frequency accommodation changes with the time course as does the decrease in the AHP (Fig. 3B). This dependent outward potassium currents. It is important to emphasize that these learning-induced alterations in the AHP are intrinsic to the neurons and, unlike LTP, do not necessarily inolve alterations in synaptic excitability. Alterations in the AHP and induction of LTP are of course not mutually exclusive-both pear to occur in eyeblink conditioning. in related studies, classical eyeblink conditioning resulted in enzyme involved in control of membrane excitability and also involved in mechanisms of LTP (Olds et al. 1989). After $1 \mathrm{~d}$ of training, the increase in PKC was localized near the cell bodies of pyramidal neurons (CA1) but after $3 \mathrm{~d}$ of training, when learning was well established, maximal PKC labeling moved from the cell bodies to the regions of the CA1 dendrites. This same translocation of PKC in CA1 cells can be induced by phorbol esters, drugs that also induce LTP in CA1 pyramidal neurons (see reviews by Van der Zee et al. 1997 and Schreurs 2000).

\section{Anatomical Correlates}

In a most interesting series of morphological studies, Geinisman and associates (2000, 2001) reported learning-induced changes in hippocampal synapses in rabbit CA1 stratum radiation following trace eyeblink conditioning. Using unbiased stereological methods, they compared tissue from trace versus control animals and found that: (1) The total number of synapses did not change; (2) the area of postsynaptic density was increased in axospinous nonperforated synapses; and (3) the number of multiplesynapse boutons was increased.

In remarkable recent work, Shors, Gould, and associates explored the fate of new adult-generated neurons in the hippocampal dentate gyrus in trace and delay eyeblink conditioning in the rat (Gould et al. 1999a,b; Shors et al. 2001). New neurons were labeled with a thymidine analog injection $1 \mathrm{wk}$ before training; delay and trace groups were given the same number of trials and both learned to the same asymptote. The trace procedure resulted in a significantly and substantially higher number of new neurons in the dentate gyrus compared to the delay and control conditions. Similar results were found for the Morris wa- 
termaze: an increase in number of neurons in spatial versus visual cue tasks. Further, injection of a toxin for proliferating cells (MAM) markedly impaired trace but not delay eyeblink acquisition. These results raise the possibility that new adult-generated neurons may play a role in trace memory formation in the hippocampus.

\section{Modulatory Effects on Eyeblink Conditioning}

There is a very large literature concerning the effects of various manipulations and drugs on the rate of learning in both delay and trace eyeblink conditioning. We sample it only briefly here. A dramatic example is provided by Berry and Swain (1989): Water deprivation markedly enhances acquisition (rabbits-delay eyeblink), and the correlation between trials to criterion and relative amount of hippocampal $\theta$ EEG frequency is 0.84 (see also Berry and Thompson 1978). In intriguing observations, Berry and associates reported that if training trials (rabbits-delay eyeblink) were given during episodes of hippocampal $\theta$ frequency slow waves, learning was substantially faster than if such trials were given during episodes of non- $\theta$ activity (Seager et al. 2002). Stress also enhances acquisition in rats (Shors 1998), as does anxiety in humans (Taylor 1951). Actually, stress enhances acquisition in male rats but impairs it in females (Shors et al. 1998, 2000; Wood and Shors 1998; Shors 2001). Drug effects on acquisition are legion. In general, drugs that enhance acetylcholine (ACh) function enhance acquisition, and drugs that impair ACh function impair acquisition, either via actions on nicotinic or muscarinic receptor systems or via acetylcholinesterase (e.g., Solomon et al. 1993; Woodruff-Pak and Ewers 2000; see above). Drugs that impair functions of certain types of calcium channels, for example, nimodipine, enhance acquisition and retention of eyeblink conditioning (Deyo et al. 1989; Straube et al. 1990; Solomon et al. 1995; Woodruff-Pak et al. 1997), consistent with the putative AHP mechanism operative in hippocampal pyramidal neurons (see above). Virtually all of this literature involves systemic or ventricular administration of the drugs. It is tempting to attribute some of these effects to actions on the hippocampus, for example, ACh and calcium channel drugs; however, it is also possible that their effective sites of action are actually on the cerebellum or other structures (see Woodruff-Pak and Ewers 2000). Although these studies can at best be only suggestive of mechanisms of learning and remembering, even a very modest and not understood enhancement of memory performance can make an enormous difference to people experiencing memory impairment (see Woodruff-Pak and Steinmetz 2000).

\section{Other Brain Areas}

The CR is completely abolished and learning is completely prevented only by lesions in the essential circuitry. The essential CS-CR pathway includes the relevant sensory nuclei, pontine nuclei, middle cerebellar peduncle, cerebellum (interpositus nucleus), superior cerebellar peduncle, red nucleus, rubral pathways, and relevant motor nuclei (see below). Lesions of the US pathway (trigeminal nucleus, inferior olive, climbing fibers) also prevent learning and result in extinction and abolition of the already learned CR (see below). Lesions of no other brain structures yet investigated can produce these effects.

Lesions of other brain structures can modulate acquisition rate and performance of the eyeblink CR. Thus, lesions of frontal cortex can alter CR latency (Fox et al. 1982); lesions of prefrontal cortex and mediodorsal thalamic nuclei slow the rate of acquisition (Buchanan and Powell 1982; Buchanan 1991; Buchanan et al. 1997a,b; Powell et al. 2000; see below), as do medial septal lesions (Berry and Thompson 1979) neostriatal lesions (Kao and Powell 1988; see also recordings by Richardson and Thompson 1985; White et al. 1994), and amygdala lesions (see below). A number of brain areas show the development of the learninginduced neuronal model of the CR in eyeblink conditioning. With only one possible exception (cerebellar cortex, see Katz and Steinmetz 1997), lesion or reversible inactivation of the interpositus nucleus by cooling completely abolishes these neuronal learning models in all other structures (Lavond and Cartford 2000). As an example, neurons bordering a region of the trigeminal nucleus show both CS and US onset-evoked responses and develop a neuronal model of the learned response (Richards et al. 1991). However, reversible inactivation of the interpositus nucleus or the red nucleus completely abolishes the neuronal model of the learned response in the trigeminal region without abolishing the CS and US onset-evoked responses, as seen in Figure 4 (Clark and Lavond 1996). Recall that inactivation of the red nucleus does not prevent learning. The neuronal learned model is relayed from the interpositus and the red nucleus to the trigeminal region neurons; it does not originate in this latter region.

Similarly, an interpositus lesion abolishes the learning-induced neuronal model in the ventrolateral thalamus (Sears et al. 1996, see above). The pontine nuclei also exhibit the neuronal model of the CR, and inactivation of the interpositus completely abolishes it (Clark et al. 1997a; Bao et al. 2000). Several lines of evidence argue for a CS relay function for the pontine nuclei in eyeblink conditioning (Steinmetz et al. 1987; Tracy et al. 1998; see above). If stimulation of the lateral reticular nucleus is used as a CS, the activated mossy fibers bypass the pontine nuclei in projecting to the cerebellum. The pontine nuclei still develop a neuronal learned model (abolished by interpositus lesions), but pontine lesions no longer impair the behavioral CR (Bao et al. 2000). The possible roles of these projections of the neuronal

\section{Day 1 Normal}

\section{Paired US alone}

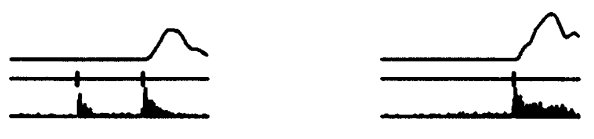

Day 4 Normal

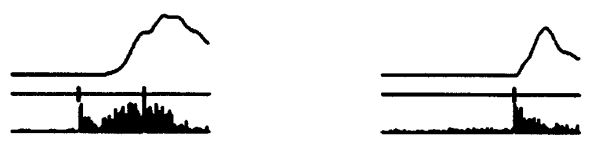

\section{Day 4 Cooling}
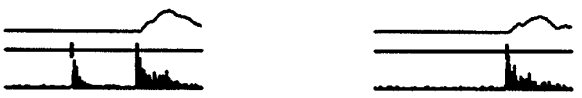

Figure 4 Multi-unit activity recorded from cells in trigeminal complex models the learned response and is dependent on input from the red nucleus. Top trace in each graph shows timecourse of nictitating membrane response; middle trace depicts onset of tone CS and airpuff US; bottom trace shows histogram of unit activity. At the beginning of the training, stimulus-evoked increases in neural activity are evident during both paired (left column) and airpuff-alone (right column) trials (top row). On the fourth day of training, increased activity in trigeminal cells mirrors the timecourse of the learned response on paired trials (middle row). Inactivation of the red nucleus via a cooling probe abolishes the learningrelated unit activity, whereas stimulus-evoked responses remain intact (bottom row). Total trace duration $750 \mathrm{msec}$ (from R.E. Clark and D.G. Lavond, pers. comm.; see also Clark and Lavond 1996).

\section{Learning \& Memory}


model of the learned response from the interpositus to other brain regions, particularly sensory relays such as the trigeminal nucleus and pontine nuclei, are interesting issues for the future.

A major unanswered question concerns the relation between the cerebellum and the hippocampus in eyeblink conditioning. Interpositus lesions that abolish the behavioral CR (delay procedure) abolish the neuronal model of the CR in the CS period in the hippocampus and reduce the neuronal model in the US period. However, retraining of the contralateral CR immediately reestablishes the hippocampal neuronal model (Clark et al. 1984; Sears and Steinmetz 1990). As noted, interpositus lesions also abolish the trace CR. The functional pathways between the cerebellum and hippocampus have yet to be determined, although several have been suggested on anatomical grounds (Berger et al. 1990). The ventrolateral thalamus exhibits the learning-induced model of the $\mathrm{CR}$, and interpositus lesions abolish this thalamic response; unfortunately, lesion of this thalamic region does not abolish the neuronal model in the hippocampus (Sears et al. 1996).

Three brain areas/systems require special treatment: frontal cortex, amygdala, and motor cortex.

\section{Frontal Cortex}

A key issue concerns the locus of the long-term memory trace for trace eyeblink conditioning after the hippocampus is no longer necessary. The medial anterior neocortex appears to be involved in some manner but the data are murky. Solomon et al. (1986) reported that lesions of retrosplenial cortex, like hippocampal lesions, impaired trace acquisition, but Weible et al. (2000) reported otherwise. Chachich and Powell $(1992,1998)$ reported that medial prefrontal lesions impair discrimination reversal. Kronforst-Collins and Disterhoft (1998) and Weible et al. (2000) reported that medial prefrontal lesions markedly impair trace acquisition, but Powell et al. (2001) reported little effect of such lesions on trace acquisition or retention. Weible et al. (2000) also reported that rostral medial prefrontal lesions retarded trace extinction. Many of these discrepancies may be due to differences in exact locations of the lesions. The key experiment-train the trace CR, wait a month, then lesion-has not yet been done. What is the role of the cerebellum in the trace memory after the hippocampus is no longer necessary? How are the cerebellar, hippocampal, and cortical systems functionally interconnected? These issues assume considerable importance given the recent work on trace eyeblink conditioning as a model of declarative memory in humans as well as in infrahuman animals noted above (e.g., Clark and Squire 1998).

\section{Amygdala}

The amygdala is critically important for conditioned fear, also termed the conditioned emotional response (CER; Fanselow 1984; McGaugh 1989; LeDoux 1996; Davis 1997). Although the amygdala is not essential for eyeblink conditioning, it can play a powerful modulatory role in both learning and performance. Lesions of the amygdala significantly slow the rate of learning of eyeblink conditioning, but this modulation of CR acquisition by the amygdala depends upon conditioning parameters (Weisz et al. 1992). Electrical stimulation of the amygdala central nucleus increases the amplitude of the eyeblink UR subsequently elicited by corneal airpuff US (Whalen and Kapp 1991) and the orbicularis oculi EMG response elicited by periorbital shock (D.J. Weisz and B.Y. Yang, pers. comm.).

The amygdala also plays a key role in reflex facilitation or conditioned potentiation of the eyeblink UR. This procedure entails pairing a neutral stimulus with a strongly aversive stimulus, usually shock, thus establishing a CER. This stimulus is then presented with elicitation of a reflex response. An early demonstra- tion of this effect was by Brown, Kalish, and Farber (1951), who showed that presentation of a light together with an auditory startle stimulus enhanced the startle response if the light had previously been paired with a shock. Davis and associates completed an elegant analysis of the neural substrates of this conditioned fear potentiation of the acoustic startle response (Davis 1992, 1997). Weisz and associates explored reflex facilitation of the eyeblink response (Weisz and LoTurco 1988). Effective CSs being trained to a corneal airpuff US facilitated the UR. Cerebellar interpositus lesions that abolish the CR had no effect on this reflex facilitation. On the other hand, lesions of the amygdala completely abolish this facilitation (Weisz et al. 1992).

In a recent series of studies, Brown and colleagues investigated reflex facilitation of the early component (R1, 4-7 msec) of the eyeblink reflex (EMG recording of orbicularis oculi) evoked by stimulation of the 5th nerve (Canli and Brown 1996; Lam et al. 1996; Choi et al. 2001). The amplitude of this short-latency response was enhanced in the presence of a tone that had previously been paired with footshock (i.e., CER). Lesions of the central nucleus of the amygdala blocked this facilitation. Rats trained first in a CER showed facilitated acquisition of eyeblink conditioning compared to controls, an effect that was prevented by prior lesions of the amygdala (Neufeld and Mintz 2001).

All these results support the long held notion of a two-factor theory of learning (e.g., Mowrer 1947; Konorski 1967; Rescorla and Solomon 1967). Wagner and Brandon (1989) developed an elegant instantiation of this idea in their AESOP model of associative learning, namely that stimulus coding involves theoretically separable emotional as well as sensory-motor components, and they developed strong behavioral support for this view (Bombace et al. 1991; Brandon and Wagner 1991; Brandon et al. 1991). Mintz and Wang-Ninio (2001) elaborated the two-factor notion into a two-stage theory: fast CER learning followed by slower motor learning, the latter being facilitated by the former (see Powell et al. 1974; Weinberger 1982; Thompson et al. 1984; also Lavond et al. 1984a). Mintz and Wang-Ninio showed that the fast CER was dependent upon the amygdala and the slower acquisition of the sensory-motor CR (eyeblink) on the cerebellar interpositus nucleus; the cerebellar lesions having no effect on acquisition of the CER.

The emotional and sensory-motor forms of learning involve separate and independent systems that can interact in modulating performance of both the conditioned and reflex responses. Such manipulations that alter UR performance have no necessary relation to memory formation in the cerebellum.

\section{Motor Cortex}

In an extensive series of studies, Woody and associates analyzed changes in excitability of neurons in primary motor cortex of cat projecting to the facial and other motor nuclei following a conditioning procedure using paired click CS and glabella-tap US (Woody and Brozek 1969a,b; Woody 1970). In this paradigm and preparation, the click CS elicits a short-latency eyeblink response (EMG recording, $\sim 20 \mathrm{msec}$ ) prior to training ( $\alpha$ response). After the response is habituated to CS alone, extensive (e.g., 500) pairings of CS and US increased the amplitude of the EMG response to the click CS (see Fig. 3 of Woody et al. 1974, p. 389). This pairing-induced increase in response amplitude is associated with evoked increases in excitability of neurons in the region of motor cortex activating relevant motor neurons and nuclei (e.g., facial nucleus). Lesions of the motor cortex were reported to impair acquisition of this short latency response (Woody et al. 1974).

Interestingly, the latency of this response did not appear to change over the course of conditioning. There are several other complications as well in this paradigm (Brons and Woody 1980; 
Brons et al. 1982). First, the increased excitability of the CRprojecting neurons did not decrease during extinction. Second, unpaired presentations of the CS resulted in increased CS-evoked motor cortex unit activity. Third, unpaired presentations of the US increased CR-projecting neuron excitability transiently. Fourth, unpaired US presentations also caused decreased excitability to extracellular stimulation (of motor cortex) and an increase in the number of functional motor cortex units projecting to the UR-related facial nucleus. Similarly, excitability of facial nucleus motor neurons was increased in both paired CS-US and US alone conditions (Matsumura and Woody 1982). In any event, Woody and associates completed an extensive analysis of second messenger cascades proposed to account for the increased excitability of motor cortex neurons (Woody et al. 1984).

The longer-latency eyeblink CR that is the focus of this review is adaptive in that the peak amplitude of the CR occurs at the onset of the US over a wide range of CS-US onset intervals, and it exhibits all the basic properties of Pavlovian conditioning, including inhibition of delay (see Gormezano et al. 1983). Further, this adaptive response is not elicited by the CS prior to training. In all these and other ways, it differs from the shortlatency $\alpha$ response studied by Woody and associates. Extensive bilateral frontal cortical lesions (rabbit) including all the primary motor cortex have little or no effect on the adaptive eyeblink CR, even using a click CS (airpuff US) and a 500-msec trace interval (Ivkovich and Thompson 1997). The short-latency eyeblink response to click in the cat appears to be a component of the startle response (Davis 1984; see also Voronin and Ioffe 1974; Woody 1982) which likely does not involve the cerebellar circuitry.

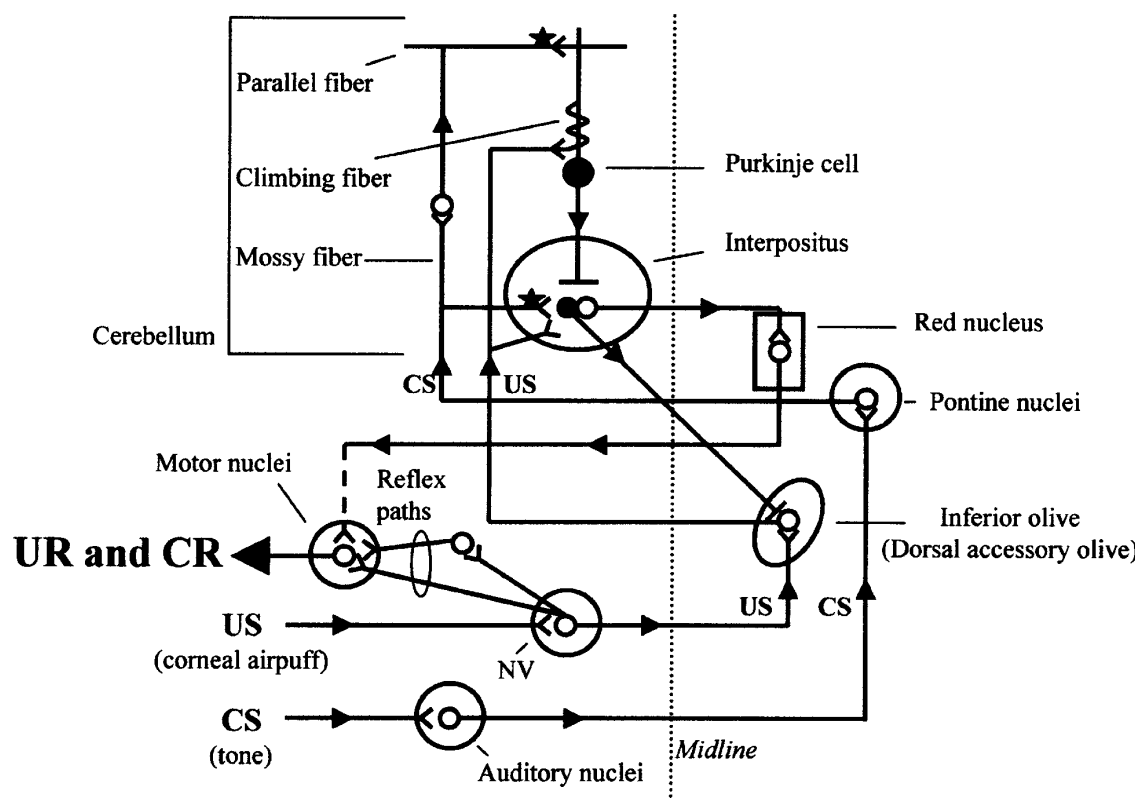

Figure 5 Simplified schematic (most interneurons omitted) of the putative essential circuitry for delay classical conditioning of eyeblink (and other discrete responses) learned with an aversive US. (The sensory and motor nuclei activated depend of course on the nature of the CS and US- the more central portions of the circuit appear to be general). The reflex US-UR pathway involves direct and indirect projection from the trigeminal nucleus to the motor nuclei (for the eyeblink UR and CR, primarily accessory 6 and 7). The tone CS pathway projects from auditory nuclei to the pontine nuclei and to the cerebellum as mossy fibers. The US pathway includes projections from the trigeminal to the inferior olive (IO) and to the cerebellum as climbing fibers. The CR pathway projects from the interpositus to the red nucleus and on to premotor and motor nuclei. There is also a direct GABAergic inhibitory projection from the interpositus to the IO. Omitted from this diagram are feedback projections from the cerebellum to several afferent structures. These projections have generally been described physiologically, not anatomically, and may well be involved in some aspect of CR modulation. See text for discussion. Solid cell bodies and bar terminals indicate inhibitory neurons; open cell bodies and fork terminals indicate excitatory neurons. Stars indicate sites of plasticity based on current evidence. See text for details. (Modified from Thompson 1986.)

\section{Cerebellar System and "Procedural” Memory}

A large literature is in general agreement in identifying the essential circuitry for classical conditioning of eyeblink and other responses (see Fig. 5). This circuitry follows closely the and is in general accord with classical theories of cerebellar learnand Kim 1996; Mauk and Donegan 1997; Thompson et al. 1997; Steinmetz 1998, 2000a; Yeo and Hesslow 1998). Where some authors have expressed doubts about particular anatomical path-

\section{The UR Pathways}

The eyeblink reflex in the rabbit is a coordinated response inclosure, eyeball retraction, and resulting passive extension of the man et al. 1962; Deaux and Gormezano 1963; McCormick et al 1982c). It is but one adaptive response with several components. responses focused on NM extension, actually eyeball retraction, muscle, innervated largely by axons of the sixth nerve originating in the accessory abducens (and to a much lesser extent, abtreve other extraocular muscles also conbus or relax in an antagonistic manner in the case of the levator palpebrae motor neurons (Cegavske et al. 1976, 1979, 1987; Berthier et al. 1987; Disterhoft et al. 1987).

At the time there was much debate about the details of innervation of the retractor bulbus muscle, which in retrospect was somewhat irrelevant because the most prominent and sensitive component of the response is EMG activity in the orbicularis oculi muscle controlling external eyelid closure (Lavond et al. 1990), innervated by the seventh nerve from the facial nucleus. Furthermore, in many mammalian species, including humans, the NM is vestigial.

In terms of the reflex pathways, there are direct projections from neurons in regions of the trigeminal nucleus to the accessory abducens (and abducens) nuclei and to the facial nucleus (Berthier et al. 1987; Cegavske et al. 1987), as well as indirect projections relaying via the brainstem reticular formation, at least to the facial nucleus (Tamai et al. 1986). Although the CR and UR share many common features, there are critical qualitative differences between the two that include variations in both the intrinsic properties and the neural substrates responsible for each response (see discussion of the amygdala above). Standard eyeblink training procedures typically result in a progressive increase in the amplitude of the UR, due to both associative and nonassociative factors (Steinmetz et al. 1992a; Wikgren and Korhonen 2001). Interpositus

\section{Learning \& Memory}

www.learnmem.org 
lesions can impair the associative component of the UR increase (Wikgren et al. 2002).

Lesions of the interpositus successful in abolishing the CR have only a transient depressive effect on UR amplitude in initial postlesion assays at the same US intensity level used in prelesion training (Steinmetz et al. 1992a). Subsequent training fully restored UR amplitudes to prelesion levels, demonstrating a lack of interpositus involvement in the sustained eyeblink reflex modification following conditioning. Steinmetz et al. (1992a) investigated numerous parameters of the UR including amplitude, rise time, frequency, and latency in the same animals at several US intensities and found no significant lasting effects of interpositus lesions in any of these properties. Ivkovich et al. (1993) lowered US intensity levels to threshold to control for discrepancies in the amplitude of prelesion CRs and URs, and it was again shown that interpositus lesions that completely abolished the CR had no significant effect on postlesion UR amplitude. Results from Kolb et al. (1997) have shown similar transient effects on unconditioned limb withdrawal with interpositus inactivation following classical conditioning of this reflex in cats, but again only 130 trials were given during inactivation, and therefore the results cannot be interpreted as demonstrating a sustained involvement of the interpositus on UR expression. In addition, infusion coordinates included regions of the posterior interpositus as well as the anterior region, although the latter area is considered critical to the acquisition and expression of the CR and is thus the primary region of interest in the dissociation of control over CR and UR expression.

In contrast to the clear results indicating that the interpositus plays no critical role in any aspect of expression or modification of the UR, there are reports that damage to the cerebellar cortex may result in an increase in UR amplitude (Logan 1991; Yeo and Hardiman 1992). This does not, however, undermine a central tenet of cerebellar learning theory that requires that the primary locus of the conditioned memory trace, the interpositus, is not necessary for UR expression. Furthermore, these cortical lesions impaired the rate of acquisition and frequency of conditioned responding, providing further evidence that the two responses are differentially modulated. Involvement of cortical regions in reflex adaptation elicited by reducing eyelid motility does not address and is not inconsistent with cerebellar control of classically conditioned eyeblinks (Pellegrini and Evinger 1997).

The argument that the CR is merely a weaker response more susceptible to interpositus lesions than similarly controlled URs (Welsh and Harvey 1989) was conclusively refuted in studies demonstrating a dissociation of the CR and UR following disruption of motor efferents common to both. Substantial lesions in the region of the accessory abducens nucleus cause virtual abolition of the NM extension response for both the CR and the UR, but the NM CR shows much greater recovery over time than does the NM UR (Disterhoft et al. 1985; Steinmetz et al. 1992a). Importantly, lesions of the cerebellum that completely and permanently abolish all components of the CR (see below) have no lasting effect on any component of the UR, at any level of US intensity, including threshold (Steinmetz et al. 1992a; Ivkovich et al. 1993). The cerebellar circuitry thus plays no essential role in performance of the reflex response. However, the same motor nuclei, nerves, and muscles are involved in both the CR and the UR.

\section{The CR Pathway}

Neurons in a localized region of the interpositus nucleus ipsilateral to the trained eye develop a neuronal model of the learned behavioral $\mathrm{CR}$; lesions of this region selectively abolish the $\mathrm{CR}$ with no effect on the UR; electrical stimulation of this region evokes the eyeblink response before training (see below). This region of the interpositus projects via the superior cerebellar peduncle to a region of the contralateral magnocellular red nucleus. Lesions of the peduncle abolish the CR, as do lesions of the key region of red nucleus, where neurons also show a model of the learned response. Stimulation of this rubral region also elicits the eyeblink response. The descending rubral pathways project contralaterally to premotor and motor nuclei, seventh for external eyelid closure, accessory sixth and sixth for NM extension. Overwhelming evidence identifies this circuit as the efferent CR pathway for the conditioned eyeblink response (for a detailed review, see Thompson and Krupa 1994). A similar pathway projecting to the spinal cord subserves classical conditioning of the limb flexion response in cat (Voneida 1999, 2000).

\section{The CS Pathway}

The pontine nuclei send axons as mossy fibers directly to the cerebellar cortex and interpositus nucleus, mostly contralaterally (Brodal 1981; J. Thompson et al. 1991; Shinoda et al. 1992; Steinmetz and Sengelaub 1992; Mihailoff 1993). The pontine nuclei in turn receive projections from auditory, visual, somatosensory, and association systems, both cortical and subcortical (Glickstein et al. 1980; Brodal 1981; Schmahmann and Pandya 1989, 1991, 1993). Appropriate lesions of the pontine nuclei can abolish the CR established to a tone CS but not a light CS; that is, they can be selective for CS modality (interpositus lesions abolish the CR to all modalities of CS; Steinmetz et al. 1987). Lesions of the region of the pons receiving projections from the auditory cortex abolish the CR established with electrical stimulation of auditory cortex as a CS (Knowlton and Thompson 1992; Knowlton et al. 1993). Extensive lesions of the middle cerebellar peduncle (mcp), which conveys mossy fibers from the pontine nuclei and other sources to the cerebellum, abolish the CR to all modalities of CS (Lewis et al. 1987).

Electrical stimulation of the pontine nuclei serves as a "supernormal" CS, yielding more rapid learning than does a tone or light CS (Steinmetz et al. 1986; Tracy et al. 1998). Stimulation of the mcp itself is an effective CS (Steinmetz 1990a; Svensson and Ivarsson 1999), and lesion of the interpositus nucleus abolishes the CR established with a pontine or middle peduncle stimulation CS (Steinmetz et al. 1986). When animals are trained using electrical stimulation of the pontine nuclei as a CS (corneal airpuff US), some animals show immediate and complete transfer of the behavioral CR and of the learning-induced neural responses in the interpositus nucleus to a tone CS (Steinmetz 1990b) and complete transfer from peripheral CSs to mossy fiber stimulation in the mcp (Hesslow et al. 1999). These results indicate that the pontine-mcp stimulus and tone must activate a large number of memory circuit elements (neurons) in common. In sum, the mossy fiber system, coming mostly from the pontine nuclei, is the CS-activated pathway to the cerebellum (Thompson et al. 1997).

\section{The US Pathway}

Neurons in the inferior olive (IO) send climbing fiber projections contralaterally directly to cerebellar cortex and interpositus nucleus (Brodal et al. 1975; Groenewegen et al. 1979; Brodal 1981; Ito 1984; Tracy et al. 1998; Sugihara et al. 2001). The critical region of the IO for eyeblink conditioning is the dorsal accessory olive (DAO), which receives predominantly somatosensory input relayed from the spinal cord and appropriate cranial nuclei, including nociceptive input (Brodal 1981). Lesions of the critical region of the IO, the face representation in the DAO, completely prevent learning if made before training and result in extinction of the CR if made after training (McCormick et al. 1985; Voneida et al. 1990 [limb flexion in cat]; Mintz et al. 1994; 
see also Yeo et al. 1986). Neurons in this critical DAO region do not respond to auditory stimuli (CS), respond only to US onset, and show no learning-related activity, and the US-evoked response decreases as animals learn (Sears and Steinmetz 1991). Electrical microstimulation of this region serves as a very effective US (Mauk et al. 1986; Steinmetz et al. 1989). All these data argue that the DAO-climbing fiber system is the essential USreinforcing pathway for the learning of discrete responses (Thompson 1989; Thompson et al. 1998).

However, the proposition that the acquisition of the conditioned eyeblink depends critically on activation of cerebello-olivary loops or recurrent activity in a circuit involving extracerebellar structures does not appear to be consistent with the preponderance of evidence. Overwhelming evidence from lesion, recording, and stimulation studies support the localization of this memory trace to a restricted region of the interpositus. Claims that inactivation of the interpositus does not prevent transfer training from one CS to another (Welsh and Harvey 1991) have not been substantiated (Cipriano et al. 1995). The critical region of the interpositus is anatomically restricted, and failure to adequately target the essential area may compromise expression but not learning of a novel CS. Lidocaine inactivation of the dorsal anterior interpositus completely blocks acquisition and expression of the $\mathrm{CR}$, whereas infusions into the ventral interpositus block expression but not acquisition (Nordholm et al. 1993). Ventral infusions selectively disrupt the efferent pathways from the dorsal interpositus and very likely impinge upon the superior cerebellar peduncle, the axonal tract relaying information from the interpositus to its downstream target, the red nucleus. Despite the profound effects of inactivation of ventral interpositus or the superior cerebellar peduncle on the expression of the CR, asymptotic levels of conditioning are attained in the absence of observable learned behavior, and therefore acquisition cannot depend upon feedback or reafference information originating in structures downstream from the dorsal interpositus. The complete abolition of acquisition during dorsal interpositus inactivation suggests that memory trace formation occurs at or efferent to this site. Although this region of the interpositus does project to the IO, as well as downstream targets, it does not appear that the IO is the site of memory formation or storage itself. Localized lesions of this region result in gradual extinction of the CR, as the IO is the essential relay for US information to the cerebellum (McCormick et al. 1985; Voneida et al. 1990). Large lesions and inactivation of the IO may result in immediate disruption of CR expression (Yeo et al. 1986; Welsh and Harvey 1998), due in part to a resultant increase in the simple spike activity of Purkinje cells (Colin et al. 1980; Montarolo et al. 1982; Savio and Tempia 1985). Increased Purkinje cell inhibition of the deep nuclei would prohibit generation of CRs that depend on sufficient increases in interpositus activity. Conditioning of reflexes elicited by cerebellar stimulation that do not rely on a peripheral US would not depend on the same activation of the IO (Shinkman et al. 1996). Cortical lesions impair acquisition and expression but do not appear to abolish or prevent conditioning (but see below). Although the essential memory circuit for classically conditioned eyeblinks to peripheral stimulation includes extracerebellar structures that receive feedback from the interpositus, evidence to date suggests that there is a highly localized pathway responsible for the generation of this learned behavior.

In a classic but largely forgotten study, Brogden and Gantt (1942) reported that stimulation of cerebellar white matter elicited discrete behavioral movements, for example, limb flexion, head turn, and eyeblink, and these movements so elicited could easily be conditioned to any neutral stimulus, for example, light or sound. These observations have been replicated and extended in recent years (Thompson et al. 2000). Swain et al. (1992) used a tone CS and showed that stimulation of cerebellar white matter in lobule HVI (rabbit) did indeed elicit movements: eyeblink, NM extension, and movements of the head and upper lip. These movements all conditioned, extinguished, and reconditioned to a tone CS in a manner identical to CRs established with aversive peripheral USs. Further, kainic acid lesions of the interpositus that spared fibers abolished both the CR and the white matter stimulation-elicited UR, thus ruling out antidromic activation via pontine nuclei or IO of the UR (Swain et al. 1999). Evidence is consistent with stimulation of climbing fibers in cerebellar white matter as the US effective for learning. To our knowledge, the IO-climbing fibers system is the only system in the brain, other than reflex afferents, where the exact response elicited by electrical stimulation can be conditioned to any neutral stimulus. Thus, such movements elicited by stimulation of the motor neocortex cannot be so conditioned (Loucks 1935; Wagner et al. 1967; Thompson et al. 2000). We therefore argue that this system is the essential reinforcing pathway for the learning of discrete responses (Thompson et al. 1998).

The interpositus nucleus sends direct GABAergic projections to the DAO (Nelson and Mugnaini 1989). Hence, as learninginduced increases in interpositus neuron activity develop, inhibition of the DAO neurons will increase (Hesslow and Ivarsson 1996). This accounts for the fact that US-evoked activity in the DAO decreases as learning develops (Sears and Steinmetz 1991), consistent with the Rescorla and Wagner (1972) formulation. This also appears to serve as a part of the neural circuit essential for the behavioral learning phenomenon of "blocking", where prior training to one CS, for example, tone, prevents subsequent learning to a light CS when it is then presented together with the tone in paired compound stimulus training (Kamin 1969). Infusion of picrotoxin in the DAO to block the GABA inhibition from the interpositus during compound stimulus training completely blocks the development of behavioral blocking (Kim et al. 1998).

\section{Conjoint Activation of CS and US Pathways}

If the above hypotheses concerning the identities of the CS and US pathways are correct, it should be possible to train behavioral conditioned responses by conjoint stimulation of these pathways. Steinmetz et al. (1989) stimulated the pontine nucleimossy fibers as a CS (below movement threshold) and DAOclimbing fibers as a US. Stimulus (US)-elicited movements included eyeblink, head turn, and limb flexion. The stimuluselicited movements were learned to the mossy fiber stimulation CS, just as was the case for peripheral CSs. In an even more reduced preparation, the CS was stimulation of parallel fibers by an electrode (concentric pair of ovoids) resting on the surface of the cortex of lobule HVI, and the US was a stimulation delivered through an electrode pair in the white matter directly beneath the surface electrode (Shinkman et al. 1996). Again, the movements elicited by white matter stimulation were learned in a normal fashion to the parallel fiber stimulation CS. It is tempting but premature to conclude that this procedure established a memory trace in the localized region of cortical tissue activated.

\section{Cerebellar Interpositus Nucleus}

Lesions

The initial discovery of the key role of the cerebellum in eyeblink conditioning involved both large aspiration lesions including cerebellar cortex and nuclei and electrolytic lesions of the dentate-interpositus nuclear region (McCormick et al. 1981). Neuronal recordings in both cortex and nuclei showed learning-induced increases of neuronal unit activity that preceded and predicted the occurrence of the behavioral CR. Stimulation of the critical nuclear region elicited the eyeblink before training; the 
circuit is hard-wired from nuclei to behavior. In a subsequent series of studies it was found that the key nuclear region is the anterior lateral interpositus nucleus ipsilateral to the trained eye. ${ }^{2}$ Very large lesions of the cerebellar cortex that did not damage the interpositus nucleus did not abolish the behavioral CR, although CR latency was altered such that the eye closed and opened before the onset of the US - the timing of the behavioral response was no longer adaptive (McCormick and Thompson 1984a,b; Logan 1991; Perrett et al. 1993).

In these initial studies it was shown that the interpositus lesion effect was ipsilateral-it abolished the eyeblink CR on the side of the lesion but did not impair eyeblink conditioning of the contralateral eye, providing a control for possible nonspecific or state variables. Furthermore, if the lesion is made before training, learning is completely prevented (Lincoln et al. 1982). These lesions had no effects at all on performance of the UR.

Yeo and associates (1985a) replicated the interpositus lesion result noted above, using light and white noise CSs and a periorbital shock US, thus extending the generality of the findings. A number of subsequent studies (using rabbit unless otherwise noted) showed identical results for interpositus lesions (Lavond et al. 1984a,b 1987; Polenchar et al. 1985; Woodruff-Pak et al. 1985; Thompson 1986; Skelton 1988 [rat]; Weisz and Lo Turco 1988; Sears and Steinmetz 1990; Steinmetz et al. 1991, 1992b; Yang and Weisz 1992; Freeman et al. 1995 [rat]; L. Chen et al. 1996 [mouse]; Katz and Steinmetz 1997; Swain et al. 1999). Interpositus-lesioned animals were trained periodically for periods up to 8 mos; no CRs ever developed (Lavond et al. 1984b; Steinmetz et al. 1992b). In these and other interpositus lesion studies it was shown that lesions effective in completely abolishing the CR had no lasting effects on any properties of the UR, that is, no effects on performance of the response (Steinmetz et al. 1992a; Ivkovich et al. 1993; see also Welsh and Harvey 1989, and the reanalysis of their data in Steinmetz et al. 1992a). Kainic acid lesions of the interpositus as small as about $1 \mathrm{~mm}^{3}$ in the anterior lateral region of the nucleus abolished the $\mathrm{CR}$, indicating extreme localization of the critical region and ruling out the possibility that fibers of passage were involved (Lavond et al. 1984a). Finally, lesions of the output of the cerebellar nuclei, the superior cerebellar peduncle (scp) abolished the behavioral CR with no effect on the UR (McCormick et al. 1982b; Rosenfeld et al. 1985; Voneida 2000 [limb flexion CR in cat]).

Results of clinical studies of eyeblink conditioning in humans with brain damage are strikingly parallel to the infrahuman animal literature. Appropriate cerebellar lesions markedly impair or completely prevent learning of the standard-delay eyeblink conditioning task; if the cerebellar damage is unilateral, only the ipsilateral eye is affected (Lye et al. 1988; Solomon et al. 1989; Daum et al. 1993; Topka et al. 1993; McGlinchey-Berroth et al. 1995; Woodruff-Pak 1997; Schugens et al. 2000). In general, effective lesions are large, including damage to cerebellar cortical regions and nuclei, although the exact extent of damage is difficult to determine from the brain scans. Schugens et al. (2000) concluded that damage to cerebellar nuclei appears likely in most of these studies. In one study of progressive supranuclear palsy (Sommer et al. 2001) where eyeblink conditioning was completely absent, it was concluded that the critical damage was to the cerebellar dentate-interpositus nuclear region.

${ }^{2}$ It is very difficult in rabbit to determine the boundary between the lateral interpositus and the medial dentate nuclei. We use the term "interpositus" to refer to this region. Learning-influenced neurons in the interpositus and dentate respond very differently following eyeblink conditioning, interpositus neurons increasing and dentate neurons decreasing discharge rates (Yang and Weisz 1992).

\section{Recordings}

As noted briefly above, recordings of neuronal unit activity from the interpositus nucleus during eyeblink conditioning revealed populations of cells in the critical region of the nucleus that, as a result of training, discharged prior to the execution of the learned eyeblink response and fired in a pattern of increased frequency of response that predicted the temporal form of the behavioral CR (the "neuronal model" of the CR; rabbits were used except where noted: McCormick et al. 1981, 1982a, 1983; Thompson 1983, 1986; Foy et al. 1984; McCormick and Thompson 1984a,b; Berthier and Moore 1990; Steinmetz 1990b; Yang and Weisz 1992; Tracy and Thompson 1993; Tracy 1995; Gould and Steinmetz 1996; Weninger and Thompson 1997; Freeman Jr. and Nicholson 2000 [rat]; Stanton and Freeman Jr. 2000 [rat]; Steinmetz 2000b; King et al. 2001; Rogers et al. 2001 [rat]; Tracy et al. 2001). Multiple unit activity recorded from the anterior interpositus shows a consistent increase in firing frequency that precedes the onset of the conditioned behavioral response in well trained animals as illustrated in Figure 6. Single-unit activity sampled from the interpositus and immediately adjacent regions can be categorized into several distinct response patterns (Tracy 1995). Some cells show stimulus-evoked activity to either or both the CS and the US over the course of training, a pattern that demonstrates appropriate convergence of sensory information in the interpositus but does not directly support a role for the interpositus in CR generation. Likewise, some cells show behavior-related changes in firing patterns coincident with but not prior to the onset of the CR (Fig. 7B). However, many cells, particularly in the critical region of the anterior dorsolateral interpositus, significantly increase firing in a precise temporal pattern that is delayed from the onset of the CS, occurs before the onset of the behavior, and is

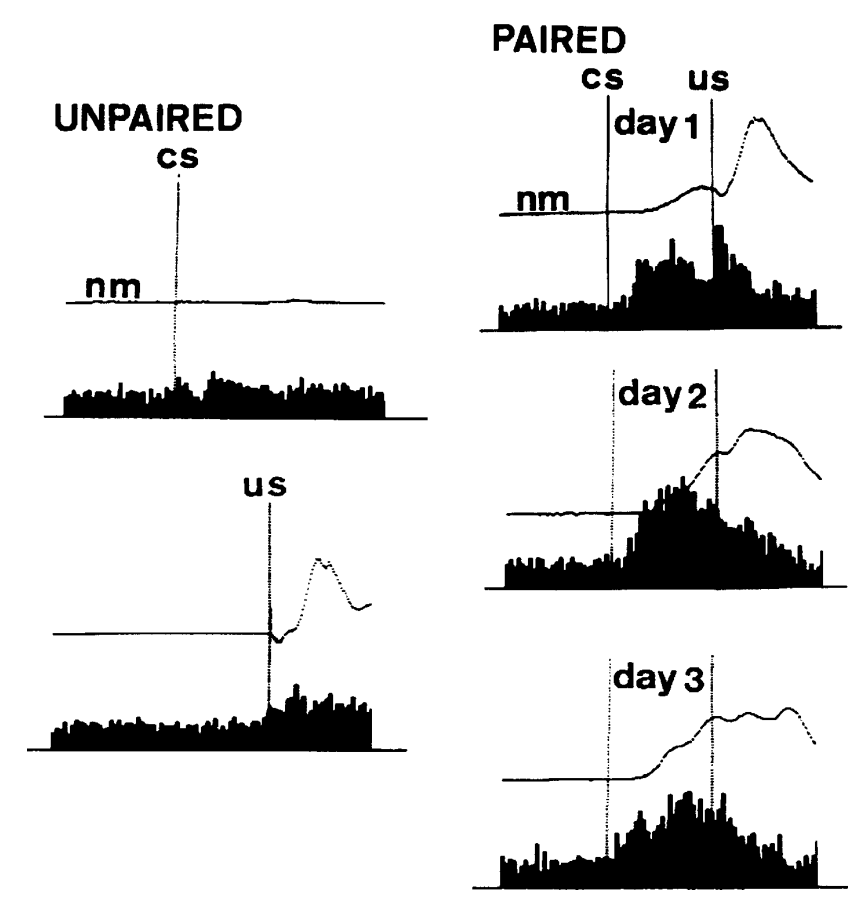

Figure 6 Neuronal model of learned eyeblink response recorded from the cerebellar interpositus nucleus. Each graph shows nictitating membrane movement (top trace) and a histogram of multiple-unit activity (bottom trace). Animals that received explicitly unpaired presentations of the conditioning stimuli do not develop altered patterns of neuronal activity (left column). Trained animals develop a neuronal model of the learned behavior, as shown by an increase in unit activity prior to the US onset (right column). Total trace duration $750 \mathrm{msec}$ (from McCormick and Thompson 1984b). 
A
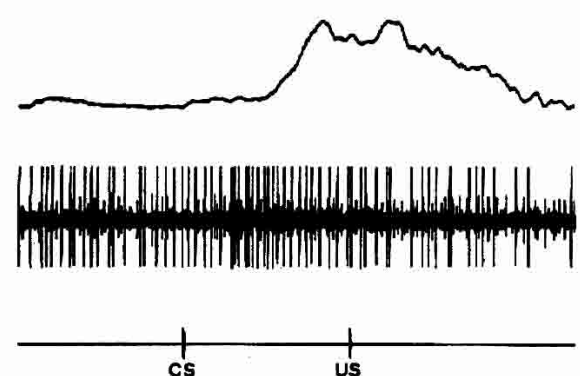

B
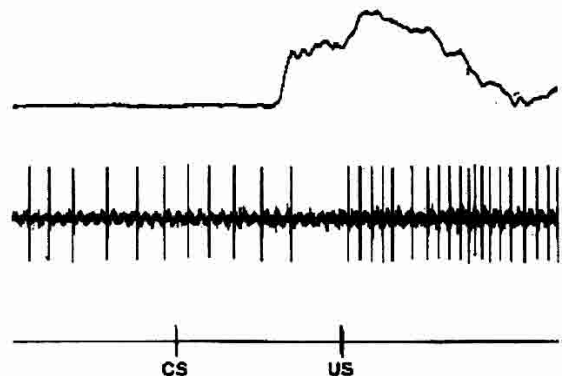

Figure 7 Single-unit recordings from the interpositus nucleus during single trials in well trained rabbits. (Top trace) Timecourse of conditioned eyeblink. (Middle trace) Raw electrophysiological data from interpositus neuron. (Bottom trace) Time of CS and US onset. (A) Changes in single-unit activity (increased firing rate) precede learned eyeblink response, consistent with the proposed role of the interpositus in generating the CR. (B) Single unit undergoes a biphasic change in firing rate, a decrease coincident with the onset of behavior and an apparent evoked increase in response to the US, neither temporally positioned to generate the behavior. Total trace duration $750 \mathrm{msec}$ (from Foy et al. 1984).

temporally correlated with the onset of the behavior (Fig. 7A). It is clear from recordings such as these that neurons in the interpositus are capable of contributing to the generation of the CR. Although there are certainly several distinct response profiles for single cells that are likely to reflect functional subdivisions within the population of neurons in the deep nuclei, it is compelling that multiple and single-unit activity recorded from the critical interpositus region reflects an increase in activity appropriately timed to effect the downstream motor pathway and culminate in the well timed CR.

Reports that single interpositus neurons in the cat show altered firing patterns during but not prior to initiation of the $\mathrm{CR}$ have been interpreted as evidence that the interpositus cannot be the site where conditioned responses are generated (Gruart et al. 2000; Delgado-Garcia and Gruart 2002; Jimenez-Diaz et al. 2002). However, each of these studies investigated properties of neurons in the posterior interpositus. It is clear from the restricted kainic

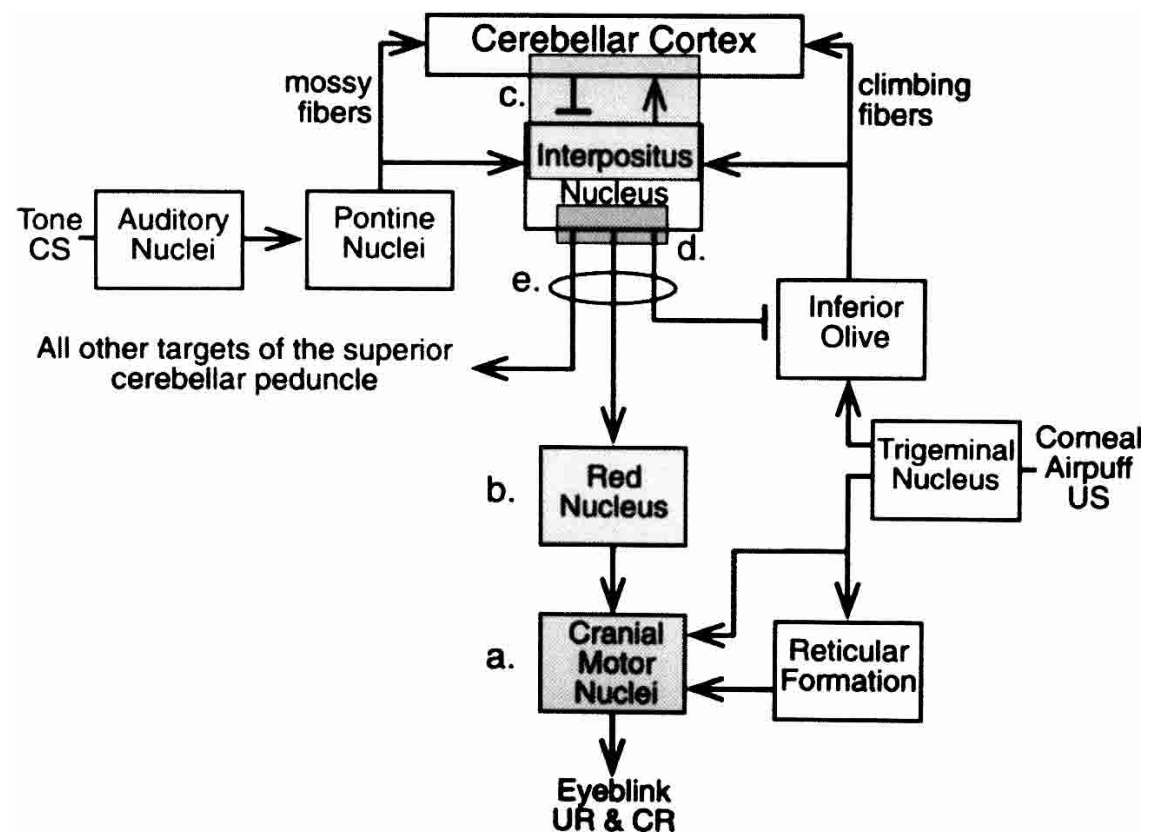

Figure 8 Highly simplified schematic of the cerebellar memory circuit to indicate reversible inactivation during training experiments. a, motor nuclei; $b$, red nucleus; $c$, interpositus and some cortex; d, only interpositus; e, superior cerebellar peduncle. See text for details. (Modified from Thompson and Krupa 1994.) acid lesion study that destruction of a single cubic millimeter of the anterior interpositus is sufficient to abolish conditioned responding (Lavond et al. 1984b). Although there may certainly be additional regions of the interpositus that show learning-related modifications not critical for initiation of the CR, it cannot be concluded from a sampling of cells in such regions that the entirety of the interpositus is therefore not involved in CR generation. To conclude that extracerebellar regions are necessary for the expression of the CR based on the existence of temporally uncorrelated neuronal activity in the posterior interpositus does not follow. Even if there are species-specific regions of the interpositus involved in eyeblink conditioning, lack of evidence demonstrating appropriately timed neural activity in the cat could simply indicate that the critical cells or regions have not been investigated. In contrast, the above cited studies in both rabbits and rats have clearly shown increases in activity recorded from precisely targeted regions of the interpositus, consistent with its proposed role as the site of origin in the initiation and control of CRs. As discussed above, lesions of the interpositus completely and permanently abolish all components of the CR. Although electrophysiological assays in humans are not generally feasible, imaging studies consistently show cerebellar activation in eyeblink conditioning (see above).

\section{Reversible Inactivation}

Several parts of the cerebellar circuit, illustrated in Figure 8 , have been reversibly inactivated for the duration of training (eyeblink conditioning) in naïve animals. Motor nuclei essential for generating the UR and CR (primarily seventh and accessory sixth and adjacent reticular regions) were inactivated by the infusion of muscimol ( 6 d) or cooling (5 d) during standard toneairpuff training (Zhang and Lavond 1991; J. Thompson et al. 1993; Krupa et al. 1996). The animals showed no CRs and no URs during this inactivation training; indeed, performance was completely abolished. However, the animals exhibited asymptotic CR performance and normal UR performance from the very beginning of postinactivation training. Thus, performance of the 
CR and UR are completely unnecessary and make no contribution at all to formation of the memory trace-they are completely efferent from the trace. Inactivation by low doses of muscimol of the magnocellular red nucleus for $6 \mathrm{~d}$ of training had no effect on the UR but completely prevented expression of the CR (Krupa et al. 1993). Animals showed asymptotic learned performance of the CR from the beginning of postinactivation training. Training during cooling of the magnocellular red nucleus gave identical results-animals learned during cooling, as evidenced in postinactivation training, but did not express CRs at all during inactivation training (Clark and Lavond 1993). However, cooling did impair performance of the UR (but the animals learned normally), yet another line of evidence against the "performance" argument. Consequently, the red nucleus must be efferent from the memory trace.

Inactivation of the dorsal anterior interpositus and overlying cortex by low doses of muscimol ( $6 \mathrm{~d}$ ), by lidocaine ( $3 \mathrm{~d}, 6 \mathrm{~d}$ ), and by cooling $(5 \mathrm{~d})$ resulted in no expression of CRs during inactivation training and in no evidence of any learning during inactivation training (Clark et al. 1992; Krupa et al. 1993; Nordholm et al. 1993; Hardiman et al. 1996). In subsequent postinactivation training, animals learned normally as though completely naïve; they showed no savings at all relative to noninactivated control animals. None of the methods of inactivation had any effect at all on the performance of the UR on US-alone trials. Infusions of very low doses of muscimol $(1.0$ nmole in $0.1 \mu \mathrm{L}$ of vehicle) limited to the anterior lateral interpositus nucleus (with no significant ${ }^{3} \mathrm{H}$ label in cerebellar cortex) completely prevented learning of the eyeblink CR, as shown in Figure 9 (Krupa and Thompson 1997). Finally, the output of the cerebellum was inactivated by infusion of tetrodotoxin (TTX) in the scp during training (Krupa and Thompson 1995). This inactivates both descending and ascending efferent projections of the cerebellar hemisphere. TTX infusion in the scp completely prevented expression of the CR (with no effect on the UR) for the $6 \mathrm{~d}$ of training. On the seventh day, TTX was not infused and the animals showed asymptotic learned performance of the CR. Control animals were infused with TTX in the scp for $6 \mathrm{~d}$ but not trained, and then trained, and showed normal learning.

Collectively, these data strongly support the hypothesis that the memory trace is formed and stored in the cerebellum. Indeed, we can conceive of no rational alternative. Inactivation of the interpositus during training completely prevents learning, but inactivation of the output pathway from the region and its necessary (for the CR) efferent target, the red nucleus, does not prevent learning at all. In no case do the drug inactivations have any effect at all on the performance of the reflex response on USalone trials. If even part of the essential memory trace was formed prior to the cerebellum in the essential circuit, then the animals would have to show savings following cerebellar inactivation training, and they show none at all. Similarly, if part of the essential memory trace was formed in the red nucleus or other efferent targets of the interpositus (e.g., brain stem), then animals could not show asymptotic CR performance following scp or red nucleus inactivation training, but they do. It is perhaps somewhat unusual in the field of behavioral neuroscience to find such complete agreement in terms of neuronal activity, effects of lesions, and effects of inactivations from many laboratories and across several species, as is the case for the role of the cerebellar interpositus nucleus in classical conditioning of the eyeblink response. These results are now established beyond question.

It is tempting but premature to conclude from these data that the memory trace is localized solely to the interpositus (e.g., muscimol inactivation limited to the anterior lateral interpositus completely prevents learning; Krupa and Thompson 1997). Neu-
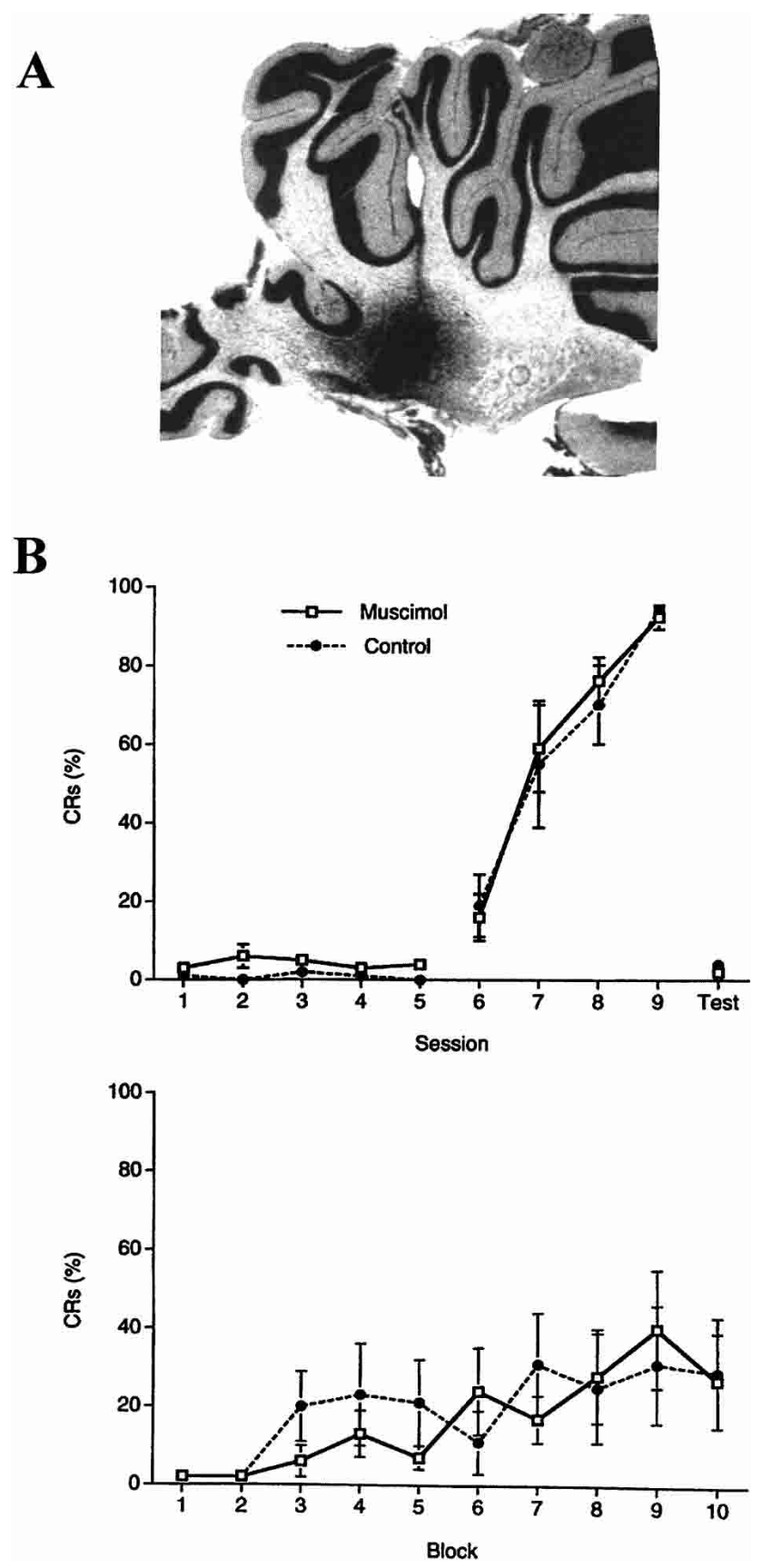

Figure 9 Inactivation of the interpositus nucleus completely blocks acquisition of the eyeblink CR. $(A)$ Autoradiograph demonstrating localized infusion of $1 \mathrm{nmole}$ of ${ }^{3} \mathrm{H}$ muscimol to the interpositus and medial dentate nuclei. $(B)$ Behavioral data from animals infused with muscimol $(\mathrm{n}=8)$ or saline (Control, $\mathrm{n}=8$ ). Top graph (Sessions $1-5$ ) shows no evidence of learning in either the Muscimol group given paired training or the Control group that was not exposed to the conditioning stimuli. No infusions were given during the subsequent paired training phase (Sessions 6-9), and the acquisition rate in the Muscimol group is similar to that of the naïve Controls. Final test session with muscimol abolishes learned response in both groups. Bottom graph plots CR\% by 10 -trial block during session 6 (first paired training session), demonstrating no significant difference between groups (from Krupa and Thompson 1997).

rons in the interpositus project to the overlying cerebellar cortex, and interactions between interpositus and cortex may play a critical role in learning. 


\section{Cerebellar Cortex}

Coincident with the initial reports localizing the memory trace to the interpositus, there was an indication that the cerebellar cortex might also play a critical role in the expression of the learned response. In the first study to explicitly address cortical function in eyeblink conditioning, aspiration lesions of ansiform or ansiform and paramedian lobules in well trained rabbits resulted in the expression of short-latency, small-amplitude CRs, as seen in Figure 10 (McCormick and Thompson 1984b). The most significant aspect of this finding is the implication that the conditioned response may not be a unitary, all-or-none phenomenon but rather a complex event consisting of separable elements related to frequency, magnitude, and timing of the response. This hypothesis has garnered significant empirical support, yet there is considerable disagreement as to the extent of cortical involvement and the location of the critical regions involved in the acquisition and maintenance of each of these elements. To date, three regions have received the bulk of the attention from investigators: Larsell's hemispheric lobule VI (HVI), the anterior lobe, and the $\mathrm{C} 1$ and $\mathrm{C} 3$ zones, parasagittal regions encompassing portions of both HVI and anterior lobe. To evaluate the plausibility of several competing theories of cortical function, a review of the key consistencies and contradictions in the literature is necessary.

\section{HVI and CR Acquisition and Expression}

HVI, the region of the cortex immediately dorsal to the anterior interpositus, receives multimodal information related to the conditioned stimulus via the pontine nuclei and the unconditioned stimulus via IO climbing fibers (Mihailoff et al. 1981; Yeo et al. 1985c; Hesslow 1994; Rosenfield and Moore 1995). It is therefore considered a likely substrate for cortical plasticity related to eyeblink conditioning. Some of the earliest studies to target this region were performed by Yeo and colleagues, and the results suggested that selective lesions of HVI or HVI and the ansiform lobule completely block expression of the conditioned response in well trained animals (Yeo et al. 1984, 1985b; Hardiman et al. 1988; Yeo and Hardiman 1988). Subsequent attempts to replicate this result have proven unsuccessful; however, even when the complex conditioning protocol used in the Yeo et al. studies is employed (Woodruff-Pak et al. 1985, 1993; Lavond et al. 1987; Clark et al. 1990; Harvey et al. 1993; Perrett and Mauk 1995).

Instead, these latter studies have shown consistently that unilateral lesions of HVI and adjacent regions in well trained animals result in a transient decrease in conditioned responding but that reacquisition to prelesion levels of CR frequency and amplitude can be achieved with additional training. Importantly, animals showed significant savings during reacquisition, requiring fewer trials to reach criterion than during initial acquisition. This result suggests that the cortical lesions did not eliminate the memory trace. The possibility that strain differences could account for the discrepancy in results was tested directly, and there does appear to be a greater postlesion deficit in the Dutch belted rabbits used by Yeo et. al. compared with the modest effect observed in New Zealand White rabbits used in all other experiments (Clark and Lavond 1994). More recent data from Yeo and associates, however, suggest that the prelesion CR frequency is recoverable to some degree in Dutch belted rabbits with postlesion training, but that a concomitant decrease in CR amplitude does not recover with additional training (Harvey et al. 1990; Yeo and Hardiman 1992; Gruart and Yeo 1995). The effects of HVI le-

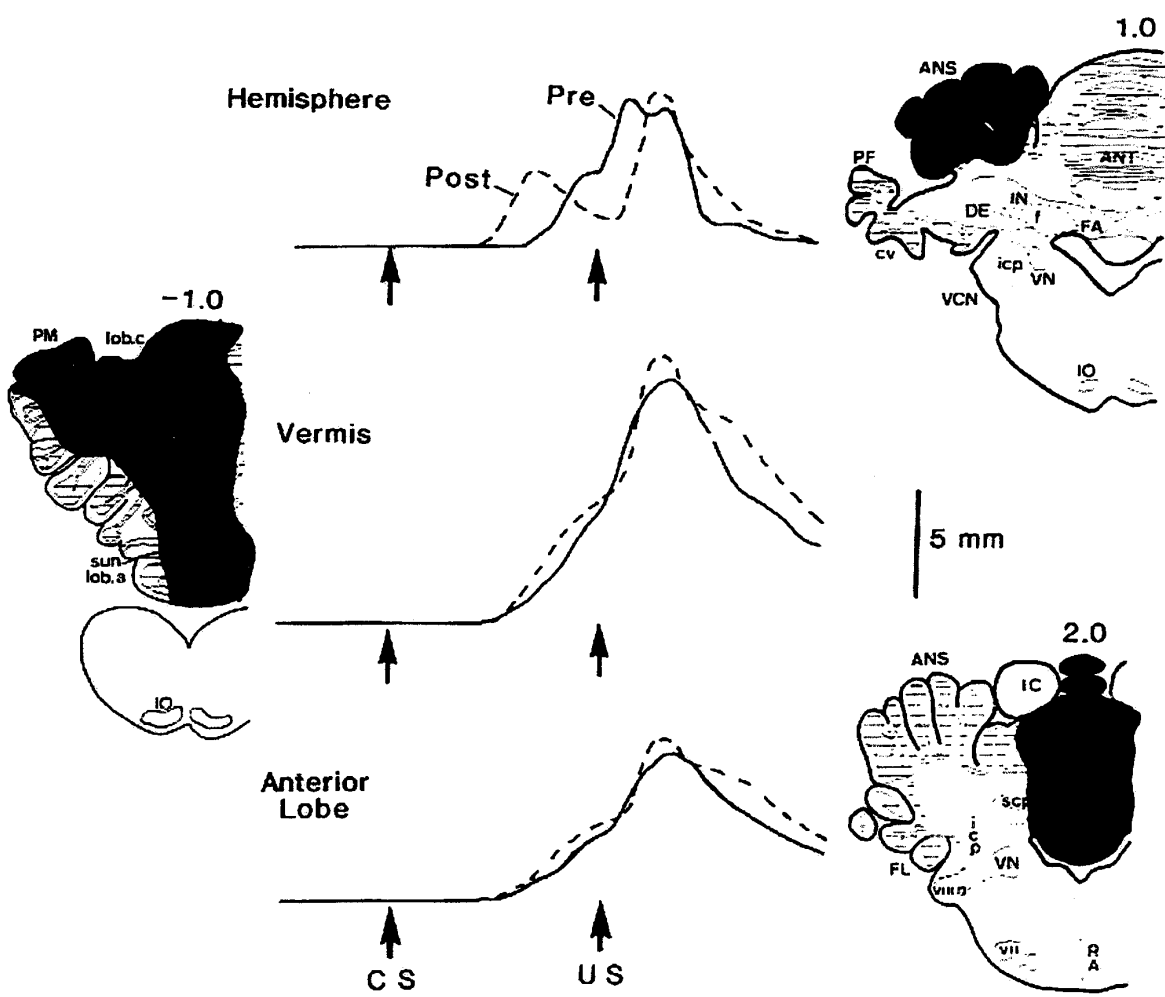

Figure 10 Cortical lesions of the ansiform and paramedian lobules in well trained animals result in small-amplitude, short-latency responses (top row). Extent of lesion indicated by black region on atlas drawings. Nictitating membrane response prior to lesion shown by solid lines, postlesion responses depicted by dotted lines. Arrowheads indicate CS and US onset. Cortical lesions of vermis and anterior lobe do not significantly alter the amplitude or timecourse of the learned response (middle and bottom row) (from McCormick and Thompson 1984b.) sions on $\mathrm{CR}$ amplitude remain in dispute, although the converging evidence suggests that unilateral lesions mini(Woodruff-Pak et al. 1985; Lavond et al. 1987; Clark et al. 1990; Perrett and Mauk 1995). Bilateral lesions of HVI have produced similarly controversial results, as the Gruart and Yeo (1995) study suggests that such lesions permanently abolish CR expression, whereas other studies indicate little qualitative difference between large unilateral and bilateral lesions (Lavond and Steinmetz 1989; Mojtahedian et al. 2001). The inconsistencies in these studies may be explained in part by the fact that Yeo et al. published only conditioned response amplitude statistics, not percentage of learned responses in the original studies (Yeo et al. 1984, 1985b). In addition, it is difficult to restrict lesions to the cortex and guarantee that the underlying interpositus nucleus, a region shown to be necessary for the expression of the conditioned response, was not damaged by the proximal aspirations in the Yeo et al. studies, without careful histological analysis.

In an experiment designed to assess the role of the cortex in acquisition, extensive unilateral lesions including complete removal of HVI and HVIIa lobules and significant portions of the anterior mally disrupt retention of the CR 
lobe were shown to significantly impair the rate of learning (Lavond and Steinmetz 1989). Lesioned animals took seven times longer to reach criterion, and asymptotic levels of CR frequency were much reduced. Despite these specific learning deficits, animals were able to achieve significant levels of conditioned responding in the absence of HVI. This result was confirmed by another study in which extensive cortical lesions were shown to significantly impair the rate of acquisition but not prevent learning (Logan 1991). Animals with complete or near complete removal of HVI and crura I and II of the ansiform lobe took six times longer to reach criterion. Rabbits with less extensive damage to HVI and the ansiform lobe showed moderate decreases in learning rates. Both moderate and extensive lesions decreased asymptotic CR frequency, whereas extensive lesions also impaired CR magnitude and timing.

Using a different methodological approach to investigate cortical function, the HVI lobule has been temporarily inactivated via infusions of the $\mathrm{GABA}_{\mathrm{A}}$ receptor agonist muscimol, during both acquisition and retention. Muscimol acts to hyperpolarize neurons, prohibitively raising the firing threshold and thus disrupting the cortical output mediated by Purkinje cells. Muscimol inactivation restricted to the ventral HVI region has no effect on the rate of acquisition or quality of the conditioned responses (Krupa 1993). Extensive cortical inactivation encompassing both HVI and portions of the anterior lobe significantly impairs but does not prevent acquisition and has no effect on the CR performance once the animal reaches asymptotic levels of conditioned responding (Krupa 1993; Thompson et al. 2001). Similarly, reversible inactivation of the HVI region achieved with a cortical cooling probe significantly decreased the learning rate but did not disrupt CR expression in well trained animals (Clark et al. 1997b).

Yeo and colleagues reversibly "inactivated" HVI with CNQX, a competitive AMPA/kainate receptor antagonist, which they reported resulted in a temporary but complete elimination of the expression of the CR in the well trained animals (Attwell et al. 1999). Glutamate transmission blockade was also reported to affect acquisition, as evidenced by the virtual absence of CRs during acquisition when HVI is inactivated, and complete lack of savings upon removal of inactivation (Attwell et al. 2001). Based on the results of the 1999 study, complete blockade of CR expression was used as a criterion for inclusion in the experimental group in the 2001 study. Rabbits demonstrating any level of conditioned responding immediately following CNQX infusion were determined to have only partial HVI inactivation and were excluded from the main analysis. This raises the possibility of incidental spread of CNQX to the interpositus, which would prevent both learning and expression. More importantly, the logic of these studies is fundamentally flawed. Purkinje neurons fire at relatively high frequencies endogenously in the absence of all excitatory synaptic input (Hausser and Clark 1997; Smith and Otis 2002). This, together with the blockade of excitatory transmission from the parallel fibers to the inhibitory stellate and basket cells, will result in a net increase in Purkinje neuron discharge frequency and a complete absence of temporally patterned discharge, hence an increase of Purkinje neuron inhibition of the interpositus, which would also prevent learning and performance of the CR. Indeed, the "inactivation" achieved via disruption of glutamatergic synaptic transmission differs dramatically from inactivation via muscimol and cooling, not only in pharmacology but also in the resultant behavior.

In a recent attempt to investigate the role of the cortex in memory consolidation, infusions of muscimol in HVI immediately following daily training sessions were reported to severely disrupt acquisition but have no effect on CR expression in well trained animals (Attwell et al. 2002). Infusions into the interposi- tus were reported to have no effect on acquisition. It is notable that the near complete block of learning (only $0.4 \%$ CRs) resulting from posttraining cortical infusions during the initial acquisition phase is a deficit much more profound than any previously reported impairment due to cortical inactivation. The implication of this result is that cortical inactivation has its most deleterious effect on learning immediately after, as opposed to during, training. It is difficult to reconcile the results of this study with those of previous studies in which inactivation of HVI during training had only moderate effects on the rate of acquisition. Furthermore, the effects of a muscimol infusion delivered prior to training would last well beyond the end of the session, inactivating the cortex during the proposed critical consolidation period (Krupa 1993; Thompson et al. 2001). Again, extensive cortical inactivation was shown to significantly impair but not block acquisition, whereas inactivation restricted to ventral HVI did not affect learning. Perhaps a more direct test of the cortical consolidation hypothesis could be achieved through pre- and posttraining infusions of protein synthesis inhibitors in HVI. Despite disagreements over the interpretation of data discussed above, the preponderance of evidence from lesion and inactivation experiments targeting HVI suggests that this region may play a role in the rate of acquisition in eyeblink classical conditioning and plays a modest role in maintaining the frequency of CR expression in the well trained animal.

\section{Timing and the Anterior Lobe}

Motivated by the initial observation of McCormick and Thompson (1984b) that cortical lesions disrupt CR amplitude and timing, efforts were made to investigate the potential cortical loci responsible for these effects. The reduction in response latency and amplitude has since been replicated in both lesion and functional inactivation studies targeting the cerebellar cortex. Currently, however, there is no consensus as to the primary locus of cortical control of timing or even whether a single cortical area does in fact mediate the development and maintenance of the temporal component of the CR. Although reciprocal influences between the cortex and interpositus are difficult to dissociate, evidence does suggest that the timing of the CR is an intrinsic property of the cerebellum. In a recent study, it was shown that constant-frequency mossy fiber stimulation at a single site supports conditioning at several interstimulus intervals (ISIs) in the same animal (Perrett 1998). Brief electrical stimulation of the mossy fibers as a CS at the onset of the CS period yields adaptive timing of the behavioral CR (Logan et al. 1985). Furthermore, well timed conditioned responses can be generated using stimulation of the parallel fibers in the molecular layer of the cortex and the underlying white matter as the CS and US, respectively (Shinkman et al. 1996). It appears unlikely, therefore, that the critical timing mechanisms are afferent to the cerebellum and either projected to or encoded in the pattern of mossy fiber activation. Identifying the intracerebellar structures and mechanisms involved in CR timing is now the focus of a significant portion of research in eyeblink classical conditioning.

McCormick and Thompson reported that damage to the ansiform and paramedian lobules was sufficient to alter the timing and magnitude of the CR. This result was confirmed and extended in a study in which widespread cortical damage decreased CR onset and peak latency (Logan 1991). In that study, the extent of the aspiration lesions correlated with behavioral deficits such that complete or near complete removal of the ansiform and paramedian lobules resulted in the most significant alterations of CR latency and frequency. Although there was a graded effect of lesion size on the frequency of conditioned responding, only the largest lesions disrupted the timing of the CR. Extensive lesions including the anterior lobe resulted in smaller-amplitude 
CRs with significantly and substantially reduced onset and peak latencies. In a similar study on the effects of large cortical lesions, Perrett et al. (1993) showed a correlation between reductions in CR onset latency, peak latency and amplitude, and the degree of damage to the anterior lobe. No significant correlation between damage to HVI or the paramedian lobule and changes in timing were observed, although reductions in peak latency did correlate with the area of damage in the ansiform lobule.

Mauk and colleagues have focused on the anterior lobe as the putative cortical site necessary for the maintenance of a well timed CR. They have investigated acquisition and extinction of conditioned responses, arguing that the anterior lobe is necessary for each form of learning (Perrett and Mauk 1995; Garcia et al. 1999). In each study, anterior lobe lesions were reported to alter CR timing, and the short-onset latency was used as a criterion for effective lesions. Lesions that resulted in short-latency conditioned responses also disrupted postlesion acquisition to a novel CS (Garcia et al. 1999). However, acquisition in naïve animals with anterior lobe lesions has yet to be tested directly. Garcia et al. argue that the significant deficits seen in postlesion CR acquisition support the idea that the anterior lobe is necessary for the animal to learn the association between a new CS and a US. If replicated, this suggests that acquisition to a novel stimulus in previously conditioned animals may represent a qualitatively different learning task, because it has been demonstrated that animals with extensive anterior lobe lesions, as shown in Figure 11, are capable of significant conditioning (Logan 1991). Additional studies in which HVI and large areas of the anterior lobe were inactivated or lesioned reveal a significant decrease in the rate of acquisition in naïve animals, although changes in CR onset or peak latency were not reported (Lavond and Steinmetz 1989; Krupa 1993). However, at least one study did report statistics related to the timing of the $\mathrm{CR}$, and extensive lesions of the
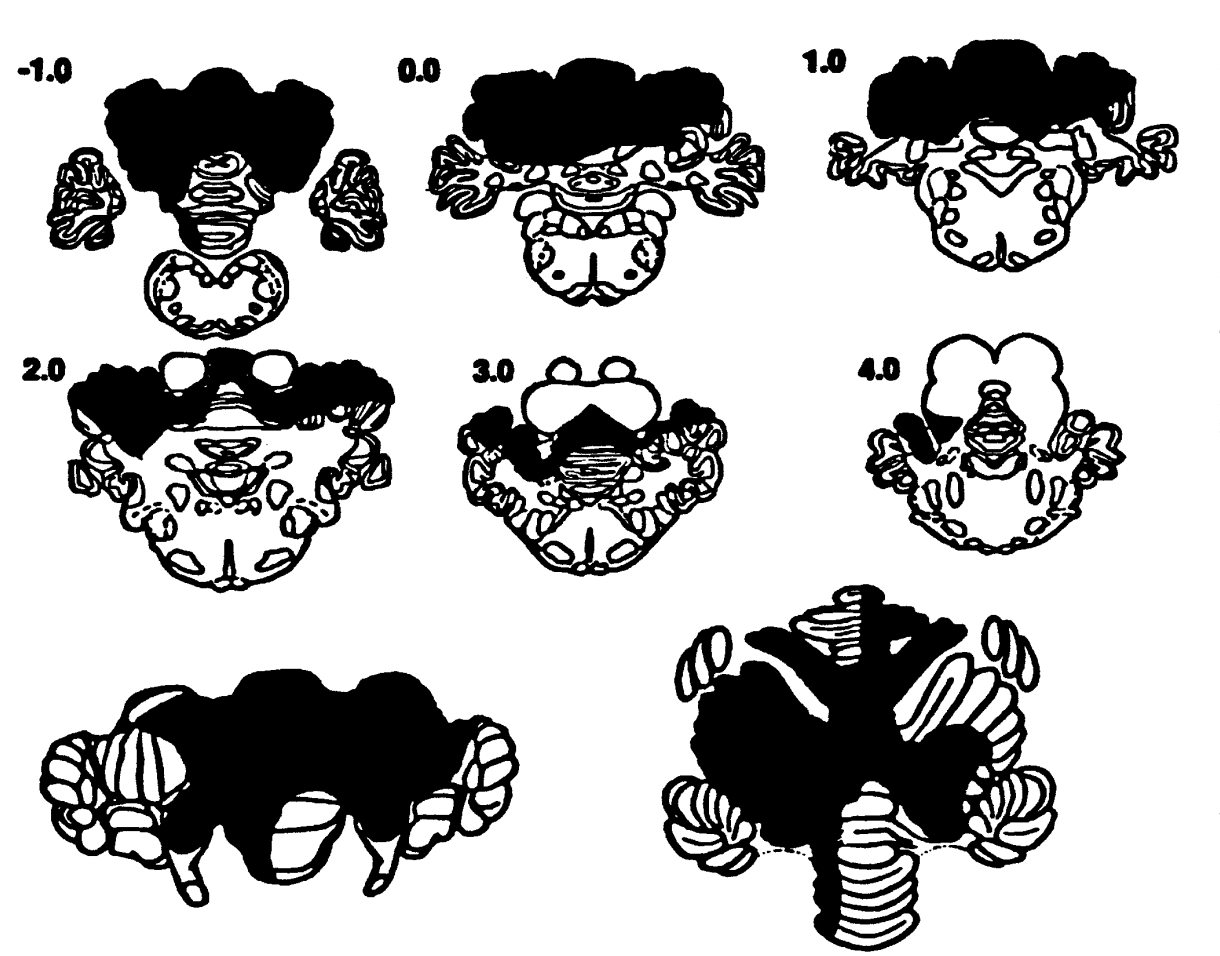

Figure 11 Extensive cortical aspiration lesions in naïve animals do not prevent acquisition of the conditioned response. Histological reconstruction of lesioned area in one rabbit shown in black (six coronal sections together with frontal and dorsal views). Despite an essentially complete bilateral lesion of the anterior lobe and very large lesions of the hemispheres, CR frequency, amplitude, onset, and peak latencies appear normal (from Logan 1991). anterior lobe were not shown to induce a change in CR latency (Woodruff-Pak et al. 1993). Response latencies following targeted disruptions of the HVI region have either not been reported or were not statistically different than prelesion latencies (Yeo et al. 1984, 1985a; Lavond and Steinmetz 1989; Krupa 1993; Clark et al. 1997b).

\section{Zones, Microzones, and Mosaics}

The inconsistency of these results may be attributable in part to the complex organization of the cortex. The cerebellar cortex nization of the deep nuclei in which damage to a single cubic millimeter of the anterior lateral interpositus will abolish a specific learned behavior, the conditioned eyeblink. Stimulation of this same region in the interpositus can elicit an eyeblink response. The convergence of evidence indicates a well delineated somatotopy within the interpositus onto which conditionable behaviors can be mapped. In the cerebellar cortex, however, the topography appears vastly more complicated.

Cortical control of eyeblink conditioning depends on the integration of information related to the CS and US. The spatial distribution of the mossy fiber and climbing fiber afferents, putative pathways carrying CS and US information, respectively, is not understood fully. Data from anatomical and microstimulation studies suggest a strict topographical relationship between the cortex, deep nuclei, and IO (Andersson and Oscarsson 1978; Groenewegen et al. 1979; for review, see Voogd and Glickstein 1998). Projections of IO subnuclei terminate in the cortex in parasagittal zones (Sanchez et al. 2002). Collaterals of these projections innervate the deep nuclei. Purkinje cells, in turn, project to the same nuclei as the IO collaterals, and a reciprocal connection is formed by inhibitory efferents of the deep nuclei to the IO. Within this circuit, somatotopic relationships appear to be preserved but are multiply expressed. In the eyeblink conditioning circuit, cortical zones $\mathrm{C} 1$ and $\mathrm{C} 3$ receive information from the DAO and project to the anterior interpositus nucleus. Evidence suggests that the zones do not display uniform receptive field properties but are instead organized into a series of microzones, patches of cortex corresponding to distinct peripheral stimulation. Therefore, within the $\mathrm{C} 1$ and C3 zones are several cortical regions responsive to periorbital stimulation (Hesslow 1994). Mossy fiber innervation of the cortex does not appear to share the zonal organization exhibited by climbing fiber afferents, but rather displays a pattern of patchy or fractured somatotopy (Shambes et al. 1978). Although the majority of evidence supports the zonal organization of the climbing fiber afferents and fractured somatotopy of mossy fiber afferents, other studies have questioned this topography and suggest that both sets of projections are fractured and relay information from the same peripheral stimulus (Brown and Bower 2001). Considerable effort will be required to resolve outstanding questions regarding the congruence of receptive field properties of cortical neurons with respect to the two excitatory input pathways. Nevertheless, learning-related alterations in

\section{Learning \& Memory}

www.learnmem.org 
simple and complex spikes suggest that Purkinje cells are positioned to integrate relevant conditioning stimuli.

In an attempt to target zones implicated in the eyeblink response circuit, aspiration lesions of the $\mathrm{C} 1$ and $\mathrm{C} 3$ zones were made following training to both light and tone CSs (WoodruffPak et al. 1993). These lesions did not prevent postlesion recovery of CRs, although retraining took significantly longer for the light CS. In animals subject to extensive anterior lobe damage, there was a decrease in response percentage, but no pattern of damage resulted in a significant change in response latency. If there are multiple and noncontiguous regions within the cerebellar cortex that receive appropriate sensory information to influence the eyeblink response, then selective lesions and inactivations may not remove all critical cortical regions. Despite efforts to target eyeblink-related areas, any partial removal or inactivation of the cerebellar cortex might be incomplete, confounding interpretation of the results.

\section{Complete Cortical Elimination}

Circumventing these anatomical complications, several attempts have been made to investigate the effects of functionally inactivating the entire cerebellar cortex. The most definitive of these studies tested acquisition of eyeblink conditioning in mutant mice (pcd mice) in which Purkinje cells degenerate approximately 2 wks postnatally (Chen et al. 1996). Elimination of these sole output neurons in the cortex effectively eliminates the cerebellar cortex itself. pcd mice show significant deficits in both the rate of acquisition and the asymptotic level of conditioning, but nevertheless express significant levels of learning and extinction in the absence of cortical input to the interpositus. Peak latencies of the CRs in the mutants were significantly decreased compared to wild-type mice, although the effect was not great. A later study confirmed that the interpositus was responsible for the residual learning, by demonstrating that bilateral lesions of the interpositus in pcd mice completely block acquisition (Chen et al. 1999).

Functional and reversible lesions of the entire cerebellar cortex can also be achieved through a targeted disruption of the Purkinje cell afferents at the level of the interpositus. In one study, application of the GABA antagonist picrotoxin into the anterior interpositus nucleus resulted in short-latency, reducedamplitude, prolonged conditioned responses but at a frequency similar to that observed in the absence of infusion (Garcia and Mauk 1998). These results are contradicted by other studies in which picrotoxin infusions into the interpositus blocked the expression of CRs completely (Mamounas et al. 1987; Bao et al. 2002). A much more precise elimination of cortical input can be achieved through sequential infusions of muscimol and picrotoxin. Muscimol first blocks the synaptic transmission from the cortex, and the baseline level of excitability in the interpositus neurons is restored through application of picrotoxin (Bao et al. 2002). With this procedure, onset and peak latencies were decreased in well trained animals, CR amplitudes were increased, and no effects (i.e., no CRs) were observed in naïve animals (see below).

In contrast to the clear and compelling evidence confirming the essential role of the interpositus in the acquisition and expression of the conditioned eyeblink response, reports of cerebellar cortical involvement have proven more difficult to interpret. The absence of savings following inactivation of the interpositus during acquisition argues against the formation of an interpositus-independent memory trace established in the cerebellar cortex. This result does not, however, eliminate the possibility of interpositus-dependent memory trace formation in the cortex or interpositus-independent cortical influences on the conditioned response in well trained animals.

\section{Cerebellar Mechanisms of Memory Storage}

From the initial discovery of the essential role of the cerebellum in eyeblink conditioning, the key question has been whether the "memory trace" is stored in the cerebellar cortex or cerebellar nuclei, or of course both. As previously discussed, evidence is overwhelming and entirely consistent that appropriate lesions limited to the interpositus nucleus completely and permanently prevent learning of the CR and completely and permanently abolish the learned CR. On the other hand, evidence that lesions limited to cerebellar cortex can completely and permanently prevent learning and completely abolish the learned CR is neither consistent nor entirely convincing. However, as noted above, such cortical lesions can markedly impair acquisition rate and asymptote, reduce CR amplitude, and alter CR timing. Perhaps the most parsimonious general hypothesis is that some forms of neuronal/synaptic plasticity develop in both cortex and interpositus nucleus as a result of training, as suggested many years ago (Thompson 1986).

\section{Interpositus Nucleus}

Several lines of evidence argue strongly for learning-induced processes that develop in the interpositus, as opposed to developing elsewhere and being relayed to the interpositus. Infusion of muscimol localized entirely to the interpositus nucleus completely prevents learning and expression of the CR (Krupa and Thompson 1997). Although it is true that this treatment will block Purkinje GABAergic action on nuclear cells, the fact that animals show no savings at all after the inactivation has been removed demonstrates that no part of the memory trace has been formed in cerebellar cortex independent of the interpositus; otherwise there would be savings. Indeed, other than the direct projections from the interpositus to the cerebellar cortex, all normal mossy and climbing fiber projections to the cortex are intact and functional (muscimol does not inactivate fibers). Yeo has argued that the circuit, for example, from cortex to interpositus to IO to cortex (and interpositus) is such that the result of inactivation of one part of the circuit is difficult to interpret because of secondary effects on other parts of the circuit (e.g., Attwell et al. 2001). Actually, inactivation of the interpositus results in blocking of interpositus inhibition of the $\mathrm{IO}$, which is a maximal condition for learning (Kim et al. 1998; Medina et al. 2002). Yet no learning at all occurs.

Nonetheless, projections from the interpositus to the cortex, either direct or indirect, could still play a role in establishing plasticity in cortex. This is a key point. Many theories and models of cerebellar cortical learning (of the eyeblink CR) focus only on cortical processes, independent of possible interpositus actions on the cortex. These models must therefore be wrong, or at least incomplete. Katz and Steinmetz (1997) showed that with interpositus lesions made after training, a number of neurons in cerebellar cortex still exhibited training-related responses. The critical complementary experiment, interpositus lesion before training with cortical neuron recording during and after training, has not yet been done.

Infusion of GABA antagonists, picrotoxin or bicuculline methiodide, into the interpositus in trained animals blocks performance of the behavioral eyeblink CR and the neuronal unit model of the $\mathrm{CR}$ in the interpositus in a dose-dependent manner, with no effects on the UR (Mamounas et al. 1987). Picrotoxin infusion in the interpositus during training completely prevents learning (Bao et al. 2002). Infusion of the $\mathrm{GABA}_{\mathrm{B}}$ antagonist baclofen in the interpositus during training similarly prevents learning and performance of the CR (Ramirez et al. 1997). These results indicate that GABA and its actions on GABA receptors in the interpositus are important for both learning and performance 
of the CR. However, equivalent doses of strychnine had no effect on the CR or the UR, suggesting that glycine receptors are not involved (Mamounas et al. 1987). Infusion of AP5 into the interpositus markedly impaired acquisition of the eyeblink CR (Chen and Steinmetz 2000). However, after learning, AP5 infusion had little effect on CRs. This argues for a role of glutamate NMDA receptors in the interpositus in acquisition but not performance of the CR.

Bracha et al. (1998) reported that infusion of anisomycin into the region of the interpositus nucleus impaired acquisition of the eyeblink CR but had no effect on expression of the CR. Gomi et al. (1999) reported that infusion of actinomycin D into the interpositus nucleus completely prevented acquisition of the eyeblink CR but had no effect on performance of the learned response. By the same token, Chen and Steinmetz (2000) reported that infusion of the protein kinase inhibitor $\mathrm{H} 7$ into the interpositus markedly impaired acquisition but had no effect on performance of the learned response. Results of all these studies argue strongly that protein synthesis in the interpositus nucleus is necessary for learning of the eyeblink CR, but not for its expression once learned. Indeed, Gomi et al. (1999) identified a kinase whose expression was increased in interpositus neurons following eyeblink conditioning. The cDNA was isolated, and the deduced amino acid sequence of the kinase contains the KKIAMRE motif, conserved among cell division cycle 2-related kinases.

All these results argue for the formation of neuronal/synaptic plasticity, a memory trace, in the interpositus itself. Perhaps the strongest evidence for this comes from the pcd mouse (see above). Although their cerebellar cortex is completely nonfunctional (no Purkinje neurons), the mice still exhibit substantial learning of the CR (Chen et al. 1996), which is completely blocked by interpositus lesions (Chen et al. 1999). Another line of evidence strongly supporting this view involves sequential application of muscimol and picrotoxin (Bao et al. 2002). In interpositus slice (mouse) with whole-cell neuronal recordings in current-clamp mode, stimulation of white matter (presumed Purkinje axons) in the presence of kynurenic acid (an ionotropic glutamate receptor antagonist) evoked large inhibitory postsynaptic potentials (IPSPs). Gradual application of muscimol (a competitive agonist) caused a marked resting or basal hyperpolarization ( $\mathrm{GABA}_{\mathrm{A}}$ action) and a complete blockade of the evoked hyperpolarization $\left(\mathrm{GABA}_{\mathrm{A}}\right.$ receptors blocked). Subsequent administration of picrotoxin (a noncompetitive GABA antagonist) reversed the resting or basal hyperpolarization but of course did not unblock the $\mathrm{GABA}_{\mathrm{A}}$ receptors, that is, no evoked hyperpolarization. These same interpositus infusion procedures were done in vivo in well trained rabbits; the results are shown in Figure 12. Muscimol completely abolished the CR (no effect on UR), as reported in earlier studies. Subsequent infusion of picrotoxin caused a complete but reversible reinstatement of the CR, but with substantially shorter onset and peak latencies. Thus, muscimol completely blocked Purkinje neuron inhibition of interpositus neurons (all cortical influences), and picrotoxin uncovered the underlying neuronal/synaptic "memory trace" that had been established in the interpositus neurons. We argue from these data that the "basic" memory trace is established in the interpositus neurons by strengthening of the mossy fiber-interpositus neuron pathway, whereas sculpting and adaptive timing of the CR is controlled by Purkinje neuron actions on interpositus neurons, resulting from plasticity in the cortex.

Extremely important direct evidence for a strengthening of the mossy fiber-interpositus neuron synapses was presented by Kleim et al (2002), using eyeblink conditioning in the rat. They demonstrated a highly significant increase in the number of excitatory synapses in the interpositus nucleus but no change in

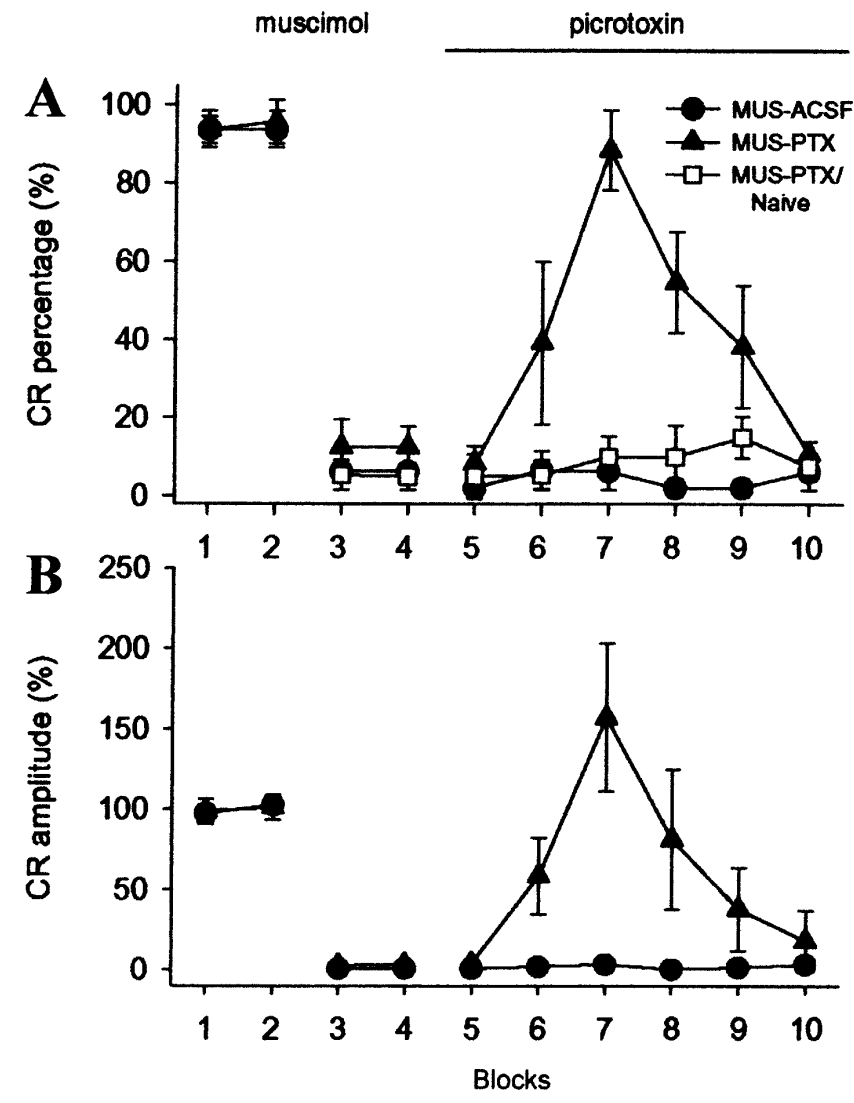

Figure 12 Rabbit eyeblink conditioning. (A) CR percentage. (B) CR amplitude normalized to the average $C R$ amplitude during the first two blocks. Well trained animals, blocks 1 and 2; muscimol $(10 \mathrm{nmol})$ infused in interpositus nucleus after block 2 and CRs abolished, blocks 3 and 4 . Picrotoxin $(10 \mathrm{nmol} / \mu \mathrm{L}, 0.13 \mu \mathrm{L} / \mathrm{min}$ ) infused beginning after block 4 . CRs return (but with significantly shorter onset and peak latencies) and then decline with continued infusion (from Bao et al. 2002; see text for details).

inhibitory synapses following eyeblink conditioning, compared to unpaired stimulation control animals (Fig. 13). We note that some years earlier Racine et al. (1986) reported the development of LTP in the interpositus following mossy fiber tetanus in the rat in vivo.

In sum, the evidence is now very strong from behavioral, physiological, pharmacological, and anatomical studies that the basic associative memory trace in eyeblink conditioning is established in the interpositus nucleus. The next step is to elucidate the causal chain from behavioral training to increased synaptic efficacy and synapse formation.

\section{Cerebellar Cortex}

Although the nature of cortical involvement in classical conditioning is not yet fully understood, it is clear from lesion, inactivation, and mutant studies that the cerebellar cortex does contribute substantially to the development of the conditioned response under normal conditions. Somewhat paradoxically, the mechanisms through which the cortex may facilitate learning have been the subject of intense investigation, although there remains a relative paucity of data describing synaptic changes in the interpositus, despite its well established role in learning and memory of the conditioned response. This discrepancy is largely due to the now classical view of the cerebellar cortex as the cornerstone of a neural system that integrates and computes the sensory information needed for motor learning. Interest in the 

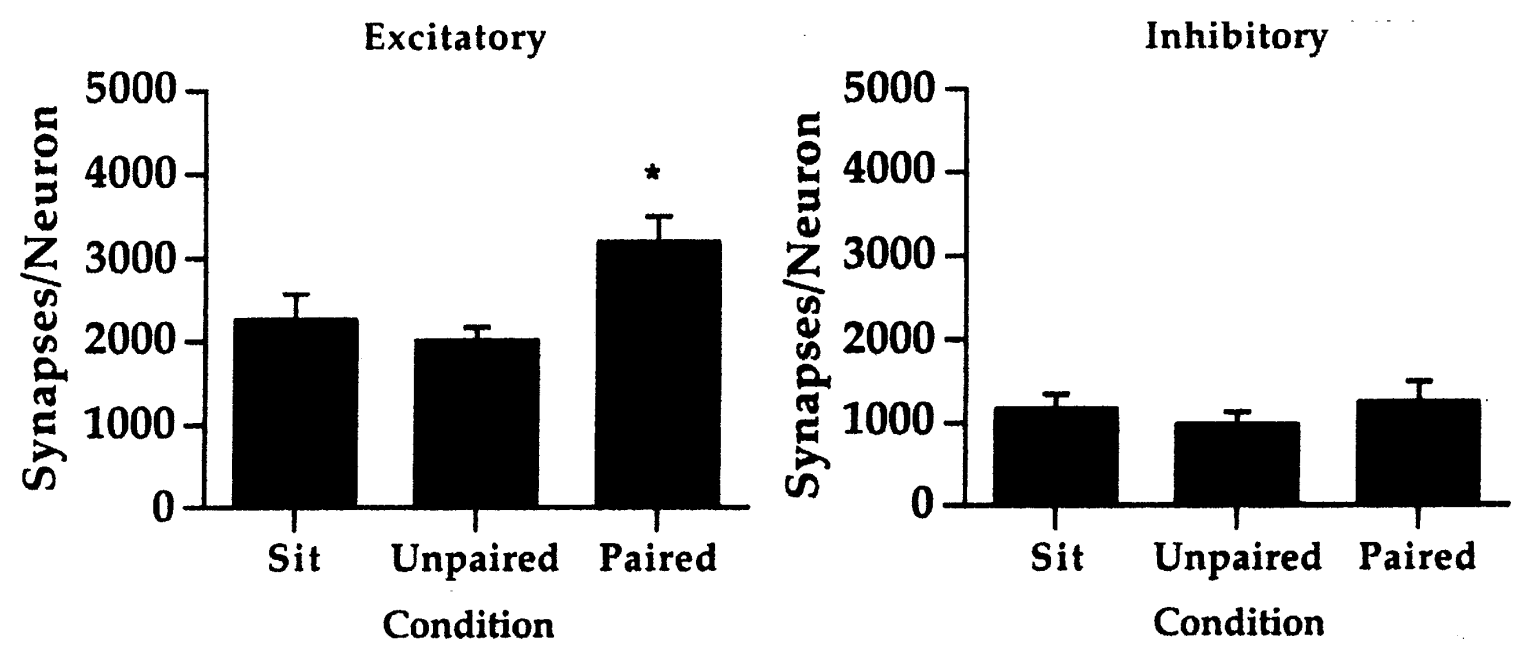

Figure 13 Synapses per neuron in the interpositus nucleus in well trained animals (rat, eyeblink conditioning) vs. home cage (sit) and unpaired controls. There is a highly significant increase in number of excitatory synapses (mossy fiber terminals?) in the trained animals but no change in the number of inhibitory synapses (Purkinje axon terminals?) in trained vs. control conditions (from Kleim et al. 2002).

cortex as an exemplary neural learning machine was driven by the confluence of several factors, including clinical evidence of cerebellar involvement in the acquisition and production of skilled movements and anatomical data showing the unique geometry of cortical cell populations with access to extensive sensory information (Eccles et al. 1967).

The organization of the cortex is remarkable in both its uniformity and precision, and it has provided the inspiration for much of cerebellar learning theory. Purkinje cells, large GABAergic neurons, are the sole efferents and project directly to the cerebellar deep and vestibular nuclei. The distinctive morphology of these neurons is characterized by an extensive and planar dendritic arbor positioned orthogonal to the longitudinal axis of the folia. Purkinje cells receive up to 150,000 excitatory synaptic contacts from nearly the same number of parallel fibers, the bifurcating axons of the cortical granule cells, which transverse the spiny dendrites. Granule cells are the most numerous in the cerebellum and relay sensory information from the pontine nuclei related to the CS (e.g., tone, light). Purkinje cells also receive hundreds of excitatory synaptic connections from a single climbing fiber, the ascending axon of a cell in the inferior olivary complex. Within this complex, the DAO receives and transmits information related to the US (e.g., airpuff, shock). The climbing fiber axon wraps around the smooth dendritic segments of the Purkinje cell, and a single action potential in a DAO cell will elicit a massive postsynaptic depolarization resulting in a multiphasic action potential or complex spike. In addition to these excitatory connections, three classes of inhibitory interneurons form feedforward and feedback loops among the cortical populations. Purkinje cells are thus positioned to receive and process a wealth of sensory information related to both the conditioned and unconditioned stimuli in distinct synaptic patterns.

The classical view predicts that the parallel fibers encode contextual information associated with the CS and the climbing fiber signal encodes US information that serves to signal movement error. This error signal could result from either the absence of an intended movement or the presence of an undesired action. Climbing fiber-evoked complex spikes occur at a very low spontaneous rate $(1-4 \mathrm{~Hz})$, allowing maximum information transfer per spike. It was further hypothesized that cortical plasticity at the parallel fiber-Purkinje cell (PF-PC) synapse provides a means to imprint physically the association between the two previously unrelated stimuli. David Marr and James Albus formalized cer- ebellar learning theory in independent reports that described a generalized mechanism for motor learning (Marr 1969; Albus 1971). Both theories posited the cerebellar cortex, specifically the PF-PC synapse, as the sole locus of learning-related plasticity, although Albus, unlike Marr, considered a loss of synaptic efficacy to be critical. Because Purkinje cells have a relatively high spontaneous firing rate in vivo $(40-70 \mathrm{~Hz})$, a decrease in this rate of simple spike firing would effectively disinhibit the interpositus nucleus, allowing for the expression of the CR. Empirical support for the decrease in synaptic efficacy proposed by Albus arrived in 1982 with Ito's discovery of long-term depression at the PF-PC synapse induced by conjunctive activation of parallel and climbing fibers (Ito and Kano 1982). At this early stage in the development of cerebellar learning theory, with the theoretical and empirical models in close agreement, it became generally accepted that cortical plasticity in the form of LTD could provide a plausible and likely mechanism for the emergence of the conditioned response. Since that time, a steadily increasing body of data has shown a correlation between learning deficits and compromised LTD.

The majority of evidence suggesting a role for cortical LTD in learning and memory comes from behavioral assays of mutant mice with deficits in LTD expression. It has been shown that activation of metabotropic and ionotropic glutamate receptors (mGluR and AMPAR) on the Purkinje cell dendrites is necessary for the induction of LTD (Linden and Connor 1993; Jeromin et al. 1996). Although the downstream signaling pathway is not entirely known, several key molecules have been identified. Factors required for LTD include $\mathrm{Ca}^{2+}$ influx via voltage-activated channels and transient PKC activation (Hansel et al. 2001). Mutant mice in which the mGluR1 subunit is not expressed, rendering the receptor nonfunctional, have shown deficient LTD and impaired eyeblink conditioning (Aiba et al. 1994). Phospholipase Cbetas are downstream signaling molecules of mGluR activation, and the PLCbeta4 isoform is expressed selectively in Purkinje cells in the rostral cerebellum, including portions of HVI. Mutant mice deficient in PLCbeta4 also show impaired LTD and an impairment in acquisition of conditioned responses in delay but not trace eyeblink conditioning (Kishimoto et al. 2001a; Miyata et al. 2001). Mutants lacking the $\delta 2$ subunit of the glutamate receptor exclusively in the cerebellar cortex are likewise impaired in LTD and delay eyeblink conditioning, but show normal levels of trace eyeblink conditioning (Kishimoto et al. 
$2001 b, c)$. The lack of effect on trace conditioning in these studies is somewhat puzzling. The behavioral impairment seen in these mutants is similar to that observed in pcd mice, in which both the acquisition rate and asymptotic levels of responding are compromised with no significant effect on either the timing or extinction of the CR. Additional support for the LTD hypothesis comes from GFAP-deficient mice, another mutation to manifest parallel impairment of LTD and eyeblink conditioning (Shibuki et al. 1996). Neurotrophins also appear critical to the normal development of CRs, as spontaneous mutants deficient in BDNF in the granule cells are behaviorally impaired, an effect potentially due to disrupted synaptic transmission (Bao et al. 1998; Qiao et al. 1998; Hashimoto et al. 1999).

Although it is clear that conjunctive activation of parallel and climbing fibers is sufficient to induce LTD, there are outstanding questions as to the spatial and temporal specificity of activation required to elicit plasticity. In order for the Purkinje cell to manifest a mechanism for associating the conditioned and unconditioned stimuli, the integration of sensory information with the climbing fiber error signal would seem to require synapse specificity and a restricted temporal order. The degree of spatial segregation depends ultimately on the topography of the sensory afferents from the pontine nuclei to the parallel fibers (Linden 1994). LTD induction from a restricted subset of parallel fibers has been shown to result in detectable spread of depression to neighboring inactive synapses (Hartell 1996; Wang et al. 2000b). It was shown that sparse stimulation of parallel fibers can trigger an IP3-mediated LTD via $\mathrm{Ca}^{2+}$ release from internal stores restricted to single spines (Wang et al. 2000a). In that study, LTD induced by sparse stimulation was most significant if parallel fiber activation preceded climbing fiber activation by 50 to 200 msec, a temporal range close to the optimal interstimulus interval (ISI) for eyeblink conditioning. Results from earlier in vitro experiments had appeared to run counter to the LTD hypothesis by demonstrating that LTD induction required simultaneous parallel fiber (PF) and climbing fiber (CF) activation or CF activation that preceded PF stimulation, a result clearly at odds with the temporal parameters required for conditioning. These experiments, however, were conducted in the presence of GABA antagonists (bicuculline), which would alter the network properties of the slice by disrupting inhibitory influences on PCs. A subsequent experiment conducted in the absence of GABA antagonists demonstrated the induction and expression of LTD in response to PF and CF stimulation at behaviorally relevant ISIs (Chen and Thompson 1995; see also Schreurs et al. 1996).

Synaptic changes in Purkinje cell morphology consistent with the induction of LTD have been observed in trained animals. A significant decrease in AMPA binding was reported in the ipsilateral cortex of trained animals compared with control subjects receiving unpaired presentations of the stimuli (Hauge et al. 1998). This result is consistent with a reduction in AMPA receptors via endocytosis as the means of LTD expression (Hansel et al. 2001). It is unlikely that this learning-related change in receptor binding is due to gross morphological changes in the dendrites, however. Decreases in dendritic branch length and the number of spiny branch arbors appear in animals receiving both paired and unpaired stimuli presentations (Anderson et al. 1999).

Although there is considerable evidence linking LTD to eyeblink conditioning from both mutant and in vitro experiments, these results must be corroborated by electrophysiological data in the intact behaving animal. If the LTD hypothesis predicts disinhibition of the interpositus via a decrease in the tonic firing of Purkinje cells, then it should be possible to observe such a pattern in the neural activity of trained animals. In addition, the transient suppression in simple spikes should occur during the CS period prior to the onset of the behavioral response in order to suggest that the plasticity is relevant to the expression of the CR. Several studies have, in fact, shown that Purkinje cells in HVI, the adjacent paramedian lobule, and the C3 microzone do exhibit learning-related decreases in firing (Berthier and Moore 1986; Foy and Thompson 1986; Thompson 1990; Foy et al. 1992; Hesslow and Ivarsson 1994; Gould and Steinmetz 1996; King et al. 2001). However, there is also evidence of learning-related increases in Purkinje cell firing during the CS period. The relative percentage of learning-related increases versus decreases differs among studies, with some investigators reporting a 2:1 ratio favoring an activity increase (Berthier and Moore 1986; Gould and Steinmetz 1996) and others reporting that the majority of cells exhibit decreases in activity (Thompson 1990; Foy et al. 1992; Hesslow and Ivarsson 1994; King et al. 2001). The functional significance of the increases in simple spike firing has not been determined, but it has been suggested that an increased inhibition of a subset of interpositus neurons may suppress non-eyeblink-related movements.

The timing of simple spike increases will be critical in determining the potential downstream behavioral effects. If the increase occurs immediately prior to and coincident with the CR expression, suppression of extraneous motor responses may be a plausible interpretation. Biphasic responses within single cells in which simple spike frequency increases in the early CS period and decreases prior to CR onset have also been reported (Hesslow and Ivarsson 1994; King et al. 2001). Temporal modulation of firing rates within single Purkinje cells suggests a heightened inhibition of the interpositus early in the CS period to counteract plasticity at the mossy fiber-interpositus synapse and delay disinhibition of the interpositus to elicit a well timed response (Perrett and Mauk 1995). Although this biphasic activity pattern has been observed in single cells, different populations of Purkinje cells may contribute to the suppression-release mechanism, allowing disparate regions of the cortex to influence CR timing.

In studies to date, on average, approximately $25 \%$ of the Purkinje cells sampled show learning-related plasticity, whereas the remaining cells are either not modulated at all or respond to presentations of the stimuli irrespective of the level of conditioning. These studies were conducted in separate populations of Purkinje cells in naïve and trained animals, and provide valuable information; however, it is also important to test the expression of plasticity in single cells during the transition from the naïve to the conditioned state. Results to date indicate that both decreases and increases in firing rates related to the production of the CR can develop over the course of learning (Christian et al. 2002). The heterogeneity in learning-related activity patterns does not appear to be strictly segregated into discrete anatomical regions of Purkinje cells. There remains a question as to the functional implication of the spatially indistinct response variability. If the information encoded by the Purkinje cells is better described by a population code, then multiple, simultaneous single-cell recordings will be required to discern a more accurate picture of conditioning-related patterns.

Multiple-unit activity recorded from the cerebellar cortex exhibits the same temporal model of the behavioral response observed in other brain structures (interpositus, red nucleus, hippocampus, etc.) and is likewise dependent on the interpositus (Clark et al. 1997a). This dependence suggests that the learningrelated pattern might not be an intrinsic feature of the cortex but rather due to responses of granule neurons or mossy fiber terminals due in turn to feedback connections from the interpositus. Interestingly, if the interpositus is lesioned in trained animals, patterns of activity in single Purkinje cells are altered, but approximately the same percentage of cells show learning-related activity as in the unlesioned controls (Katz and Steinmetz 1997). The percentage of cells showing an increase versus a decrease has 
shifted, however, so that both patterns are equally likely to occur. Perhaps the most intriguing aspect of this study was the effect on the timing of the conditioning-related activity. In lesioned animals the firing rate modulation tended to occur much earlier in the CS period, an effect that was variable in degree but consistent overall. This suggests that the interpositus may play a critical role in the timing of the cortical plasticity and that the reciprocal connections between the two structures are essentially involved in the development of the well timed response.

In so far as cerebellar cortex is concerned, most evidence supports LTD as a mechanism of synaptic plasticity underlying eyeblink conditioning, as noted. However, the evidence is indirect, in marked contrast to the more direct evidence of synapse formation in the interpositus nucleus. In a most interesting review article, David Linden and associates identify a number of sites of synaptic and nonsynaptic plasticity in the cerebellar cortex and nuclei that could subserve eyeblink conditioning (Hansel et al. 2001). These are based on studies of cerebellar tissue culture or slice. Thus, LTP-like processes have been described for mossy fiber-granule cell synapses, GABA interneuron-Purkinje neuron synapses, and Purkinje neuron-nuclear cell synapses; LTD for parallel fiber-Purkinje dendrite synapses, climbing fiber-Purkinje dendrite synapses, and Purkinje neuron-nuclear cell synapses; and intrinsic changes for granule cells and nuclear cells. In so far as cortex is concerned, all these processes (and others yet to be described) are candidate mechanisms. There is much yet to be done.

\section{Conclusion}

Although the focus of this review has been on the neural substrates of eyeblink conditioning, to the extent studied the findings described here apply equally to the learning of any discrete response (e.g., limb flexion, head turn, lip movement, etc.) learned with an effective US.

In this form of learning, the hippocampus becomes massively engaged. Indeed, the learning-induced increase in frequency of discharge of pyramidal neurons precedes and predicts the occurrence and temporal form of the learned behavioral response over a wide range of conditions, including both delay and trace paradigms. This learning-induced increase in hippocampal neuron activity begins to develop in the first few trials of training and exhibits the properties of a "declarative" memory trace.

Large hippocampal lesions have relatively little effect on acquisition and retention of the behavioral CR in the delay paradigm. However, in the trace procedure, such lesions yield marked anterograde amnesia and severe but time-limited retrograde amnesia, the hallmarks of declarative memory impairment with medial temporal lobe-hippocampal lesions in humans. Indeed, trace eyeblink conditioning is now considered by many to be an elementary model of declarative memory.

In terms of mechanisms of plasticity underlying the learning-induced increase in hippocampal neuronal activity, synaptic, intrinsic, and growth processes are all involved. Considerable evidence implicates LTP as a synaptic mechanism, and alterations in the slow afterhyperpolarization as an intrinsic mechanism. In trace conditioning there is also evidence of new neuron formation and alterations in synaptic structures in the hippocampus. Indeed, trace eyeblink conditioning may prove to be the Rosetta stone for identifying neuronal/synaptic mechanisms underlying declarative memory formation in the brain.

It is now established beyond reasonable doubt that the cerebellum and its associated circuitry is the essential (necessary and sufficient) brain system for delay classical conditioning of eyeblink and other discrete responses learned with an effective US. Indeed, the exact response elicited by the US is learned to any neutral stimulus. Effective USs include stimulation of reflex afferents, electrical stimulation of the DAO-climbing fiber system, and electrical stimulation of cerebellar white matter. Movements elicited by stimulation of other brain systems cannot be so conditioned. The cerebellar system is unique for the learning of discrete, precisely timed, "skilled" movements.

Evidence is now very strong that the essential basic CS-CR association is formed and stored in the interpositus nucleus. Indeed, appropriate lesions here completely prevent and abolish all components of both delay and trace CRs, and reversible inactivation here during training completely prevents learning. The evidence is also strong that synaptic plasticity is established in the cerebellar cortex in eyeblink conditioning. Whether or not such plasticity is essential for learning is not yet entirely clear. However, regions of cerebellar cortex play key roles in normal acquisition and in adaptive timing of the CR.

It now seems clear that increased synaptic efficacy and new synaptic terminal formation serve as mechanisms of memory storage in the interpositus nucleus. Whether or not the cerebellar cortex plays a key role in the establishment of this interpositus memory trace is not yet clear. In general terms, the "memory trace" in the interpositus nucleus appears to involve the strengthening of preexisting connections. Indeed, this may be the basic mechanism of procedural memory formation and storage in the mammalian brain. If true, a strong prediction from this hypothesis for eyeblink conditioning is that appropriate manipulations should reveal the functional existence of these connections before training.

In so far as cortical plasticity is concerned, evidence to date supports the process of LTD at parallel fiber synapses on Purkinje neuron dendrites as a key mechanism, just as with adaptation of the vestibulo-ocular reflex (Ito 1989). Other forms and loci of neuronal/synaptic plasticity in the cerebellar cortex are also viable candidates. It appears that eyeblink conditioning may be the first paradigm where the entire causal chain from mechanisms of neuronal/synaptic plasticity in brain structures to behavioral phenomena of learning and memory will be elucidated, the first form of memory storage in the mammalian brain where nature will yield up its secrets.

\section{ACKNOWLEDGMENTS}

Work described in this paper was supported in part by National Science Foundation Grant IBN-9215069, National Institutes of Aging Grant AG14751, and a grant from the Sankyo Company.

\section{NOTE ADDED IN PROOF}

A recent paper by Koekkoek et al. (2003) reports that interpositus lesions in mouse do not abolish the eyeblink conditioned response (CR). Their results are in marked contrast to many previous studies reviewed above (which they do not cite) showing that interpositus lesions completely prevent learning and completely and permanently abolish the eyeblink CR. It appears that their lesions are too small to appropriately remove the interpositus in the mouse (Chen et al. 1999). Indeed, their results replicate exactly the incomplete lesion results reported by Clark et al. (1984). Using a mutant deficient in cerebellar cortical LTD, Koekkoek et al. (2003) also report that CR latencies are shorter than normal and argue a causal relation. However, many of the onset latencies they show are much too short to be conditioned responses. We (Shibuki et al. 1996) showed that in the GFAP deficient mutant mouse, cerebellar cortical LTD was completely absent yet the timing of the eyeblink CRs was completely normal and identical to $C R$ latencies in wild-type controls. The relation they claim between cerebellar cortical LTD and CR latencies would seem to be spurious. 


\section{REFERENCES}

Aiba, A., Kano, M., Chen, C., Stanton, M.E., Fox, G.D., Herrup, K., Zwingman, T.A., and Tonegawa, S. 1994. Deficient cerebellar long-term depression and impaired motor learning in mGluR1 mutant mice. Cell 79: 377-388.

Akase, E., Alkon, D.L., and Disterhoft, J.F. 1989. Hippocampal lesions impair memory of short-delay conditioned eye blink in rabbits. Behav. Neurosci. 103: 935-943.

Albus, J.S. 1971. A theory of cerebellar function. Math Biosci. 10: 25-61.

Anderson, B.J., Relucio, K., Haglund, K., Logan, C., Knowlton, B., Thompson, J., Steinmetz, J.E., Thompson, R.F., and Greenough, W.T. 1999. Effects of paired and unpaired eye-blink conditioning on Purkinje cell morphology. Learn. Mem. 6: 128-137.

Andersson, G. and Oscarsson, O. 1978. Climbing fiber microzones in cerebellar vermis and their projection to different groups of cells in the lateral vestibular nucleus. Exp. Brain Res. 32: 565-579.

Attwell, P.J., Rahman, S., Ivarsson, M., and Yeo, C.H. 1999. Cerebellar cortical AMPA-kainate receptor blockade prevents performance of classically conditioned nictitating membrane responses. J. Neurosci. 19: RC45.

Attwell, P.J., Rahman, S., and Yeo, C.H. 2001. Acquisition of eyeblink conditioning is critically dependent on normal function in cerebellar cortical lobule HVI. J. Neurosci. 21: 5715-5722.

Attwell, P.J., Cooke, S.F., and Yeo, C.H. 2002. Cerebellar function in consolidation of a motor memory. Neuron 34: 1011-1020.

Bao, S., Chen, L., Qiao, X., Knusel, B., and Thompson, R.F. 1998. Impaired eye-blink conditioning in waggler, a mutant mouse with cerebellar BDNF deficiency. Learn. Mem. 5: 355-364.

Bao, S., Chen, L., and Thompson, R.F. 2000. Learning- and cerebellum-dependent neuronal activity in the lateral pontine nucleus. Behav. Neurosci. 114: 254-261.

Bao, S., Chen, L., Kim, J.J., and Thompson, R.F. 2002. Cerebellar cortical inhibition and classical eyeblink conditioning. Proc. Natl. Acad. Sci. 99: 1592-1597.

Berger, T.W. 1984. Long-term potentiation of hippocampal synaptic transmission affects rate of behavioral learning. Science 224: $627-630$.

Berger, T.W. and Orr, W.B. 1983. Hippocampectomy selectively disrupts discrimination reversal conditioning of the rabbit nictitating membrane response. Behav. Brain Res. 8: 49-68.

Berger, T.W. and Thompson, R.F. 1977. Limbic system interrelations: Functional division among hippocampal-septal connections. Science 197: $587-589$

. 1978a. Identification of pyramidal cells as the critical elements in hippocampal neuronal plasticity during learning. Proc. Natl. Acad. Sci. 75: 1572-1576.

. 1978 b. Neuronal plasticity in the limbic system during classical conditioning of the rabbit nictitating membrane response. I. The hippocampus. Brain Res. 145: 323-346.

. 1978c. Neuronal plasticity in the limbic system during classical conditioning of the rabbit nictitating membrane response. II: Septum and mammillary bodies. Brain Res. 156: 293-314.

Berger, T.W., Alger, B., and Thompson, R.F. 1976. Neuronal substrate of classical conditioning in the hippocampus. Science 192: 483-485.

Berger, T.W., Rinaldi, P.C., Weisz, D.J., and Thompson, R.F. 1983. Single-unit analysis of different hippocampal cell types during classical conditioning of rabbit nictitating membrane response. $J$. Neurophysiol. 50: 1197-1219.

Berger, T.W., Berry, S.D., and Thompson, R.F. 1986. Role of the hippocampus in classical conditioning of aversive and appetitive behaviors. In The hippocampus (eds. R.L. Isaacson and K.H. Pribram), Vol. 3-4, pp. 203-239. Plenum, New York.

Berger, T.W., Bassett, J.L., and Orr, W.B. 1990. Multiple memory systems and their contribution to classical conditioning. In Current topics in animal learning: Brain, emotion, and cognition (eds. L. Dachowski and C. Flaherty), pp. 271-310. Plenum, New York.

Berry, S.D. and Swain, R.A. 1989. Water deprivation optimizes hippocampal activity and facilitates nictitating membrane conditioning. Behav. Neurosci. 103: 71-76.

Berry, S.D. and Thompson, R.F. 1978. Prediction of learning rate from the hippocampal electroencephalogram. Science 200: 1298-1300. . 1979. Medial septal lesions retard classical conditioning of the nictitating membrane response in rabbits. Science 205: 209-211.

Berthier, N.E. and Moore, J.W. 1986. Cerebellar Purkinje cell activity related to the classically conditioned nictitating membrane response. Exp. Brain Res. 63: 341-350.

. 1990. Activity of deep cerebellar nuclear cells during classical conditioning of nictitating membrane extension in rabbits. Exp. Brain Res. 83: 44-54.

Berthier, N.E., Desmond, J.E., and Moore, J.W. 1987. Brainstem control of the nictitating membrane response. In Classical conditioning (eds.
I. Gormezano, W.F. Prokasy, and R.F. Thompson), pp. 275-286. Lawrence Erlbaum Associates, Hillsdale, NJ.

Beylin, A.V., Gandhi, C.C., Wood, G.E., Talk, A.C., Matzel, L.D., and Shors, T.J. 2001. The role of the hippocampus in trace conditioning: Temporal discontinuity or task difficulty? Neurobiol. Learn. Mem. 76: $447-461$.

Blaxton, T.A., Zeffiro, T.A., Gabrieli, J.D., Bookheimer, S.Y., Carrillo, M.C., Theodore, W.H., and Disterhoft, J.F.1996. Functional mapping of human learning: A positron emission tomography activation study of eyeblink conditioning. J. Neurosci. 16: 4032-4040.

Bombace, J.C., Brandon, S.E., and Wagner, A.R. 1991. Modulation of a conditioned eyeblink response by a putative emotive stimulus conditioned with hindleg shock. J. Exp. Psychol. Anim. Behav. Process 17: 323-333.

Bracha, V., Zhao, L., Wunderlich, D.A., Morrissy, S.J., and Bloedel, J.R. 1997. Patients with cerebellar lesions cannot acquire but are able to retain conditioned eyeblink reflexes. Brain 120: 1401-1413.

Bracha, V., Irwin, K.B., Webster, M.L., Wunderlich, D.A., Stachowiak, M.K., and Bloedel, J.R. 1998. Microinjections of anisomycin into the intermediate cerebellum during learning affect the acquisition of classically conditioned responses in the rabbit. Brain Res. 788: $169-178$

Bracha, V., Zhao, L., Irwin, K.B., and Bloedel, J.R. 2000. The human cerebellum and associative learning: Dissociation between the acquisition, retention and extinction of conditioned eyeblinks. Brain Res. 860: 87-94.

Brandon, S.E. and Wagner, A.R. 1991. Modulation of a discrete Pavlovian conditioned reflex by a putative emotive Pavlovian conditioned stimulus. J. Exp. Psychol. Anim. Behav. Process 17: 299-311.

Brandon, S.E., Bombace, J.C., Falls, W.A., and Wagner, A.R. 1991. Modulation of unconditioned defense reflexes by a putative emotive Pavlovian conditioned stimulus. J. Exp. Psychol. Anim. Behav. Process 17: 312-322.

Brodal, A. 1981. Neurological anatomy. Oxford University Press, New York.

Brodal, A., Walberg, F., and Hoddevik, G.H. 1975. The olivocerebellar projection in the cat studied with the method of retrograde axonal transport of horseradish peroxidase. J. Comp. Neurol. 164: 449-469.

Brogden, W.J. and Gantt, W.H. 1942. Interneural conditioning: Cerebellar conditioned reflexes. Arch. Neurol. Psychiatry 48: 437-455.

Brons, J.F. and Woody, C.D. 1980. Long-term changes in excitability of cortical neurons after Pavlovian conditioning and extinction. $J$. Neurophysiol. 44: 605-615.

Brons, J.F., Woody, C.D., and Allon, N. 1982. Changes in excitability to weak-intensity extracellular electrical stimulation of units of pericruciate cortex in cats. J. Neurophysiol. 47: 377-388.

Brown, I.E. and Bower, J.M. 2001. Congruence of mossy fiber and climbing fiber tactile projections in the lateral hemispheres of the rat cerebellum. J. Comp. Neurol. 429: 59-70.

Brown, J.S., Kalish, H.I., and Farber, I.E. 1951. Conditioned fear as revealed by magnitude of startle response to an auditory stimulus. $J$. Exp. Psychol. 41: 317-328.

Buchanan, S.L. 1991. Differential and reversal Pavlovian conditioning in rabbits with mediodorsal thalamic lesions: Assessment of heart rate and eyeblink responses. Exp. Brain Res. 86: 174-181.

Buchanan, S.L. and Powell, D.A. 1982. Cingulate cortex: Its role in Pavlovian conditioning. J. Comp. Physiol. Psychol. 96: 755-774.

Buchanan, S.L., Beylotte III, F.M., and Powell, D.A. 1997a. Lesions of the thalamic reticular nucleus or the basal forebrain impair Pavlovian eyeblink conditioning and attenuate learning-related multiple-unit activity in the mediodorsal nucleus of the thalamus. Psychobiology 25: $45-58$

Buchanan, S.L., Penney, J., Tebbutt, D., and Powell, D.A. 1997b. Lesions of the mediodorsal nucleus of the thalamus and classical eyeblink conditioning under less-than-optimal stimulus conditions: Role of partial reinforcement and interstimulus interval. Behav. Neurosci. 111: $1075-1085$.

Canli, T. and Brown, T.H. 1996. Amygdala stimulation enhances the rat eyeblink reflex through a short-latency mechanism. Behav. Neurosci. 110: $51-59$.

Carrillo, M.C., Gabrieli, J.D., Hopkins, R.O., McGlinchey-Berroth, R., Fortier, C.B., Kesner, R.P., and Disterhoft, J.F. 2001. Spared discrimination and impaired reversal eyeblink conditioning in patients with temporal lobe amnesia. Behav. Neurosci. 115: $1171-1179$.

Cegavske, C.F., Thompson, R.F., Patterson, M.M., and Gormezano, I. 1976. Mechanisms of efferent neuronal control of the reflex nictitating membrane response in rabbit (Oryctolagus cuniculus). $J$. Comp. Physiol. Psychol. 90: 411-423.

Cegavske, C.F., Patterson, M.M., and Thompson, R.F. 1979. Neuronal unit activity in the abducens nucleus during classical conditioning 
of the nictitating membrane response in the rabbit (Oryctolagus cuniculus). J. Comp. Physiol. Psychol. 93: 595-609.

Cegavske, C.F., Harrison, T.A., and Torigoe, Y. 1987. Identification of the substrates of the unconditioned response in the classically conditioned rabbit, nictitating-membrane preparation. In Classical conditioning (eds. I. Gormezano, W.F. Prokasy, and R.F. Thompson), pp. 65-90. Lawrence Erlbaum Associates, Hillsdale, NJ.

Chacich, M. and Powell, D.A. 1992. Lesions of the medial prefrontal cortex impair reversal of classically conditioned eyeblink response. Abstr. Soc. Neurosci. 18: 338.

- 1998. Both medial prefrontal and amygdala central nucleus lesions abolish heart rate classical conditioning, but only prefrontal lesions impair reversal of eyeblink differential conditioning. Neurosci. Lett. 257: 151-154.

Chen, C. and Thompson, R.F. 1995. Temporal specificity of long-term depression in parallel fiber-Purkinje synapses in rat cerebellar slice. Learn. Mem. 2: 185-198.

Chen, G. and Steinmetz, J.E. 2000. Intracerebellar infusion of NMDA receptor antagonist AP5 disrupts classical eyeblink conditioning in rabbits. Brain Res. 887: 144-156.

Chen, L., Bao, S., Lockard, J.M., Kim, J.K., and Thompson, R.F. 1996. Impaired classical eyeblink conditioning in cerebellar-lesioned and Purkinje cell degeneration (pcd) mutant mice. J. Neurosci. 16: 2829-2838.

Chen, L., Bao, S., and Thompson, R.F. 1999. Bilateral lesions of the interpositus nucleus completely prevent eyeblink conditioning in Purkinje cell-degeneration mutant mice. Behav. Neurosci. 113: 204-210.

Choi, J.S., Lindquist, D.H., and Brown, T.H. 2001. Amygdala lesions block conditioned enhancement of the early component of the rat eyeblink reflex. Behav. Neurosci. 115: 764-775.

Christian, K.M., Poulos, A.M., and Thompson, R.F. 2002. Purkinje cell activity during classical conditioning of the eyeblink reflex in rabbits. Abstr. Soc. Neurosci. 28: 79.9 .

Cipriano, B.D., Krupa, D.J., Almanza, W., and Thompson, R.F. 1995. Inactivation of the interpositus nucleus prevents transfer of the rabbit's classically conditioned eyeblink response from a light to a tone CS. Abstr. Soc. Neurosci. 21: 1221.

Clark, G.A., McCormick, D.A., Lavond, D.G., and Thompson, R.F. 1984. Effects of lesions of cerebellar nuclei on conditioned behavioral and hippocampal neuronal responses. Brain Res. 291: 125-136.

Clark, R.E. and Lavond, D.G. 1993. Reversible lesions of the red nucleus during acquisition and retention of a classically conditioned behavior in rabbits. Behav. Neurosci. 107: 264-270.

_. 1994. Reacquisition of eyeblink classical conditioning following large cerebellar cortical lesions in Dutch belted rabbits. Behav. Brain Res. 61: 101-106.

. 1996. Neural unit activity in the trigeminal complex with interpositus or red nucleus inactivation during classical eyeblink conditioning. Behav. Neurosci. 110: 13-21.

Clark, R.E. and Squire, L.R. 1998. Classical conditioning and brain systems: The role of awareness. Science 280: 77-81.

. 1999. Human eyeblink classical conditioning: Effects of manipulating awareness of the stimulus contingencies. Psychol. Sci. 10: $14-18$.

. 2000. Awareness and the conditioned eyeblink response. In Eyeblink classical conditioning: Applications in humans (eds. D.S. Woodruff-Pak and J.E. Steinmetz), Vol. 1, pp. 229-251. Kluwer Academic Publishers, Boston.

Clark, R.E., Brown, D.J., Thompson, R.F., and Lavond, D.G. 1990. Reacquisition of classical conditioning after removal of cerebellar cortex in Dutch Belted rabbits. Abstr. Soc. Neurosci. 16: 271.

Clark, R.E., Zhang, A.A., and Lavond, D.G. 1992. Reversible lesions of the cerebellar interpositus nucleus during acquisition and retention of a classically conditioned behavior. Behav. Neurosci. 106: 879-888.

Clark, R.E., Gohl, E.B., and Lavond, D.G. 1997a. The learning-related activity that develops in the pontine nuclei during classical eye-blink conditioning is dependent on the interpositus nucleus. Learn. Mem. 3: 532-544.

Clark, R.E., Zhang, A.A., and Lavond, D.G. 1997b. The importance of cerebellar cortex and facial nucleus in acquisition and retention of eyeblink/NM conditioning: Evidence for critical unilateral regulation of the conditioned response. Neurobiol. Learn. Mem. 67: 96-111.

Clark, R.E., Manns, J.R., and Squire, L.R. 2001. Trace and delay eyeblink conditioning: Contrasting phenomena of declarative and nondeclarative memory. Psychol. Sci. 12: 304-308.

Colin, F., Manil, J., and Desclin, J.C. 1980. The olivocerebellar system. I. Delayed and slow inhibitory effects: An overlooked salient feature of cerebellar climbing fibers. Brain Res. 187: 3-27.

Coulter, D.A., Lo Turco, J.J., Kubota, M., Disterhoft, J.F., Moore, J.W., and Alkon, D.L. 1989. Classical conditioning reduces amplitude and duration of calcium-dependent afterhyperpolarization in rabbit hippocampal pyramidal cells. J. Neurophysiol. 61: 971-981.

Cox, J., Guthrie, R., Macrae, M., and Kehoe, E.J. 1994. MK801 impairs acquisition and expression of conditioned responses in the rabbit nictitating membrane preparation. Psychobiology 22: 156-166.

Daum, I., Channon, S., Polkey, C.E., and Gray, J.A. 1991. Classical conditioning after temporal lobe lesions in man: Impairment in conditional discrimination. Behav. Neurosci. 105: 396-408.

Daum, I., Channon, S., and Gray, J.A. 1992. Classical conditioning after temporal lobe lesions in man: Sparing of simple discrimination and extinction. Behav. Brain Res. 52: 159-165.

Daum, I., Schugens, M.M., Ackermann, H., Lutzenberger, W., Dichgans, J., and Birbaumer, N. 1993. Classical conditioning after cerebellar lesions in humans. Behav. Neurosci. 107: 748-756.

Davis, M. 1984. Mammalian startle response. In Neural mechanisms of startle behavior (ed. R.C. Eaton), pp. 287-351. Plenum, New York. . 1992. The role of the amygdala in fear and anxiety. Annu. Rev. Neurosci. 15: 353-375.

1997. Neurobiology of fear responses: The role of the amygdala. J. Neuropsychiatry Clin. Neurosci. 9: 382-402.

Deaux, E.G. and Gormezano, I. 1963. Eyeball retraction: Classical conditioning and extinction in the albino rabbit. Science 141: $630-631$.

de Jonge, M.C., Black, J., Deyo, R.A., and Disterhoft, J.F. 1990. Learning-induced afterhyperpolarization reductions in hippocampus are specific for cell type and potassium conductance. Exp. Brain Res. 80: $456-462$.

Delgado-Garcia, J.M. and Gruart, A. 2002. The role of the interpositus nucleus in eyelid conditioned responses. Cerebellum 1: 289-308.

Deyo, R.A., Straube, K.T., and Disterhoft, J.F. 1989. Nimodipine facilitates associative learning in aging rabbits. Science 243: 809-811.

Disterhoft, J.F. and McEchron, M.D. 2000. Cellular alterations in hippocampus during acquisition and consolidation of hippocampus-dependent trace eyeblink conditioning. In Eyeblink classical conditioning: Animal models (eds. D.S. Woodruff-Pak and J.E. Steinmetz), Vol. 2, pp. 313-334. Kluwer Academic Publishers, Boston.

Disterhoft, J.F., Quinn, K.J., Weiss, C., and Shipley, M.T. 1985. Accessory abducens nucleus and conditioned eye retraction/nictitating membrane extension in rabbit. $J$. Neurosci. 5: 941-950.

Disterhoft, J.F., Coulter, D.A., and Alkon, D.L. 1986. Conditioning-specific membrane changes of rabbit hippocampal neurons measured in vitro. Proc. Natl. Acad. Sci. 83: 2733-2737.

Disterhoft, J.F., Quinn, K.J., and Weiss, C. 1987. Analysis of the auditory input and motor output pathways in rabbit nictitating membrane conditioning. In Classical conditioning (eds. I. Gormezano, W.F. Prokasy, and R.F. Thompson), pp. 93-116. Lawrence Erlbaum Associates, Hillsdale, NJ.

Eccles, J.C. 1977. An instruction-selection theory of learning in the cerebellar cortex. Brain Res. 127: 327-352.

Eccles, J.C., Ito, M., and Szentagothai, J. 1967. Cerebellum as a neuronal machine. Springer-Verlag, New York.

Fanselow, M.S. 1984. What is conditioned fear? Trends Neurosci. 7: $460-462$.

Fox, P.C., Eichenbaum, H., and Butter, C.M. 1982. The role of frontal cortex-reticular interactions in performance and extinction of the classically conditioned nictitating membrane response in the rabbit. Behav. Brain Res. 5: 143-156.

Foy, M.R. and Thompson, R.F. 1986. Single unit analysis of Purkinje cell discharge in classically conditioned and untrained rabbits. Abstr. Soc. Neurosci. 12: 518

Foy, M.R., Steinmetz, J.E., and Thompson, R.F. 1984. Single unit analysis of cerebellum during classically conditioned eyelid responses. Abstr. Soc. Neurosci. 10: 122 .

Foy, M.R., Krupa, D.J., Tracy, J., and Thompson, R.F. 1992. Analysis of single unit recordings from cerebellar cortex of classically conditioned rabbits. Abstr. Soc. Neurosci. 18: 1215.

Freeman Jr., J.H., and Nicholson, D.A. 2000. Developmental changes in eye-blink conditioning and neuronal activity in the cerebellar interpositus nucleus. J. Neurosci. 20: 813-819.

Freeman Jr., J.H., Carter, C.S., and Stanton, M.E. 1995. Early cerebellar lesions impair eyeblink conditioning in developing rats: Differential effects of unilateral lesions on postnatal day 10 or 20 . Behav. Neurosci. 109: 893-902.

Gabrieli, J.D., Brewer, J.B., and Poldrack, R.A. 1998. Images of medial temporal lobe functions in human learning and memory. Neurobiol. Learn. Mem. 70: 275-283.

Garcia, K.S. and Mauk, M.D. 1998. Pharmacological analysis of cerebellar contributions to the timing and expression of conditioned eyelid responses. Neuropharmacology 37: 471-480.

Garcia, K.S., Steele, P.M., and Mauk, M.D. 1999. Cerebellar cortex lesions prevent acquisition of conditioned eyelid responses. $J$. Neurosci. 19: 10940-10947. 
Geinisman, Y., Disterhoft, J.F., Gundersen, H.J., McEchron, M.D., Persina, I.S., Power, J.M., van der Zee, E.A., and West, M.J. 2000. Remodeling of hippocampal synapses after hippocampus-dependent associative learning. J. Comp. Neurol. 417: 49-59.

Geinisman, Y., Berry, R.W., Disterhoft, J.F., Power, J.M., and van der Zee, E.A. 2001. Associative learning elicits the formation of multiple-synapse boutons. J. Neurosci. 21: 5568-5573.

Gilbert, P. 1975. How the cerebellum could memorise movements. Nature 254: 688-689.

Glickstein, M., Cohen, J.L., Dixon, B., Gibson, A., Hollins, M. Labossiere, E., and Robinson, F. 1980. Corticopontine visual projections in macaque monkeys. J. Comp. Neurol. 190: 209-229.

Gomi, H., Sun, W., Finch, C.E., Itohara, S., Yoshimi, K., and Thompson, R.F. 1999. Learning induces a CDC2-related protein kinase, KKIAMRE. J. Neurosci. 19: 9530-9537.

Gormezano, I., Schneiderman, N., Deaux, E.G., and Fuentes, J. 1962. Nictitating membrane classical conditioning and extinction in the albino rabbit. Science 138: 33-34.

Gormezano, I., Kehoe, E.J., and Marshall, B.S. 1983. Twenty years of classical conditioning with the rabbit. Prog. Psychobio. Physiol. Psychol. 10: 197-275.

Gould, E., Beylin, A., Tanapat, P., Reeves, A., and Shors, T.J. 1999a. Learning enhances adult neurogenesis in the hippocampal formation. Nat. Neurosci. 2: 260-265.

Gould, E., Tanapat, P., Hastings, N.B., and Shors, T.J. 1999b. Neurogenesis in adulthood: A possible role in learning. Trends Cogn. Sci. 3: 186-192.

Gould, T.J. and Steinmetz, J.E. 1996. Changes in rabbit cerebellar cortical and interpositus nucleus activity during acquisition, extinction, and backward classical eyelid conditioning. Neurobiol. Learn. Mem. 65: 17-34.

Green, J.T. and Woodruff-Pak, D.S. 2000a. Eyeblink classical conditioning in aging animals. In Eyeblink classical conditioning: Animal models (eds. D.S. Woodruff-Pak and J.E. Steinmetz), Vol. 2, pp. 155-178. Kluwer Academic Publishers, Boston.

. 2000b. Eyeblink classical conditioning: Hippocampal formation is for neutral stimulus associations as cerebellum is for association-response. Psychol. Bull. 126: 138-158.

Groenewegen, H.J., Voogd, J., and Freedman, S.L. 1979. The parasagittal zonation within the olivocerebellar projection. II. Climbing fiber distribution in the intermediate and hemispheric parts of cat cerebellum. J. Comp. Neurol. 183: 551-601.

Gruart, A. and Yeo, C.H. 1995. Cerebellar cortex and eyeblink conditioning: Bilateral regulation of conditioned responses. Exp. Brain Res. 104: $431-448$.

Gruart, A., Guillazo-Blanch, G., Fernandez-Mas, R., Jimenez-Diaz, L., and Delgado-Garcia, J.M. 2000. Cerebellar posterior interpositus nucleus as an enhancer of classically conditioned eyelid responses in alert cats. J. Neurophysiol. 84: 2680-2690.

Hansel, C., Linden, D.J., and D'Angelo, E. 2001. Beyond parallel fiber LTD: The diversity of synaptic and nonsynaptic plasticity in the cerebellum. Nat. Neurosci. 4: 467-475.

Hardiman, M.J., Glickstin, M., and Yeo, C.H. 1988. Kainic acid lesions of the cerebellar cortex abolish the classically conditioned nictitating membrane response of the rabbit. Abstr. Soc. Neurosci. 14: 784.

Hardiman, M.J., Ramnani, N., and Yeo, C.H. 1996. Reversible inactivations of the cerebellum with muscimol prevent the acquisition and extinction of conditioned nictitating membrane responses in the rabbit. Exp. Brain Res. 110: 235-247.

Hartell, N.A. 1996. Strong activation of parallel fibers produces localized calcium transients and a form of LTD that spreads to distant synapses. Neuron 16: 601-610.

Harvey, J.A., Yeo, C.H., Welsh, J.P., and Romano, A.G. 1990. Recoverable and nonrecoverable deficits in conditioned responses (CRs) after cerebellar cortical lesions. Abstr. Soc. Neurosci. 16: 268.

Harvey, J.A., Welsh, J.P., Yeo, C.H., and Romano, A.G. 1993. Recoverable and nonrecoverable deficits in conditioned responses after cerebellar cortical lesions. J. Neurosci. 13: 1624-1635.

Hashimoto, K., Fukaya, M., Qiao, X., Sakimura, K., Watanabe, M., and Kano, M. 1999. Impairment of AMPA receptor function in cerebellar granule cells of ataxic mutant mouse stargazer. J. Neurosci. 19: 6027-6036.

Hauge, S.A., Tracy, J.A., Baudry, M., and Thompson, R.F. 1998. Selective changes in AMPA receptors in rabbit cerebellum following classical conditioning of the eyelid-nictitating membrane response. Brain Res. 803: $9-18$.

Hausser, M. and Clark, B.A. 1997. Tonic synaptic inhibition modulates neuronal output pattern and spatiotemporal synaptic integration. Neuron 19: 665-678

Hesslow, G. 1994. Correspondence between climbing fibre input and motor output in eyeblink-related areas in cat cerebellar cortex. $J$. Physiol. 476: 229-244.
Hesslow, G. and Ivarsson, M. 1994. Suppression of cerebellar Purkinje cells during conditioned responses in ferrets. Neuroreport 5: 649-652. . 1996. Inhibition of the inferior olive during conditioned responses in the decerebrate ferret. Exp. Brain Res. 110: 36-46.

Hesslow, G., Svensson, P., and Ivarsson, M. 1999. Learned movements elicited by direct stimulation of cerebellar mossy fiber afferents. Neuron 24: 179-185.

Ito, M. 1972. Neural design of the cerebellar motor control system. Brain Res. 40: $81-84$.

1984. The cerebellum and neural control Raven Press, New York.

. 1989. Long-term depression. Annu. Rev. Neurosci. 12: 85-102.

Ito, M. and Kano, M. 1982. Long-lasting depression of parallel fiber-Purkinje cell transmission induced by conjunctive stimulation of parallel fibers and climbing fibers in the cerebellar cortex. Neurosci. Lett. 33: 253-258.

Ivkovich, D. and Thompson, R.F. 1997. Motor cortex lesions do not affect learning or performance of the eyeblink response in rabbits. Behav. Neurosci. 111: 727-738.

Ivkovich, D., Lockard, J.M., and Thompson, R.F. 1993. Interpositus lesion abolition of the eyeblink conditioned response is not due to effects on performance. Behav. Neurosci. 107: 530-532.

Ivkovich, D., Eckman, C.O., Krasnegor, N.A., and Stanton, M.E. 2000. Using eyeblink conditioning to assess neurocognitive development in human infants. In Eyeblink classical conditioning: Applications in humans (eds. D.S. Woodruff-Pak and J.E. Steinmetz), Vol. 1, pp 119-142. Kluwer Academic Publishers, Boston.

James, G.O., Hardiman, M.J., and Yeo, C.H. 1987. Hippocampal lesions and trace conditioning in the rabbit. Behav. Brain Res. 23: 109-116.

Jeromin, A., Huganir, R.L., and Linden, D.J. 1996. Suppression of the glutamate receptor $\delta 2$ subunit produces a specific impairment in cerebellar long-term depression. J. Neurophysiol. 76: 3578-3583.

Jimenez-Diaz, L., Gruart, A., Minano, F.J., and Delgado-Garcia, J.M. 2002. An experimental study of posterior interpositus involvement in the genesis and control of conditioned eyelid responses. Ann. N.Y. Acad. Sci. 978: 106-118.

Kamin, L.J. 1969. Predictability, surprise, attention, and conditioning. In Punishment and aversive behavior (eds. B.A. Campbell and R.M. Church), pp. 276-296. Appleton-Century-Crofts, New York.

Kaneko, T. and Thompson, R.F. 1997. Disruption of trace conditioning of the nictitating membrane response in rabbits by central cholinergic blockade. Psychopharmacology (Berl). 131: 161-166.

Kao, K.T. and Powell, D.A. 1988. Lesions of the substantia nigra retard Pavlovian eye-blink but not heart rate conditioning in the rabbit. Behav. Neurosci. 102: 515-525.

Katz, D.B. and Steinmetz, J.E. 1994. How long do relational representations last in the hippocampus during classical conditioning? Behav. Brain Sci. 17: 484-485.

1997. Single-unit evidence for eye-blink conditioning in cerebellar cortex is altered, but not eliminated, by interpositus nucleus lesions. Learn. Mem. 4: 88-104.

Kim, J.J. and Fanselow, M.S. 1992. Modality-specific retrograde amnesia of fear. Science 256: 675-677.

Kim, J.J., Clark, R.E., and Thompson, R.F. 1995. Hippocampectomy impairs the memory of recently, but not remotely, acquired trace eyeblink conditioned responses. Behav. Neurosci. 109: 195-203.

Kim, J.J., Krupa, D.J., and Thompson, R.F. 1998. Inhibitory cerebello-olivary projections and blocking effect in classical conditioning. Science 279: 570-573.

King, D.A., Krupa, D.J., Foy, M.R., and Thompson, R.F. 2001. Mechanisms of neuronal conditioning. Int. Rev. Neurobiol. 45: $313-337$.

Kishimoto, Y., Hirono, M., Sugiyama, T., Kawahara, S., Nakao, K., Kishio, M., Katsuki, M., Yoshioka, T., and Kirino, Y. 2001a. Impaired delay but normal trace eyeblink conditioning in PLC $\beta 4$ mutant mice. Neuroreport 12: 2919-2922.

Kishimoto, Y., Kawahara, S., Fujimichi, R., Mori, H., Mishina, M., and Kirino, Y. 2001b. Impairment of eyeblink conditioning in GluR82-mutant mice depends on the temporal overlap between conditioned and unconditioned stimuli. Eur. J. Neurosci. 14: $1515-1521$.

Kishimoto, Y., Kawahara, S., Suzuki, M., Mori, H., Mishina, M., and Kirino, Y. 2001c. Classical eyeblink conditioning in glutamate receptor subunit $\delta 2$ mutant mice is impaired in the delay paradigm but not in the trace paradigm. Eur. J. Neurosci. 13: 1249-1253.

Kleim, J.A., Freeman Jr., J.H., Bruneau, R., Nolan, B.C., Cooper, N.R., Zook, A., and Walters, D. 2002. Synapse formation is associated with memory storage in the cerebellum. Proc. Natl. Acad. Sci. 99: 13228-13231.

Knowlton, B.J. and Thompson, R.F. 1992. Conditioning using a cerebral cortical conditioned stimulus is dependent on the cerebellum and brain stem circuitry. Behav. Neurosci. 106: 509-517.

Knowlton, B.J., Thompson, J.K., and Thompson, R.F. 1993. Projections 
from the auditory cortex to the pontine nuclei in the rabbit. Behav. Brain Res. 56: 23-30.

Knuttinen, M.G., Power, J.M., Preston, A.R., and Disterhoft, J.F. 2001 Awareness in classical differential eyeblink conditioning in young and aging humans. Behav. Neurosci. 115: 747-757.

Koekkoek, S.K., Hulscher, H.C., Dortland, B.R., Hensbroek, R.A., Elgersma, Y., Ruigrok, T.J., and De Zeeuw, C.I. 2003. Cerebellar LTD and learning-dependent timing of conditioned eyelid responses. Science 301: 1736-1739.

Kolb, F.P., Irwin, K.B., Bloedel, J.R, and Bracha, V. 1997. Conditioned and unconditioned forelimb reflex systems in the cat: Involvement of the intermediate cerebellum. Exp. Brain Res. 114: 255-270.

Konorski, J. 1967. Integrative activity of the brain. University of Chicago Press, Chicago.

Kronforst-Collins, M.A. and Disterhoft, J.F. 1998. Lesions of the caudal area of rabbit medial prefrontal cortex impair trace eyeblink conditioning. Neurobiol. Learn. Mem. 69: 147-162.

Krupa, D.J. 1993. Localization of the essential memory trace for a classically conditioned behavior. University of Southern California, Los Angeles.

Krupa, D.J. and Thompson, R.F. 1995. Inactivation of the superior cerebellar peduncle blocks expression but not acquisition of the rabbit's classically conditioned eye-blink response. Proc. Natl. Acad. Sci. 92: 5097-5101.

. 1997. Reversible inactivation of the cerebellar interpositus nucleus completely prevents acquisition of the classically conditioned eye-blink response. Learn. Mem. 3: 545-556.

Krupa, D.J., Thompson, J.K., and Thompson, R.F. 1993. Localization of a memory trace in the mammalian brain. Science 260: 989-991.

Krupa, D.J., Weng, J., and Thompson, R.F. 1996. Inactivation of brainstem motor nuclei blocks expression but not acquisition of the rabbit's classically conditioned eyeblink response. Behav. Neurosci. 110: $219-227$.

LaBar, K.S. and Disterhoft, J.F. 1998. Conditioning, awareness, and the hippocampus. Hippocampus 8: 620-626.

Lam, Y.W., Wong, A., Canli, T., and Brown, T.H. 1996. Conditioned enhancement of the early component of the rat eyeblink reflex. Neurobiol. Learn. Mem. 66: 212-220.

Lavond, D.G. and Cartford, M.C. 2000. Eyeblink conditioning circuitry: Tracing, lesion, and reversible lesion experiments. In Eyeblink classical conditioning: Animal models (eds. D.S. Woodruff-Pak and J.E. Steinmetz), Vol. 2, pp. 51-80. Kluwer Academic Publishers, Boston.

Lavond, D.G. and Steinmetz, J.E. 1989. Acquisition of classical conditioning without cerebellar cortex. Behav. Brain Res. 33: $113-164$

Lavond, D.G., Lincoln, J.S., McCormick, D.A., and Thompson, R.F. 1984a. Effect of bilateral lesions of the dentate and interpositus cerebellar nuclei on conditioning of heart-rate and nictitating membrane/eyelid responses in the rabbit. Brain Res. 305: 323-330.

Lavond, D.G., McCormick, D.A., and Thompson, R.F. 1984b. A nonrecoverable learning deficit. Physiol. Psychol. 12: 103-110

Lavond, D.G., Steinmetz, J.E., Yokaitis, M.H., and Thompson, R.F. 1987. Reacquisition of classical conditioning after removal of cerebellar cortex. Exp. Brain Res. 67: 569-593.

Lavond, D.G., Logan, C.G., Sohn, J.H., Garner, W.D., and Kanzawa, S.A. 1990. Lesions of the cerebellar interpositus nucleus abolish both nictitating membrane and eyelid EMG conditioned responses. Brain Res. 514: $238-248$

LeDoux, J. 1996. Emotional networks and motor control: A fearful view. Prog. Brain Res. 107: 437-446.

Lemieux, S.K. and Woodruff-Pak, D.S. 2000. Functional MRI studies of eyeblink classical conditioning. In Eyeblink classical conditioning: Applications in humans (eds. D.S. Woodruff-Pak and J.E. Steinmetz), Vol. 1, pp. 71-93. Kluwer Academic Publishers, Boston.

Lewis, J.L., Lo Turco, J.J., and Solomon, P.R. 1987. Lesions of the middle cerebellar peduncle disrupt acquisition and retention of the rabbit's classically conditioned nictitating membrane response. Behav. Neurosci. 101: 151-157.

Lincoln, J.S., McCormick, D.A., and Thompson, R.F. 1982. Ipsilateral cerebellar lesions prevent learning of the classically conditioned nictitating membrane/eyelid response. Brain Res. 242: 190-193.

Linden, D.J. 1994. Input-specific induction of cerebellar long-term depression does not require presynaptic alteration. Learn. Mem. 1: $121-128$.

Linden, D.J. and Connor, J.A. 1993. Cellular mechanisms of long-term depression in the cerebellum. Curr. Opin. Neurobiol. 3: 401-406.

Logan, C. 1991. Cerebellar cortical involvement in excitatory and inhibitory classical conditioning. Stanford University, Palo Alto, CA.

Logan, C.G. and Grafton, S.T. 1995. Functional anatomy of human eyeblink conditioning determined with regional cerebral glucose metabolism and positron-emission tomography. Proc. Natl. Acad. Sci. 92: $7500-7504$.

Logan, C.G., Steinmetz, J.E., Woodruff-Pak, D.S., and Thompson, R.F.
1985. Short-duration mossy fiber stimulation is effective as a CS in eyelid classical conditioning. Abstr. Soc. Neurosci. 11: 835.

Loucks, R.B. 1935. The experimental delimitation of neural structures essential for learning: The attempt to condition striped muscle response with faradization of the sigmoid gyri. J. Psychol. 1: 5-44.

Lye, R.H., O'Boyle, D.J., Ramsden, R.T., and Schady, W. 1988. Effects of a unilateral cerebellar lesion on the acquisition of eye-blink conditioning in man. J. Physiol. 403: 58P.

Mamounas, L.A., Thompson, R.F., and Madden, J. 1987. Cerebellar GABAergic processes: Evidence for critical involvement in a form of simple associative learning in the rabbit. Proc. Natl. Acad. Sci. 84: 2101-2105.

Manns, J.R., Clark, R.E., and Squire, L.R. 2000a. Awareness predicts the magnitude of single-cue trace eyeblink conditioning. Hippocampus 10: $181-186$.

2000b. Parallel acquisition of awareness and trace eyeblink classical conditioning. Learn. Mem. 7: 267-272.

Maren, S., Tocco, G., Standley, S., Baudry, M., and Thompson, R.F. 1993. Postsynaptic factors in the expression of long-term potentiation (LTP): Increased glutamate receptor binding following LTP induction in vivo. Proc. Natl. Acad. Sci. 90: 9654-9658.

Marr, D. 1969. A theory of cerebellar cortex. J. Physiol. 202: 437-470.

Matsumura, M. and Woody, C.D. 1982. Excitability changes of facial motoneurons of cats related to conditioned and unconditioned facial motor responses. In Conditioning: Representation of involved neural functions (ed. C.D. Woody), pp. 451-458. Plenum, New York.

Mauk, M.D. and Donegan, N.H. 1997. A model of Pavlovian eyelid conditioning based on the synaptic organization of the cerebellum. Learn. Mem. 4: 130-158.

Mauk, M.D., Steinmetz, J.E., and Thompson, R.F. 1986. Classical conditioning using stimulation of the inferior olive as the unconditioned stimulus. Proc. Natl. Acad. Sci. 83: 5349-5353.

McCormick, D.A. and Thompson, R.F. 1984a. Cerebellum: Essential involvement in the classically conditioned eyelid response. Science 223: 296-299.

. 1984b. Neuronal responses of the rabbit cerebellum during acquisition and performance of a classically conditioned nictitating membrane-eyelid response. J. Neurosci. 4: 2811-2822.

McCormick, D.A., Lavond, D.G., Clark, G.A., Kettner, R.E., and Thompson, R.F. 1981. The engram found? Role of the cerebellum in classical conditioning of nictitating membrane and eyelid responses. Bull. Psychon. Soc. 28: 769-775.

McCormick, D.A., Clark, G.A., Lavond, D.G., and Thompson, R.F. 1982a. Initial localization of the memory trace for a basic form of learning. Proc. Natl. Acad. Sci. 79: 2731-2735.

McCormick, D.A., Guyer, P.E., and Thompson, R.F. 1982b. Superior cerebellar peduncle lesions selectively abolish the ipsilateral classically conditioned nictitating membrane/eyelid response of the rabbit. Brain Res. 244: $347-350$.

McCormick, D.A., Lavond, D.G., and Thompson, R.F. 1982c. Concomitant classical conditioning of the rabbit nictitating membrane and eyelid responses: Correlations and implications. Physiol. Behav. 28: 769-775.

. 1983. Neuronal responses of the rabbit brainstem during performance of the classically conditioned nictitating membrane (NM)/eyelid response. Brain Res. 271: 73-88.

McCormick, D.A., Steinmetz, J.E., and Thompson, R.F. 1985. Lesions of the inferior olivary complex cause extinction of the classically conditioned eyeblink response. Brain Res. 359: 120-130.

McEchron, M.D. and Disterhoft, J.F. 1997. Sequence of single neuron changes in CA1 hippocampus of rabbits during acquisition of trace eyeblink conditioned responses. J. Neurophysiol. 78: 1030-1044.

McGaugh, J.L. 1989. Involvement of hormonal and neuromodulatory systems in the regulation of memory storage. Annu. Rev. Neurosci. 12: $255-287$.

McGlinchey-Berroth, R. 2000. Eyeblink classical conditioning in amnesia. In Eyeblink classical conditioning: Applications in humans (eds. D.S. Woodruff-Pak and J.E. Steinmetz), Vol. 1, pp. 205-227. Kluwer Academic Publishers, Boston.

McGlinchey-Berroth, R., Cermak, L.S., Carrillo, M.C., Armfield, S., Gabrieli, J.D., and Disterhoft, J.F. 1995. Impaired delay eyeblink conditioning in amnesic Korsakoff's patients and recovered alcoholics. Alcohol Clin. Exp. Res. 19: 1127-1132.

McGlinchey-Berroth, R., Carrillo, M.C., Gabrieli, J.D., Brawn, C.M., and Disterhoft, J.F. 1997. Impaired trace eyeblink conditioning in bilateral, medial-temporal lobe amnesia. Behav. Neurosci. 111: $873-882$.

McIntosh, A.R. and Schreurs, B.G. 2000. Functional networks underlying human eyeblink conditioning. In Eyeblink classical conditioning: Applications in humans (eds. D.S. Woodruff-Pak and J.E. Steinmetz), Vol. 1, pp. 51-70. Kluwer Academic Publishers, Boston.

Medina, J.F., Nores, W.L., and Mauk, M.D. 2002. Inhibition of climbing 
fibres is a signal for the extinction of conditioned eyelid responses. Nature 416: $330-333$.

Mihailoff, G.A. 1993. Cerebellar nuclear projections from the basilar pontine nuclei and nucleus reticularis tegmenti pontis as demonstrated with PHA-L tracing in the rat. J. Comp. Neurol. 330: $130-146$.

Mihailoff, G.A., Burne, R.A., Azizi, S.A., Norell, G., and Woodward, D.J. 1981. The pontocerebellar system in the rat: An HRP study. II. Hemispheral components. J. Comp. Neurol. 197: 559-577.

Mintz, M. and Wang-Ninio, Y. 2001. Two-stage theory of conditioning: Involvement of the cerebellum and the amygdala. Brain Res. 897: $150-156$.

Mintz, M., Lavond, D.G., Zhang, A.A., Yun, Y., and Thompson, R.F. 1994. Unilateral inferior olive NMDA lesion leads to unilateral deficit in acquisition and retention of eyelid classical conditioning. Behav. Neural Biol. 61: 218-224.

Miyata, M., Kim, H.T., Hashimoto, K., Lee, T.K., Cho, S.Y., Jiang, H., Wu, Y., Jun, K., Wu, D., Kano, M., et al. 2001. Deficient long-term synaptic depression in the rostral cerebellum correlated with impaired motor learning in phospholipase C $\beta 4$ mutant mice. Eur. J. Neurosci. 13: 1945-1954.

Mojtahedian, S., Kanzawa, S., Lavond, D., and Thompson, R. 2001. Effects of bilateral lesions of the cerebellar cortex on eyeblink conditioning. Abstr. Soc. Neurosci. 27: 75.6

Molchan, S.E., Sunderland, T., McIntosh, A.R., Herscovitch, P., and Schreurs, B.G. 1994. A functional anatomical study of associative learning in humans. Proc. Natl. Acad. Sci. 91: 8122-8126.

Montarolo, P.G., Palestini, M., and Strata, P. 1982. The inhibitory effect of the olivocerebellar input on the cerebellar Purkinje cells in the rat. J. Physiol. 332: 187-202.

Mowrer, O.H. 1947. On the dual nature of learning-A reinterpretation of "conditioning" and "problem solving". Harv. Educ. Rev. 17: 102-148.

Moyer Jr., J.R., Deyo, R.A., and Disterhoft, J.F. 1990. Hippocampectomy disrupts trace eye-blink conditioning in rabbits. Behav. Neurosci. 104: $243-252$.

Moyer Jr., J.R., Thompson, L.T., and Disterhoft, J.F. 1996. Trace eyeblink conditioning increases CA1 excitability in a transient and learning-specific manner. I. Neurosci. 16: 5536-5546.

Myers, C.E., DeLuca, J., Schultheis, M.T., Schnirman, G.M., Ermita, B.R., Diamond, B., Warren, S.G., and Gluck, M.A. 2001. Impaired delay eyeblink classical conditioning in individuals with anterograde amnesia resulting from anterior communicating artery aneurysm rupture. Behav. Neurosci. 115: 560-570.

Nelson, B. and Mugnaini, E. 1989. GABAergic innervation of the inferior olivary complex and experimental evidence for its origin. In The olivocerebellar system in motor control (ed. P. Strata), pp. 86-107. Springer-Verlag, New York.

Neufeld, M. and Mintz, M. 2001. Involvement of the amygdala in classical conditioning of eyeblink response in the rat. Brain Res. 889: $112-117$.

Nordholm, A.F., Thompson, J.K., Dersarkissian, C., and Thompson, R.F. 1993. Lidocaine infusion in a critical region of cerebellum completely prevents learning of the conditioned eyeblink response. Behav. Neurosci. 107: 882-886.

Nores, W.L., Medina, J.F., Steele, P.M., and Mauk, M.M. 2000. Relative contributions of the cerebellar cortex and cerebellar nucleus to eyelid conditioning. In Eyeblink classical conditioning: Animal models (eds. D.S. Woodruff-Pak and J.E. Steinmetz), Vol. 2, pp. 205-228. Kluwer Academic Publishers, Boston.

Olds, J.L., Anderson, M.L., McPhie, D.L., Staten, L.D., and Alkon, D.L. 1989. Imaging of memory-specific changes in the distribution of protein kinase C in the hippocampus. Science 245: 866-869.

Pellegrini, J.J. and Evinger, C. 1997. Role of cerebellum in adaptive modification of reflex blinks. Learn. Mem. 4: 77-87.

Perrett, S.P. 1998. Temporal discrimination in the cerebellar cortex during conditioned eyelid responses [published erratum appears in Exp. Brain Res. 1998 Aug;121(3):359]. Exp. Brain Res. 121: 115-124.

Perrett, S.P. and Mauk, M.D. 1995. Extinction of conditioned eyelid responses requires the anterior lobe of cerebellar cortex. J. Neurosci. 15: 2074-2080.

Perrett, S.P., Ruiz, B.P., and Mauk, M.D. 1993. Cerebellar cortex lesions disrupt learning-dependent timing of conditioned eyelid responses. J. Neurosci. 13: $1708-1718$.

Polenchar, B.E., Patterson, M.M., Lavond, D.G., and Thompson, R.F. 1985. Cerebellar lesions abolish an avoidance response in rabbit. Behav. Neural Biol. 44: 221-227.

Port, R.L. and Patterson, M.M. 1984. Fimbrial lesions and sensory preconditioning. Behav. Neurosci. 98: 584-589.

Port, R.L., Romano, A.G., Steinmetz, J.E., Mikhail, A.A., and Patterson, M.M. 1986. Retention and acquisition of classical trace conditioned responses by rabbits with hippocampal lesions. Behav. Neurosci.
100: $745-752$.

Port, R.L., Beggs, A.L., and Patterson, M.M. 1987. Hippocampal substrate of sensory associations. Physiol. Behav. 39: 643-647.

Powell, D.A., Kipkin, M., and Milligan, W.L. 1974. Concomitant changes in classically conditioned heart rate and corneoretinal potential discrimination in the rabbit (Oryctolagus cuniculus). Learning Motiv. 5: 532-547.

Powell, D.A., McLaughlin, J., and Chachich, M. 2000. Classical conditioning of autonomic somatomotor responses and their central nervous system substrates. In Eyeblink classical conditioning: Animal models (eds. D.S. Woodruff-Pak and J.E. Steinmetz), Vol. 2, pp. 257-286. Kluwer Academic Publishers, Boston.

Powell, D.A., Skaggs, H., Churchwell, J., and McLaughlin, J. 2001. Posttraining lesions of the medial prefrontal cortex impair performance of Pavlovian eyeblink conditioning but have no effect on concomitant heart rate changes in rabbits (Oryctolagus cuniculus). Behav. Neurosci. 115: 1029-1038.

Qiao, X., Chen, L., Gao, H., Bao, S., Hefti, F., Thompson, R.F., and Knusel, B. 1998. Cerebellar brain-derived neurotrophic factor-TrkB defect associated with impairment of eyeblink conditioning in Stargazer mutant mice. J. Neurosci. 18: 6990-6999.

Racine, R.J., Wilson, D.A., Gingell, R., and Sunderland, D. 1986. Long-term potentiation in the interpositus and vestibular nuclei in the rat. Exp. Brain Res. 63: 158-162.

Ramirez, O.A., Nordholm, A.F., Gellerman, D., Thompson, J.K., and Thompson, R.F. 1997. The conditioned eyeblink response: A role for the GABA-B receptor? Pharmacol. Biochem. Behav. 58: 127-132.

Ramnani, N., Toni, I., Josephs, O., Ashburner, J., and Passingham, R.F. 1999. Learning-related plasticity during human classical eyeblink conditioning: Whole-brain, event related fMRI. Neuroimage. 9: S980.

Raymond, J.L., Lisberger, S.G., and Mauk, M.D. 1996. The cerebellum: A neuronal learning machine? Science 272: 1126-1131.

Rescorla, R.A. and Solomon, R.L. 1967. Two-process learning theory: Relationships between Pavlovian conditioning and instrumental learning. Psychol. Rev. 74: 151-182.

Rescorla, R.A. and Wagner, A.R. 1972. A theory of Pavlovian conditioning: Variations in the effectiveness of reinforcement and nonreinforcement. In Classical conditioning II: Current theory and research (eds. A.H. Black and W.F. Prokasy), pp. 64-99. Appleton-Century-Crofts, New York.

Richards, W.G., Ricciardi, T.N., and Moore, J.W. 1991. Activity of spinal trigeminal pars oralis and adjacent reticular formation units during differential conditioning of the rabbit nictitating membrane response. Behav. Brain Res. 44: 195-204.

Richardson, R.T. and Thompson, R.F. 1985. Unit activity recorded from the globus pallidus during classical conditioning of the rabbit nictitating membrane response. Brain Res. 332: 219-229.

Rogers, R.F., Britton, G.B., and Steinmetz, J.E. 2001. Learning-related interpositus activity is conserved across species as studied during eyeblink conditioning in the rat. Brain Res. 905: 171-177.

Rosenfield, M.E. and Moore, J.W. 1995. Connections to cerebellar cortex (Larsell's HVI) in the rabbit: A WGA-HRP study with implications for classical eyeblink conditioning. Behav. Neurosci. 109: 1106-1118.

Rosenfield, M.E., Dovydaitis, A., and Moore, J.W. 1985. Brachium conjuntivum and rubrobulbar tract: Brain stem projections of red nucleus essential for the conditioned nictitating membrane response. Physiol. Behav. 34: 751-759.

Ross, R.T., Orr, W.B., Holland, P.C., and Berger, T.W. 1984. Hippocampectomy disrupts acquisition and retention of learned conditional responding. Behav. Neurosci. 98: 211-225.

Salvatierra, A.T. and Berry, S.D. 1989. Scopolamine disruption of septo-hippocampal activity and classical conditioning. Behav. Neurosci. 103: 715-721.

Sanchez, M., Sillitoe, R.V., Attwell, P.J., Ivarsson, M., Rahman, S., Yeo, C.H., and Hawkes, R. 2002. Compartmentation of the rabbit cerebellar cortex. J. Comp. Neurol. 444: 159-173.

Sanchez-Andres, J.V. and Alkon, D.L. 1991. Voltage-clamp analysis of the effects of classical conditioning on the hippocampus. $J$. Neurophysiol. 65: 796-807.

Savio, T. and Tempia, F. 1985. On the Purkinje cell activity increase induced by suppression of inferior olive activity. Exp. Brain Res. 57: 456-463.

Schmahmann, J.D. and Pandya, D.N. 1989. Anatomical investigation of projections to the basis pontis from posterior parietal association cortices in rhesus monkey. J. Comp. Neurol. 289: 53-73.

. 1991. Projections to the basis pontis from the superior temporal sulcus and superior temporal region in the rhesus monkey. J. Comp. Neurol. 308: 224-248.

. 1993. Prelunate, occipitotemporal, and parahippocampal projections to the basis pontis in rhesus monkey. J. Comp. Neurol. 337: $94-112$.

Schmajuk, N.A. and DiCarlo, J.J. 1992. Stimulus configuration, classical

\section{Learning \& Memory


conditioning, and hippocampal function. Psychol. Rev. 99: 268-305.

Schmaltz, L.W. and Theios, J. 1972. Acquisition and extinction of a classically conditioned response in hippocampectomized rabbits (Oryctolagus cuniculus). J. Comp. Physiol. Psychol. 79: 328-333.

Schneiderman, N., Fuentes, I., and Gormezano, I. 1962. Acquisition and extinction of the classically conditioned eyelid response in the albino rabbit. Science 136: 650-652.

Schreurs, B.G. 2000. Cellular correlates of eyeblink classical conditioning. In Eyeblink classical conditioning: Animal models (eds. D.S. Woodruff-Pak and J.E. Steinmetz), Vol. 2, pp. 179-204. Kluwer Academic Publishers, Boston.

Schreurs, B.G., Oh, M.M., and Alkon, D.L. 1996. Pairing-specific long-term depression of Purkinje cell excitatory postsynaptic potentials results from a classical conditioning procedure in the rabbit cerebellar slice. J. Neurophysiol. 75: 1051-1060.

Schreurs, B.G., McIntosh, A.R., Bahro, M., Herscovitch, P., Sunderland, T., and Molchan, S.E. 1997. Lateralization and behavioral correlation of changes in regional cerebral blood flow with classical conditioning of the human eyeblink response. J. Neurophysiol. 77: $2153-2163$.

Schugens, M.M., Topka, H.R., and Daum, I. 2000. Eyeblink conditioning in neurological patients with motor impairments. In Eyeblink classical conditioning: Applications in humans (eds. D.S. Woodruff-Pak and J.E. Steinmetz), Vol. 1, pp. 191-204. Kluwer Academic Publishers, Boston.

Scoville, W.B. and Milner, B. 1957. Loss of recent memory after bilateral hippocampal lesions. J. Neurol. Neurosurg. Psychiatr. 20: 11-21.

Seager, M.A., Johnson, L.D., Chabot, E.S., Asaka, Y., and Berry, S.D. 2002. Oscillatory brain states and learning: Impact of hippocampal $\theta$-contingent training. Proc. Natl. Acad. Sci. 99: 1616-1620.

Sears, L.L. and Steinmetz, J.E. 1990. Acquisition of classically conditioned-related activity in the hippocampus is affected by lesions of the cerebellar interpositus nucleus. Behav. Neurosci. 104: $681-692$.

. 1991. Dorsal accessory inferior olive activity diminishes during acquisition of the rabbit classically conditioned eyelid response. Brain Res. 545: 114-122.

Sears, L.L., Logue, S.F., and Steinmetz, J.E. 1996. Involvement of the ventrolateral thalamic nucleus in rabbit classical eyeblink conditioning. Behav. Brain Res. 74: 105-117.

Servatius, R.J. and Shors, T.J. 1996. Early acquisition, but not retention, of the classically conditioned eyeblink response is N-methyl-D-aspartate (NMDA) receptor dependent. Behav. Neurosci. 110: $1040-1048$.

Shambes, G.M., Gibson, J.M., and Welker, W. 1978. Fractured somatotopy in granule cell tactile areas of rat cerebellar hemispheres revealed by micromapping. Brain Behav. Evol. 15: 94-140.

Shibuki, K., Gomi, H., Chen, L., Bao, S., Kim, J.J., Wakatsuki, H., Fujisaki, T., Fujimoto, K., Katoh, A., Ikeda, T., et al. 1996. Deficient cerebellar long-term depression, impaired eyeblink conditioning, and normal motor coordination in GFAP mutant mice. Neuron 16: $587-599$.

Shinkman, P.G., Swain, R.A., and Thompson, R.F. 1996. Classical conditioning with electrical stimulation of cerebellum as both conditioned and unconditioned stimulus. Behav. Neurosci. 110: 914-921.

Shinoda, Y., Sugiuchi, Y., Futami, T., and Izawa, R. 1992. Axon collaterals of mossy fibers from the pontine nucleus in the cerebellar dentate nucleus. J. Neurophysiol. 67: 547-560.

Shors, T.J. 1998. Stress and sex effects on associative learning: For better or for worse. Neuroscientist 4: 353-364.

. 2001. Acute stress rapidly and persistently enhances memory formation in the male rat. Neurobiol. Learn. Mem. 75: 10-29.

Shors, T.J. and Matzel, L.D. 1997. Long-term potentiation: What's learning got to do with it? Behav. Brain Sci. 20: 597-614; discussion 614-655.

Shors, T.J., Lewczyk, C., Pacynski, M., Mathew, P.R., and Pickett, J. 1998. Stages of estrous mediate the stress-induced impairment of associative learning in the female rat. Neuroreport 9: 419-423.

Shors, T.J., Beylin, A.V., Wood, G.E., and Gould, E. 2000. The modulation of Pavlovian memory. Behav. Brain Res. 110: 39-52.

Shors, T.J., Miesegaes, G., Beylin, A., Zhao, M., Rydel, T., and Gould, E. 2001. Neurogenesis in the adult is involved in the formation of trace memories. Nature 410: $372-376$.

Skelton, R.W. 1988. Bilateral cerebellar lesions disrupt conditioned eyelid responses in unrestrained rats. Behav. Neurosci. 102: 586-590.

Smith, S.L. and Otis, T.S. 2002. NO/cGMP pathway causes persistent changes in Purkinje neuron spontaneous activity. Abstr. Soc. Neurosci. 28: 146.11 .

Solomon, P.R. and Groccia-Ellison, M.E. 1996. Classic conditioning in aged rabbits: Delay, trace, and long-delay conditioning. Behav. Neurosci. 110: 427-435.
Solomon, P.R. and Moore, J.W. 1975. Latent inhibition and stimulus generalization of the classically conditioned nictitating membrane response in rabbits (Oryctolagus cuniculus) following dorsal hippocampal ablation. J. Comp. Physiol. Psychol. 89: 1192-1203.

Solomon, P.R., Solomon, S.D., Schaaf, E.V., and Perry, H.E. 1983. Altered activity in the hippocampus is more detrimental to classical conditioning than removing the structure. Science 220: 329-331.

Solomon, P.R., Vander Schaaf, E.R., Thompson, R.F., and Weisz, D.J. 1986. Hippocampus and trace conditioning of the rabbit's classically conditioned nictitating membrane response. Behav. Neurosci. 100: $729-744$.

Solomon, P.R., Stowe, G.T., and Pendlbeury, W.W. 1989. Disrupted eyelid conditioning in a patient with damage to cerebellar afferents. Behav. Neurosci. 103: 898-902.

Solomon, P.R., Groccia-Ellison, M.E., Flynn, D., Mirak, J., Edwards, K.R., Dunehew, A., and Stanton, M.E. 1993. Disruption of human eyeblink conditioning after central cholinergic blockade with scopolamine. Behav. Neurosci. 107: 271-279.

Solomon, P.R., Wood, M.S., Groccia-Ellison, M.E., Yang, B.Y., Fanelli, R.J., and Mervis, R.F. 1995. Nimodipine facilitates retention of the classically conditioned nictitating membrane response in aged rabbits over long retention intervals. Neurobiol. Aging 16: 791-796.

Sommer, M., Grafman, J., Litvan, I., and Hallett, M. 2001. Impairment of eyeblink classical conditioning in progressive supranuclear palsy. Mov. Disord. 16: 240-251.

Squire, L.R. 1992. Memory and the hippocampus: A synthesis from findings with rats, monkeys, and humans. Psychol. Rev. 99: 195-231.

Stanton, M.E. and Freeman Jr., J.H. 2000. Developmental studies of eyeblink conditioning in the rat. In Eyeblink classical conditioning: Animal models (eds. D.S. Woodruff-Pak and J.E. Steinmetz), Vol. 2, pp. 105-134. Kluwer Academic Publishers, Boston.

Staubli, U. and Lynch, G. 1987. Stable hippocampal long-term potentiation elicited by "theta" pattern stimulation. Brain Res. 435: $227-234$

Steinmetz, J.E. 1990a. Classical nictitating membrane conditioning in rabbits with varying interstimulus intervals and direct activation of cerebellar mossy fibers as the CS. Behav. Brain Res. 38: 97-108. - 1990b. Neural activity in the cerebellar interpositus nucleus during classical NM conditioning with a pontine stimulation CS. Psychol. Sci. 1: 378-382.

. 1998. The localization of a simple type of learning and memory. Curr. Dir. Psychol. Sci. 7: 72-77.

. 2000a. Brain substrates of classical eyeblink conditioning: A highly localized but also distributed system. Behav. Brain Res. 110: $13-24$.

. 2000b. Electrophysiological recording and brain stimulation studies of eyeblink conditioning. In Eyeblink classical conditioning: Animal models (eds. D.S. Woodruff-Pak and J.E. Steinmetz), Vol. 2, pp. 81-103. Kluwer Academic Publishers, Boston.

Steinmetz, J.E. and Sengelaub, D.R. 1992. Possible conditioned stimulus pathway for classical eyelid conditioning in rabbits. I. Anatomical evidence for direct projections from the pontine nuclei to the cerebellar interpositus nucleus. Behav. Neural Biol. 57: 103-115.

Steinmetz, J.E. and Woodruff-Pak, D.S. 2000. Animal models in eyeblink classical conditioning. In Eyeblink classical conditioning: Animal models (eds. D.S. Woodruff-Pak and J.E. Steinmetz), Vol. 2, pp. 81-103. Kluwer Academic Publishers, Boston.

Steinmetz, J.E., Rosen, D.J., Chapman, P.F., Lavond, D.G., and Thompson, R.F. 1986. Classical conditioning of the rabbit eyelid response with a mossy-fiber stimulation CS: I. Pontine nuclei and middle cerebellar peduncle stimulation. Behav. Neurosci. 100: $878-887$

Steinmetz, J.E., Logan, C.G., Rosen, D.J., Thompson, J.K., Lavond, D.G., and Thompson, R.F. 1987. Initial localization of the acoustic conditioned stimulus projection system to the cerebellum essential for classical eyelid conditioning. Proc. Natl. Acad. Sci. 84: 3531-3535.

Steinmetz, J.E., Lavond, D.G., and Thompson, R.F. 1989. Classical conditioning in rabbits using pontine nucleus stimulation as a conditioned stimulus and inferior olive stimulation as an unconditioned stimulus. Synapse 3: 225-233.

Steinmetz, J.E., Sears, L.L., Gabriel, M., Kubota, Y., Poremba, A., and Kang, E. 1991. Cerebellar interpositus nucleus lesions disrupt classical nictitating membrane conditioning but not discriminative avoidance learning in rabbits. Behav. Brain Res. 45: 71-80.

Steinmetz, J.E., Lavond, D.G., Ivkovich, D., Logan, C.G., and Thompson, R.F. 1992a. Disruption of classical eyelid conditioning after cerebellar lesions: Damage to a memory trace system or a simple performance deficit? J. Neurosci. 12: 4403-4426.

Steinmetz, J.E., Logue, S.F., and Steinmetz, S.S. 1992b. Rabbit classically conditioned eyelid responses do not reappear after interpositus nucleus lesion and extensive postlesion training. Behav. Brain Res. 51: 103-114. 
Straube, K.T., Deyo, R.A., Moyer Jr., J.R., and Disterhoft, J.F. 1990 Dietary nimodipine improves associative learning in aging rabbits. Neurobiol. Aging 11: 659-661.

Sugihara, I., Wu, H.S., and Shinoda, Y. 2001. The entire trajectories of single olivocerebellar axons in the cerebellar cortex and their contribution to cerebellar compartmentalization. J. Neurosci. 21: $7715-7723$.

Svensson, P. and Ivarsson, M. 1999. Short-lasting conditioned stimulus applied to the middle cerebellar peduncle elicits delayed conditioned eye blink responses in the decerebrate ferret. Eur. J. Neurosci. 11: 4333-4340.

Swain, R.A., Shinkman, P.G., Nordholm, A.F., and Thompson, R.F. 1992. Cerebellar stimulation as an unconditioned stimulus in classical conditioning. Behav. Neurosci. 106: 739-750.

Swain, R.A., Shinkman, P.G., Thompson, J.K., Grethe, J.S., and Thompson, R.F. 1999. Essential neuronal pathways for reflex and conditioned response initiation in an intracerebellar stimulation paradigm and the impact of unconditioned stimulus pre-exposure on learning rate. Neurobiol. Learn. Mem. 71: 167-193.

Swanson, L.W., Teyler, T.J., and Thompson, R.F. 1982. Mechanisms and functional implications of hippocampal LTP. Neuroscience Research Program. Vol. 20. MIT Press, Boston.

Tamai, Y., Iwamoto, M., and Tsujimoto, T. 1986. Pathway of the blink reflex in the brainstem of the cat: Interneurons between the trigeminal nuclei and the facial nucleus. Brain Res. 380: 19-25.

Taylor, J.A. 1951. The relationship of anxiety to the conditioned eyelid response. J. Exp. Psychol. 41: 81-92.

Thach, W.T., Goodkin, H.P., and Keating, J.G. 1992. The cerebellum and the adaptive coordination of movement. Annu. Rev. Neurosci. 15: $403-442$.

Thompson, J.K., Spangler, W.J., and Thompson, R.F. 1991. Differential projections of pontine nuclei to interpositus nucleus and lobule HVI. Abstr. Soc. Neurosci. 17: 871.

Thompson, J.K., Krupa, D.J., Weng, J., and Thompson, R.F. 1993. Inactivation of motor nuclei blocks expression but not acquisition of rabbit's classically conditioned eyeblink response. Abstr. Soc. Neurosci. 19: 999.

Thompson, L.T. and Disterhoft, J.F. 1997. N-methyl-D-aspartate receptors in associative eyeblink conditioning: Both MK-801 and phencyclidine produce task- and dose-dependent impairments. $J$. Pharmacol. Exp. Ther. 281: 928-940.

Thompson, L.T., Moskal, J.R., and Disterhoft, J.F. 1992. Hippocampus-dependent learning facilitated by a monoclonal antibody or D-cycloserine. Nature 359: 638-641.

Thompson, L.T., Moyer Jr., J.R., and Disterhoft, J.F. 1996. Trace eyeblink conditioning in rabbits demonstrates heterogeneity of learning ability both between and within age groups. Neurobiol. Aging 17: 619-629.

Thompson, R.F. 1983. Neuronal substrates of simple associative learning: Classical conditioning. Trends Neurosci. 6: 270-275. . 1986. The neurobiology of learning and memory. Science 233: 941-947.

. 1989. Role of the inferior olive in classical conditioning. Exp. Brain Res. 17: 347-362.

. 1990. Neural mechanisms of classical conditioning in mammals. Philos. Trans. R. Soc. Lond. B. Biol. Sci. 329: 161-170.

. 1997. Classical conditioning has much to do with LTP. Behav. Brain Sci. 20: 632-633.

Thompson, R.F. and Kim, J.J. 1996. Memory systems in the brain and localization of a memory. Proc. Natl. Acad. Sci. 93: 13438-13444.

Thompson, R.F. and Krupa, D.J. 1994. Organization of memory traces in the mammalian brain. Annu. Rev. Neurosci. 17: 519-549.

Thompson, R.F., Clark, G.A., Donegan, N.H., Lavond, D.G., Lincoln, J.S., Madden, J.I., Mamounas, L.A., Mauk, M.D., McCormick, D.A., and Thompson, J.K. 1984. Neuronal substrates of learning and memory: A "multiple trace" view. In Neurobiology of learning and memory (eds. J.L. McGaugh, G. Lynch, and N.M. Weinberger), pp. 137-164. Guilford Press, New York.

Thompson, R.F., Bao, S., Chen, L., Cipriano, B.D., Grethe, J.S., Kim, J.J., Thompson, J.K., Tracy, J.A., Weninger, M.S., and Krupa, D.J. 1997. Associative learning. Int. Rev. Neurobiol. 41: 151-189.

Thompson, R.F., Thompson, J.K., Kim, J.J., Krupa, D.J., and Shinkman, P.G. 1998. The nature of reinforcement in cerebellar learning Neurobiol. Learn. Mem. 70: 150-176.

Thompson, R.F., Swain, R., Clark, R., and Shinkman, P. 2000. Intracerebellar conditioning-Brogden and Gantt revisited. Behav. Brain Res. 110: 3-11.

Thompson, R.F., Christian, K.M., and Krupa, D.J. 2001. Functional dissociation of the cerebellar cortex and interpositus nucleus during eyeblink classical conditioning. Abstr. Soc. Neurosci. 27: 640.11.

Timmann, D., Kolb, F.P., Baier, C., Rijntjes, M., Muller, S.P., Diener, H.C., and Weiller, C. 1996. Cerebellar activation during classical conditioning of the human flexion reflex: A PET study. Neuroreport 7: 2056-2060.

Tocco, G., Shors, T.J., Baudry, M., and Thompson, R.F. 1991. Selective increase of AMPA binding to the AMPA/quisqualate receptor in the hippocampus in response to acute stress. Brain Res. 559: 168-171.

Tocco, G., Annala, A.J., Baudry, M., and Thompson, R.F. 1992a. Learning of a hippocampal-dependent conditioning task changes the binding properties of AMPA receptors in rabbit hippocampus. Behav. Neural Biol. 58: 222-231.

Tocco, G., Maren, S., Shors, T.J., Baudry, M., and Thompson, R.F. 1992b. Long-term potentiation is associated with increased [3H]AMPA binding in rat hippocampus. Brain Res. 573: 228-234.

Topka, H., Valls-Sole, J., Massaquoi, S.G., and Hallett, M. 1993. Deficit in classical conditioning in patients with cerebellar degeneration. Brain 116: 961-969.

Tracy, J. and Thompson, R.F. 1993. Single unit mapping of the cerebellar deep nuclei in well-trained rabbits following NM conditioning. Abstr. Soc. Neurosci. 19: 998.

Tracy, J.A. 1995. Brain and behavior correlates in classical conditioning of the rabbit eyeblink response. University of Southern California, Los Angeles, CA.

Tracy, J.A., Thompson, J.K., Krupa, D.J., and Thompson, R.F. 1998. Evidence of plasticity in the pontocerebellar conditioned stimulus pathway during classical conditioning of the eyeblink response in the rabbit. Behav. Neurosci. 112: 267-285.

Tracy, J.A., Britton, G.B., and Steinmetz, J.E. 2001. Comparison of single unit responses to tone, light, and compound conditioned stimuli during rabbit classical eyeblink conditioning. Neurobiol. Learn. Mem. 76: $253-267$.

Van der Zee, E.A., Luiten, P.G., and Disterhoft, J.F. 1997. Learning-induced alterations in hippocampal PKC-immunoreactivity: A review and hypothesis of its functional significance. Prog. Neuropsychopharmacol. Biol. Psychiatry. 21: $531-572$.

Voneida, T.J. 1999. The effect of rubrospinal tractotomy on a conditioned limb response in the cat. Behav. Brain Res. 105: $151-162$.

. 2000. The effect of brachium conjunctivum transection on a conditioned limb response in the cat. Behav. Brain Res. 109: $167-175$

Voneida, T.J., Christie, D., Bogdanski, R., and Chopko, B. 1990. Changes in instrumentally and classically conditioned limb-flexion responses following inferior olivary lesions and olivocerebellar tractotomy in the cat. J. Neurosci. 10: 3583-3593.

Voogd, J. and Glickstein, M. 1998. The anatomy of the cerebellum. Trends Neurosci. 21: 370-375.

Voronin, L.L. and Ioffe, S.V. 1974. Changes in unit postsynaptic responses at sensorimotor cortex with conditioning in rabbits. Acto Neurobiol. Exp. 34: 504-513.

Wagner, A.R. and Brandon, S.E. 1989. Evolution of a structured connectionist model of Pavlovian conditioning (Aesop). In Contemporary learning theories: Pavlovian conditioning and the status of traditional learning theory (eds. S.B. Klein and R.R. Mowrer), pp. 149-190. Erlbaum, Hillsdale, NJ.

Wagner, A.R. and Donegan, N.H. 1989. Some relationships between a computational model (SOP) and a neural circuit for Pavlovian (rabbit eyeblink) conditioning. In The psychology of learning and motivation (eds. R.D. Hawkins and G.H. Bower), Vol. 22, pp. 157-203. Academic Press, San Diego, CA.

Wagner, A.R., Thomas, E., and Norton, T. 1967. Conditioning with electrical stimulation of motor cortex: Evidence of a possible source of motivation. J. Comp. Physiol. Psychol. 64: 191-199.

Wang, S.S., Denk, W., and Hausser, M. 2000a. Coincidence detection in single dendritic spines mediated by calcium release. Nat. Neurosci. 3: $1266-1273$

Wang, S.S., Khiroug, L., and Augustine, G.J. 2000b. Quantification of spread of cerebellar long-term depression with chemical two-photon uncaging of glutamate. Proc. Natl. Acad. Sci. 97: 8635-8640.

Weible, A.P., McEchron, M.D., and Disterhoft, J.F. 2000. Cortical involvement in acquisition and extinction of trace eyeblink conditioning. Behav. Neurosci. 114: 1058-1067.

Weinberger, N.M. 1982. Effects of conditioned arousal on the auditory system. In The neural basis of behavior (ed. A.L. Beckman), Spectrum, Jamaica, NY.

Weiskrantz, L. and Warrington, E.K. 1979. Conditioning in amnesic patients. Neuropsychologia 17: 187-194.

Weisz, D.J. and LoTurco, J.J. 1988. Reflex facilitation of the nictitating membrane response remains after cerebellar lesions. Behav. Neurosci. 102: 203-209.

Weisz, D.J., Clark, G.A., and Thompson, R.F. 1984. Increased responsivity of dentate granule cells during nictitating membrane response conditioning in rabbit. Behav. Brain Res. 12: 145-154. 
Weisz, D.J., Harden, D.G., and Xiang, Z. 1992. Effects of amygdala lesions on reflex facilitation and conditioned response acquisition during nictitating membrane response conditioning in rabbit. Behav. Neurosci. 106: 262-273.

Welsh, J.P. and Harvey, J.A. 1989. Cerebellar lesions and the nictitating membrane reflex: Performance deficits of the conditioned and unconditioned response. J. Neurosci. 9: 299-311.

Welsh, J.P. and Harvey, J.A. 1991. Pavlovian conditioning in the rabbit during inactivation of the interpositus nucleus. J. Physiol.

444: $459-480$.

Welsh, J.P. and Harvey, J.A. 1998. Acute inactivation of the inferior olive blocks associative learning. Eur. J. Neurosci. 10: 3321-3332.

Weninger, M.S. and Thompson, R.F. 1997. Neural response in the deep nuclei of the cerebellum in rabbits conditioned to both a light and tone CS. Abstr. Soc. Neurosci. 23: 779.

Whalen, P.J. and Kapp, B.S. 1991. Contributions of the amygdaloid central nucleus to the modulation of the nictitating membrane reflex in the rabbit. Behav. Neurosci. 105: 141-153.

White, I.M., Miller, D.P., White, W., Dike, G.L., Rebec, G.V., and Steinmetz, J.E. 1994. Neuronal activity in rabbit neostriatum during classical eyelid conditioning. Exp. Brain Res. 99: 179-190.

Wikgren, J. and Korhonen, T. 2001. Interpositus nucleus inactivation reduces unconditioned response amplitude after paired but not explicitly unpaired treatment in rabbit eyeblink conditioning. Neurosci. Lett. 308: 181-184.

Wikgren, J., Ruusuvirta, T., and Korhonen, T. 2002. Reflex facilitation during eyeblink conditioning and subsequent interpositus nucleus inactivation in the rabbit (Oryctolagus cuniculus). Behav. Neurosci. 116: $1052-1058$

Wood, G.E. and Shors, T.J. 1998. Stress facilitates classical conditioning in males, but impairs classical conditioning in females through activational effects of ovarian hormones. Proc. Natl. Acad. Sci. 95: 4066-4071.

Woodruff-Pak, D.S. 1997. Evidence for the role of cerebellum in classical conditioning in humans. In The cerebellum and cognition (ed. J.D. Schmahmann), pp. 341-366. Academic Press, San Diego, CA. . 2000. Human eyeblink conditioning in normal aging and Alzheimer's disease. In Eyeblink classical conditioning: Applications in humans (eds. D.S. Woodruff-Pak and J.E. Steinmetz), Vol. 1, pp. 163-189. Kluwer Academic Publishers, Boston.

Woodruff-Pak, D.S. and Ewers, M. 2000. Cognitive-enhancing drugs and eyeblink classical conditioning. In Eyeblink classical conditioning: Animal models (eds. D.S. Woodruff-Pak and J.E. Steinmetz), Vol. 2 pp. 335-356. Kluwer Academic Publishers, Boston.

Woodruff-Pak, D.S. and Papka, M. 1996. Alzheimer's disease and eyeblink conditioning: $750 \mathrm{~ms}$ trace vs. $400 \mathrm{~ms}$ delay paradigm. Neurobiol. Aging 17: 397-404.

Woodruff-Pak, D.S. and Steinmetz, J.E. 2000. Past, present, and future of human eyeblink classical conditioning. In Eyeblink classical conditioning: Applications in humans (eds. D.S. Woodruff-Pak and J.E. Steinmetz), Vol. 1, pp. 1-17. Kluwer Academic Publishers, Boston.

Woodruff-Pak, D.S., Lavond, D.G., and Thompson, R.F. 1985. Trace conditioning: Abolished by cerebellar nuclear lesions but not lateral cerebellar cortex aspirations. Brain Res. 348: 249-260.

Woodruff-Pak, D.S., Lavond, D.G., Logan, C.G., Steinmetz, J.E., and
Thompson, R.F. 1993. Cerebellar cortical lesions and reacquisition in classical conditioning of the nictitating membrane response in rabbits. Brain Res. 608: 67-77.

Woodruff-Pak, D.S., Chi, J., Li, Y.T., Pak, M.H., and Fanelli, R.J. 1997. Nimodipine ameliorates impaired eyeblink classical conditioning in older rabbits in the long-delay paradigm. Neurobiol. Aging 18: 641-649.

Woody, C., Yarowsky, P., Owens, J., Black-Cleworth, P., and Crow, T. 1974. Effect of lesions of cortical motor areas on acquisition of conditioned eye blink in the cat. J. Neurophysiol. 37: 385-394.

Woody, C.D. 1970. Conditioned eye blink: Gross potential activity at coronal-precruciate cortex of the cat. J. Neurophysiol. 33: 838-850. . 1982. Memory, learning, and higher function: A cellular view. Springer-Verlag, New York.

Woody, C.D. and Brozek, G. 1969a. Changes in evoked responses from facial nucleus of cat with conditioning and extinction of an eye blink. J. Neurophysiol. 32: 717-725.

Woody, C.D. and Brozek, G. 1969b. Conditioned eye blink in the cat: Evoked responses of short latency. Brain Res. 12: 257-260.

Woody, C.D., Alkon, D.L., and Hay, B. 1984. Depolarization-induced effects of $\mathrm{Ca}^{2+}$-calmodulin-dependent protein kinase injection, in vivo, in single neurons of cat motor cortex. Brain Res. 321: 192-197.

Yang, B.Y. and Weisz, D.J. 1992. An auditory conditioned stimulus modulates unconditioned stimulus-elicited neuronal activity in the cerebellar anterior interpositus and dentate nuclei during nictitating membrane response conditioning in rabbits. Behav. Neurosci. 106: 889-899.

Yeo, C.H. and Hardiman, M.J. 1988. Loss of conditioned responses following cerebellar cortical lesion is not a performance deficit. Abstr. Soc. Neurosci. 14: 3.

Yeo, C.H. and Hardiman, M.J. 1992. Cerebellar cortex and eyeblink conditioning: A re-examination. Exp. Brain Res. 88: 623-638.

Yeo, C.H. and Hesslow, G. 1998. Cerebellum and conditioned reflexes. Trends Cogn. Sci. 2: 322-330.

Yeo, C.H., Hardiman, M.J., and Glickstein, M. 1984. Discrete lesions of the cerebellar cortex abolish the classically conditioned nictitating membrane response of the rabbit. Behav. Brain Res. 13: 261-266.

Yeo, C.H., Hardiman, M.J., and Glickstein, M. 1985a. Classical conditioning of the nictitating membrane response of the rabbit. I. Lesions of the cerebellar nuclei. Exp. Brain Res. 60: 87-98. . 1985b. Classical conditioning of the nictitating membrane response of the rabbit. II. Lesions of the cerebellar cortex. Exp. Brain Res. 60: 99-113.

. 1985c. Classical conditioning of the nictitating membrane response of the rabbit. III. Connections of cerebellar lobule HVI. Exp. Brain Res. 60: 114-126.

. 1986. Classical conditioning of the nictitating membrane response of the rabbit. IV. Lesions of the inferior olive. Exp. Brain Res. 63: 81-92.

Zhang, A.A. and Lavond, D.G. 1991. Effects of reversible lesion of reticular or facial neurons during eyeblink conditioning. Abstr. Soc. Neurosci. 17: 869 .

Zola-Morgan, S.M. and Squire, L.R. 1990. The primate hippocampal formation: Evidence for a time-limited role in memory storage. Science 250: 288-290. 


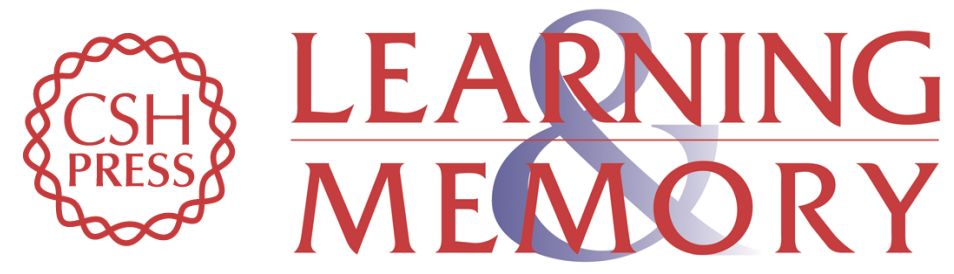

\section{Neural Substrates of Eyeblink Conditioning: Acquisition and Retention}

Kimberly M. Christian and Richard F. Thompson

Learn. Mem. 2003, 10:

Access the most recent version at doi:10.1101/lm.59603

References This article cites 347 articles, 66 of which can be accessed free at: http://learnmem.cshlp.org/content/10/6/427.full.html\#ref-list-1

License

Email Alerting Receive free email alerts when new articles cite this article - sign up in the box at the Service top right corner of the article or click here. 